\title{
Modern insights in foam sclerotherapy for varicose veins $=$ Moderne inzichten in schuim sclerotherapie voor varices
}

\author{
Citation for published version (APA):
}

Ceulen, R. P. M. (2012). Modern insights in foam sclerotherapy for varicose veins = Moderne inzichten in schuim sclerotherapie voor varices. [Doctoral Thesis, Maastricht University]. Maastricht University. https://doi.org/10.26481/dis.20121005rc

Document status and date:

Published: 01/01/2012

DOI:

10.26481/dis.20121005rc

Document Version:

Publisher's PDF, also known as Version of record

\section{Please check the document version of this publication:}

- A submitted manuscript is the version of the article upon submission and before peer-review. There can be important differences between the submitted version and the official published version of record. People interested in the research are advised to contact the author for the final version of the publication, or visit the DOI to the publisher's website.

- The final author version and the galley proof are versions of the publication after peer review.

- The final published version features the final layout of the paper including the volume, issue and page numbers.

Link to publication

\footnotetext{
General rights rights.

- You may freely distribute the URL identifying the publication in the public portal. please follow below link for the End User Agreement:

www.umlib.nl/taverne-license

Take down policy

If you believe that this document breaches copyright please contact us at:

repository@maastrichtuniversity.nl

providing details and we will investigate your claim.
}

Copyright and moral rights for the publications made accessible in the public portal are retained by the authors and/or other copyright owners and it is a condition of accessing publications that users recognise and abide by the legal requirements associated with these

- Users may download and print one copy of any publication from the public portal for the purpose of private study or research.

- You may not further distribute the material or use it for any profit-making activity or commercial gain

If the publication is distributed under the terms of Article $25 \mathrm{fa}$ of the Dutch Copyright Act, indicated by the "Taverne" license above, 


\section{Modern insights in foam sclerotherapy for varicose veins}

Roeland P.M. Ceulen 


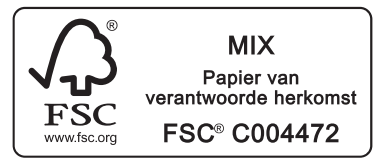

Financial support for printing this thesis was generously provided by:

Sigma-Tau BV and Medi Nederland BV

and also by Medireva v.o.f., Kreussler \& Co. GmbH, Oldekamp Medisch BV, URGO Medical, Bo-Pharma BV, DeclaCare, Leo Pharma BV, Tobrix, Varitex NV, Varodem SA, BAP-Medical BV, L'Oréal Nederland BV, Abbott BV, Astellas Pharma BV, Bauerfeind benelux BV, BSN medical BV, Dalton Medical BV, Esaote Benelux, Galderma, Laservision instruments BV, Fagron BV, Louis Widmer Nederland, Mediq i.s.m. Pierre Fabre Dermo-Cosmétique.

ISBN 978-94-6169-280-1

Copyright: Roeland P.M. Ceulen, Maastricht 2012

Cover design: Optima Grafische Communicatie, Rotterdam, The Netherlands

Layout and printing: Optima Grafische Communicatie, Rotterdam, The Netherlands 


\title{
Modern insights in foam sclerotherapy for varicose veins
}

Moderne inzichten in schuim sclerotherapie voor varices

\author{
Proefschrift
}

ter verkrijging van de graad van doctor aan de Universiteit Maastricht, op gezag van de Rector Magnificus, Prof.dr. L.L.G. Soete volgens het besluit van het College van Decanen,

in het openbaar te verdedigen op vrijdag 5 oktober 2012 om 12:00 uur

door

Roeland Petrus Maria Ceulen

geboren te Meijel, 30 oktober 1977 


\section{Promotor}

Prof. dr. P.M. Steijlen

\section{Beoordelingscommissie}

Prof. dr. T. Delhaas (voorzitter)

Prof. dr. G.J. Dinant

Dr. J.A. Lawson (St. Flebologisch Centrum Oosterwal, Alkmaar)

Prof. Dr. T.E.C. Nijsten (Erasmus MC, Rotterdam)

Prof. Dr. M.A.M. van Steensel 
Aan mijn ouders 


\section{List of frequently used abbreviations}

CVD, chronic venous disease

$\mathrm{CVI}$, chronic venous insufficiency

DSS, double syringe system

DVT, deep vein thrombosis

EVLA, endovenous laser ablation

EVTA, endovenous thermal ablation

$\mathrm{FHT}$, foam half time

FS, ultrasound guided foam sclerotherapy

GSV, great saphenous vein

PFO, patent foramen ovale

$\mathrm{POL}$, polidocanol

$\mathrm{RCT}$, randomised controlled trial

RFA, radiofrequency ablation

SFJ, saphenofemoral junction

SSV, small saphenous vein

SPJ, saphenopopliteal junction

VAS, visual analogue scale

VCSS, venous clinical severity score 


\section{Contents}

\section{Chapter 1}

Introduction

\section{Chapter 2}

Foam sclerotherapy versus surgery for incompetent great saphenous veins.

Br J Surg. 2012 May 25. [Epub ahead of print]

\section{Chapter 3}

Foam characteristics.

Dermatol Surg. 2011;37:1448-55.

\section{Chapter 4}

Clinical outcome of foam sclerotherapy with $1 \%$ versus 3\% POL foam.

Dermatol Surg. 2007;33:276-81.

\section{Chapter 5}

Compression after foam sclerotherapy.

Submitted

\section{Chapter 6}

Microembolism during foam sclerotherapy.

N Engl J Med. 2008;358:1525-26.

\section{Chapter 7}

Blocking the SFJ during foam sclerotherapy - assessment of a presumed safety measure procedure.

Eur J Vasc Endovasc Surg. 2010;40:772-76.

\section{Chapter 8}

Lateral venous ulceration and insufficiency of the small saphenous vein.

Dermatol Surg. 2007;33:727-30.

\section{Chapter 9}

Literature review: treatment of small saphenous varicose veins.

Phlebology. 2011;26:179-84. 


\section{Chapter 10}

General discussion

More on microembolism and foam sclerotherapy.

N Engl J Med. 2008;359:656-657.

Reply to letter regarding article titled 'Microembolism during foam sclerotherapy of varicose veins' in the New England Journal of Medicine.

Phlebology. 2008;23:250.

\section{Chapter 11}

Summary

Samenvatting

Curriculum Vitae

Grants \& Awards

List of publications

\section{Chapter 12}

Dankwoord 
CHAPTER 1

\section{Introduction}





\section{Introduction}

Foam sclerotherapy (FS) is a relatively novel minimally invasive technique that is used to treat varicose veins. Varicose veins are a common manifestation of venous incompetence in the lower limb and appear as dilated, elongated or tortuous superficial veins. Varicose veins may lead to changes in the skin and the subcutaneous tissues, which are often clinically referred to as chronic venous disease. ${ }^{1}$

\section{Epidemiology}

Chronic venous disease (CVD) of the legs is a common medical disorder and ranges in severity from minor asymptomatic incompetence of the venous valves to chronic leg ulceration. Several epidemiological studies of CVD in various countries have been performed over the past several decades. ${ }^{1-6}$ The prevalence of chronic venous insufficiency $(\mathrm{CVI})$ ranges from $1 \%$ to $40 \%$ in females and from $1 \%$ to $17 \%$ in males. ${ }^{2}$ The prevalence of varicose veins varies from $25 \%$ to $33 \%$ of females and from $10 \%$ to $20 \%$ of males in Western countries. ${ }^{1,2,5}$ The reported variation in these data can be partially explained by the use of different definitions for varicose veins and venous disease, the inclusion of different age groups and a frequent failure of studies to include a random sample of the general population.

It is estimated that venous leg ulceration, the end stage of $\mathrm{CVI}$, affects $1 \%$ of the population at some point in their lives. ${ }^{7}$ It is assumed that approximately $50 \%$ of venous leg ulcers are the result of superficial varicose veins. ${ }^{8}$ However, it is nearly impossible to predict which patient with varicose veins will eventually develop a venous leg ulcer. The lack of effective therapies and the recurrent nature of CVD place a heavy burden on national healthcare budgets. In the Netherlands, EUR 274 million is spent on the treatment of venous diseases annually, accounting for $6 \%$ of the total health care costs. ${ }^{9}$ Therefore, the treatment of varicose veins, which may reduce the incidence of leg ulcers by $50 \%$, is likely to be cost-effective.

Important risk factors for varicose veins include an older age, a female gender, a family history and deep vein thrombosis (DVT). ${ }^{1,2,4,10}$ The prevalence of venous diseases increases approximately linearly with age and applies to men and women equally. ${ }^{10-15}$ Varicose veins even occur in children and adolescents. ${ }^{10}$ The Edinburgh vein study demonstrated that the prevalence of truncal varicose veins increases from $12 \%$ in 18-24-year-olds group to $56 \%$ among 55-64-year-olds. ${ }^{3}$ This finding is consistent with the data from the Framingham study that demonstrated nearly no varicose veins among men younger than 30 and a less than $10 \%$ prevalence in women under 30 . In men and women aged 70 years, the prevalence increased to $57 \%$ and $77 \%$, respectively. ${ }^{10}$ As a result of varicose veins, functional venous disease increases with age. The San Diego study demonstrated that individuals aged 70-79 years exhibit twice 
the prevalence of varicose veins as individuals aged 40-49 years, whereas the prevalence of trophic changes in the oldest group was four times as high. ${ }^{16}$ Small-calibre varicose veins appear to be more common in women than in men. This difference may be explained by a selection bias, as women consider varicose veins a cosmetic problem more frequently than men, resulting in more frequent visits to varicose vein clinics and therefore a higher likelihood of participating in studies. More severe forms of varicose veins and CVI occur equally in both sexes. ${ }^{13}$ Many doctors and patients assume an inheritance of varicose veins, although family histories are not very reliable, partly because individuals with venous pathology will be more aware than healthy individuals of venous disorders among their relatives. Most studies report a positive family history without actually having examined the family. Only one case-control study of 134 French families demonstrates the risk of developing varicose veins to be $25 \%$ for men and $62 \%$ for women when one parent had varicose veins and $90 \%$ if both parents had varicose veins compared to $20 \%$ when neither parent had varicose veins. ${ }^{17}$

\section{Anatomy}

\section{Superficial veins}

Superficial veins of the lower limb are located between the deep fascia, which cover the muscles of the limb, and the skin. The primary superficial veins are the great saphenous vein (GSV) and the short saphenous vein (SSV).

The GSV begins on the dorsum of the foot and ascends in front of the medial malleolus along the medial border of the tibia, next to the saphenous nerve. It continues along the medial aspect of the leg across the anteromedial thigh. There are posterior and anterior accessory saphenous veins in the calf and the thigh. The saphenofemoral junction (SFJ) is the confluence of the superficial inguinal veins, comprising the GSV and the superficial circumflex iliac, superficial epigastric, and external pudendal veins. The GSV lies on the deep fascia and is enclosed by a loose compartment of fat and areolar tissue. In fact, the GSV is sandwiched between the deep and superficial fascia. A very characteristic appearance is observed on duplex scanning and has been referred to as the "Egyptian eye" (Figure 1).

The SSV is the most important posterior superficial vein of the leg (Figure 2a). It originates at the lateral aspect of the foot and drains blood into the popliteal vein, joining it usually just proximal to the knee crease (saphenopopliteal junction (SPJ)). The SSV may also join the GSV in the thigh via an oblique epifascial vein (the vein of Giacomini). ${ }^{18}$ 


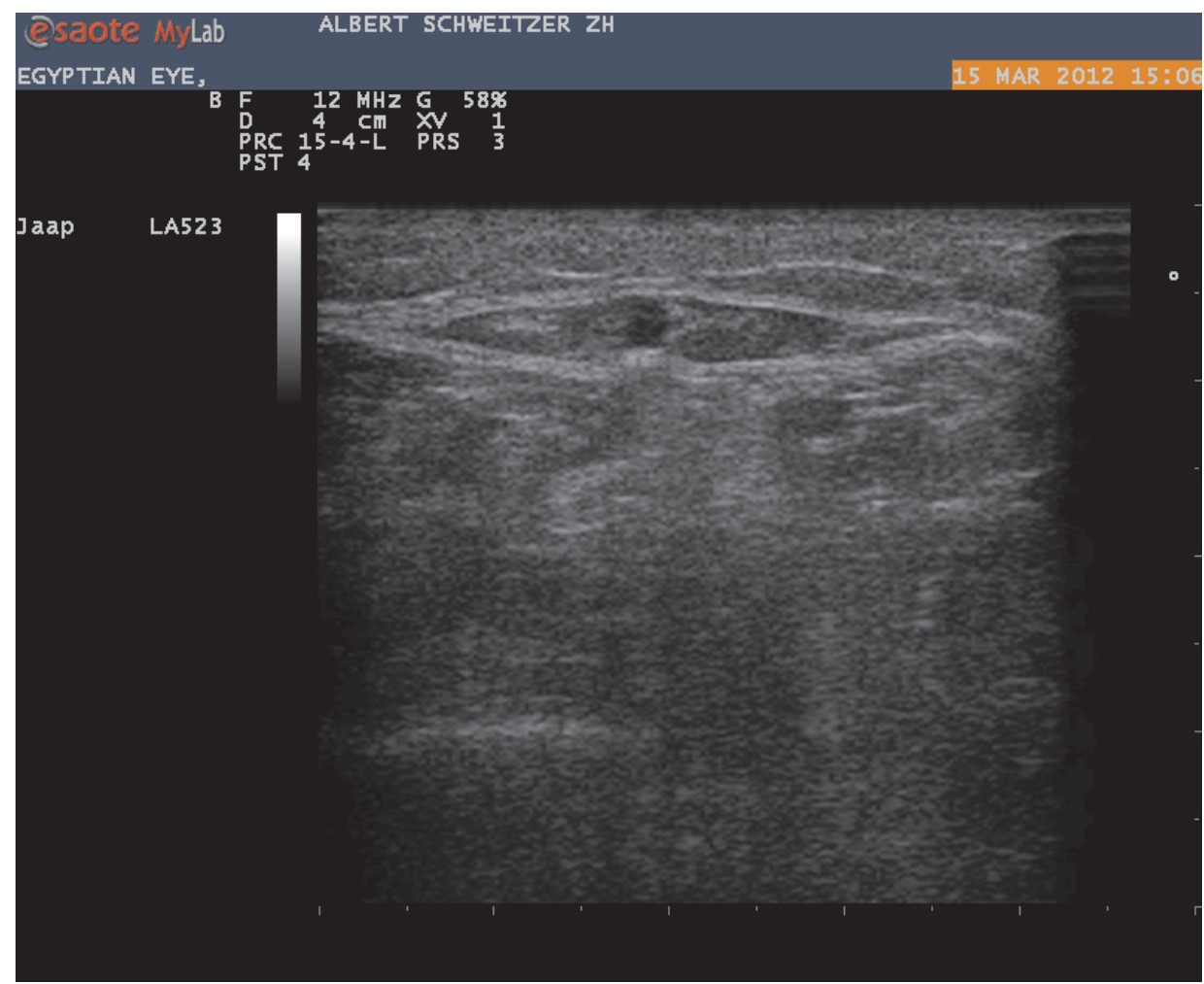

Figure 1. Egyptian eye, the GSV is sandwiched between deep and superficial fascia.

\section{Deep veins}

Deep veins accompany the corresponding arteries of the lower limb and pelvis. The deep veins of the calf (anterior, posterior tibial, and peroneal veins) run in richly anastomosing pairs, and the popliteal and femoral veins may also be paired. The gastrocnemius and soleal veins are important deep tributaries. The femoral vein connects the popliteal to the common femoral vein.

\section{Perforating veins}

Perforating veins are veins that initially lie superficially but then pass directly or obliquely through fascial defects and between muscle bundles to carry blood from superficial veins into the deep venous system. Communicating veins connect veins within the same system. The medial calf perforators are clinically the most significant. The posterior tibial perforating veins (also known as Cockett's perforators) connect the posterior accessory GSV (also known as posterior arch vein) with the posterior tibial veins. They are located immediately retromalleolar (lower group), 7 to $9 \mathrm{~cm}$ (middle group) and 10 to $12 \mathrm{~cm}$ (upper group) proximal from the tip 
a

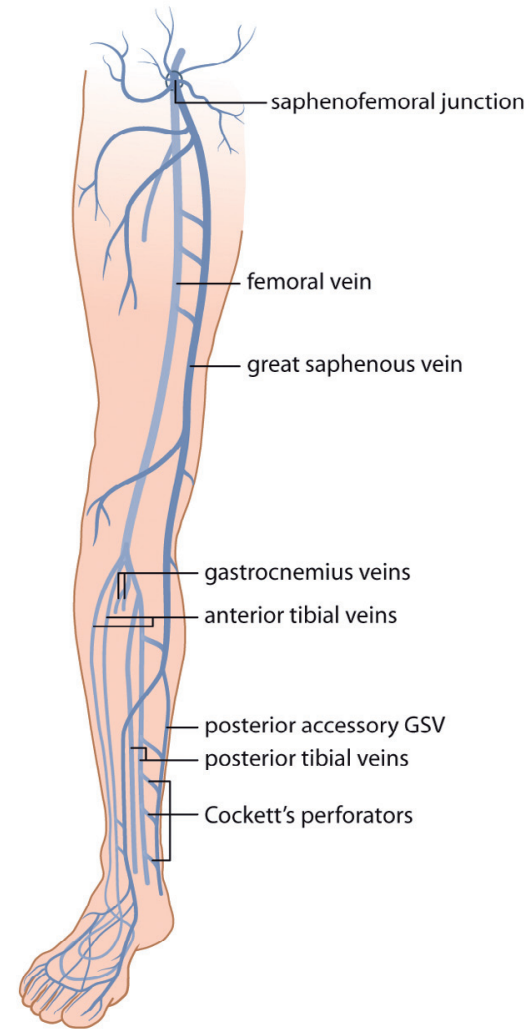

b

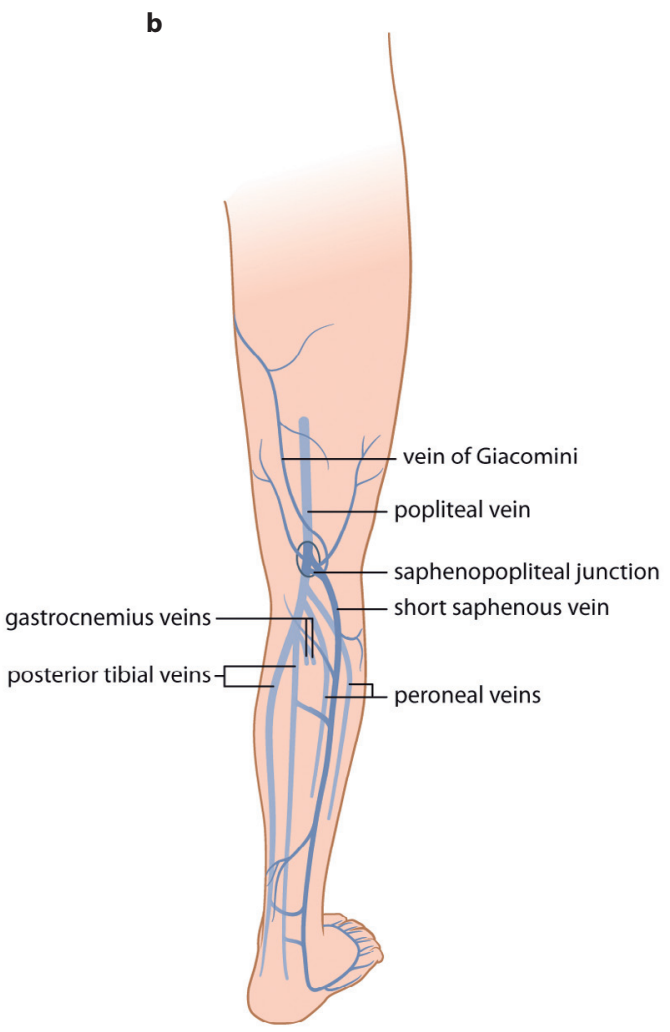

Figure $\mathbf{2 a}$ and $\mathbf{2 b}$. Venous anatomy of the lower extremities: Figure $2 \mathrm{a}$ (frontomedial view) \& Figure $2 \mathrm{~b}$ (dorsal view). Images on behalf of RPM Ceulen, designed and produced by Maartje Kunen, Medical Visual, 's-Hertogenbosch, The Netherlands, January $13^{\text {th }}, 2012$.

of the medial malleolus, within 2 to $4 \mathrm{~cm}$ from the medial edge of the tibia. ${ }^{19}$ (Figure 2b). The paratibial perforating veins connect the GSV with the posterior tibial veins. The upper midthigh perforators of the femoral canal usually directly connect the GSV to the femoral vein.

\section{Venous valves}

Bicuspid venous valves are important structures in assisting unidirectional flow in the normal venous system. The GSV generally has at least 6 valves (range 4-25), with a constant valve present within 2 to $3 \mathrm{~cm}$ of the SFJ in $85 \%$ of individuals. ${ }^{20}$ The SSV has 7 to 10 valves (range 4-13). ${ }^{21}$ There are valves in the deep venous system, but at low frequencies. The common femoral and external iliac veins have only one valve in approximately $63 \%$ of cases, and no valves are observed in $27 \%$ of cases. ${ }^{21}$ 


\section{Pathophysiology}

CVD of the legs (or the 'lower extremities') is characterised by the appearance of reflux in the veins. When the total amount of blood volume that flows back into the extremities due to the existing reflux becomes greater than the maximum capacity of all of the return mechanisms (i.e., muscle pumps), the venous systems fails and hence decompensates.

A pressure difference exists within the venous system. The blood column between the right atrium and the foot defines the pressure in the venous vein system. A standing person still will have a pressure of $80-100 \mathrm{mmHg}$ in the ankle region. During walking, this orthostatic pressure must decrease to $<25 \mathrm{mmHg}$ to guarantee good venous drainage (or 'outflow'). However, in CVD, there is an insufficient decrease in pressure when walking. In cases of severe insufficiency, the pressure can remain at $60-70 \mathrm{mmHg}$. This condition is referred to as increased ambulant venous pressure or venous hypertension.

Abnormalities of the venous system can be primary and secondary, and CVD can develop due to multiple primary varicose veins. Early theories assumed that varicose veins arose from the combination of the effects of valvular incompetence and venous hypertension and arose in a descending direction from valvular incompetence at the SFJ or the SPJ. Today, detailed studies of surgical specimens and ultrasound observations suggest that primary valvular incompetence is a multicentric process that develops simultaneously in discontinuous venous segments. ${ }^{22}$ This explanation can be derived from the general principle that excessive vasodilatation of the vein wall causes the abnormal remodelling that is observed in affected veins. Secondary varicose veins occur due to disease. The most common cause is DVT. Venous hypertension occurs due to damage of the valves and recanalisation (i.e., reflux type) or residual obstruction (i.e., obstructive type). Other causes are primary insufficiency of the valves in the deep system, such as congenital agenesis and aplasia. ${ }^{17}$ Secondary varicose veins cannot necessarily be treated, nor do they necessarily require treatment.

There are several known causes of primary varicose veins. The first lies in changes in the structure of the extracellular matrix of the veins and the valves. ${ }^{23}$ Hypoxia, which is due to disturbed venous circulation, activates endothelial cells, which subsequently cause the adhesion of white blood cells. ${ }^{24}$ Due to this 'white cell trapping', inflammatory mediators are released, eventually resulting in the increased synthesis of collagen in the extracellular matrix and a decrease in the number of contractile elements. ${ }^{25}$ These effects result in a rigid, poorly contracting vein.

The second cause of primary varicose veins lies in the destruction of valves. A highly decreased bloodstream occurs in the cusps, whereby the deposition of fibrin and thrombocytes thickens the wall, inducing thrombogenesis. Subsequently, leukocyte adhesion occurs. ${ }^{26}$ These changes lead to microthrombosis around the valves, resulting in valve dysfunction and thus venous hypertension. ${ }^{27}$ 
Reflux in the leg can occur anywhere in the venous system. The insufficiency of valve functioning in the SFJ or SPJ causes descending varicose veins. Alternatively, saphenous insufficiency without incompetence of the junction may arise from insufficient perforating veins and tributaries. Calf veins can also be primarily insufficient due to this stasis in the veins. In this context, calf pump contraction produces a strong pressure increase that can lead to insufficiency in the ascending direction..$^{28,29}$

Increased venous pressure leads to the formation of a varicose vein in several ways. First, there is increased expression of matrix-metallo-proteinases (MMPs) in the vein wall. MMPs influence the elasticity and firmness of the vein wall. Furthermore, the endothelium damage that is caused by these MMPs leads to an inflammatory reaction. ${ }^{30}$

Second, changes occur in the expression of oestrogen receptor-b, leading to disturbance in the generation of muscle segments in the vein wall, resulting in their weakening. ${ }^{31}$ Third, a change in collagen/elastin ratio occurs in varicose veins due to an increased amount of collagen, leading to hypertrophy of the intima. ${ }^{32}$

Venous hypertension plays a key role in the skin changes that occur in CVD, with a linear trend toward more severe skin changes with increasing post-exercise venous pressure. ${ }^{33}$ In all CVD patients, capillary hypertension eventually causes increased plasma levels of vascular endothelial growth factor (VEGF), leading to high microvascular permeability. ${ }^{34}$ This increased permeability causes capillary leakage of water and proteins, resulting in oedema and chronic inflammation. These effects are characterised by the increased expression and activity of MMPs that is observed in lipodermatosclerosis and in venous ulcers and their exudate. ${ }^{35-37}$ Moreover, elevated fibrogenic cytokines stimulate collagen production by dermal fibroblasts, culminating in dermal fibrosis. ${ }^{38}$ The hyperpigmentation of skin observed in lipodermatosclerosis is caused by the extravasation of red cells, resulting in elevated levels of ferritin and ferric iron in the affected skin. ${ }^{39}$ These skin changes lead to a skin that is vulnerable to leg ulceration. ${ }^{40}$

\section{Clinical characteristics and classification}

Varicose veins and CVI are associated with multiple and generally subjective symptoms, which may occur at an early stage or over time. The classic symptoms are tingling, aching, burning, muscle cramps, swelling, itching skin and leg tiredness. These symptoms may affect the health-related quality of life and can be measured with the Aberdeen Varicose Vein Questionnaire (AVVQ) ${ }^{41}$ or the Chronic Venous Insufficiency Quality of Life Questionnaire (CIVIQ). ${ }^{42}$ The clinical features of CVD arise over time. The progression of CVD proceeds in three stages: the adaptation stage, the compensation stage and the decompensation stage. The clinical 


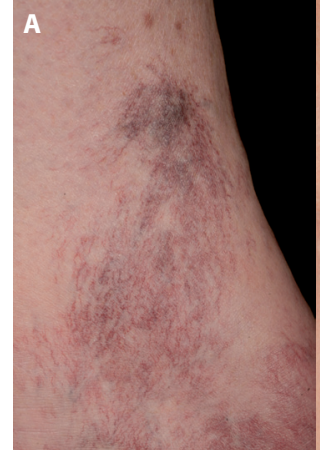

E

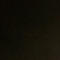

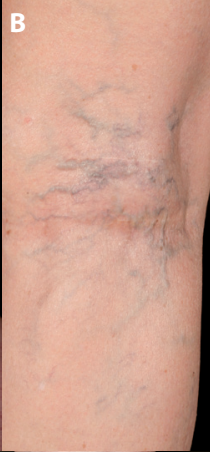

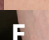

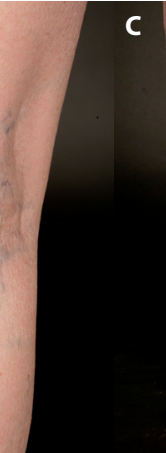

G

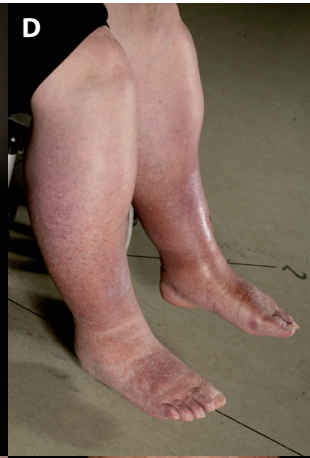

H
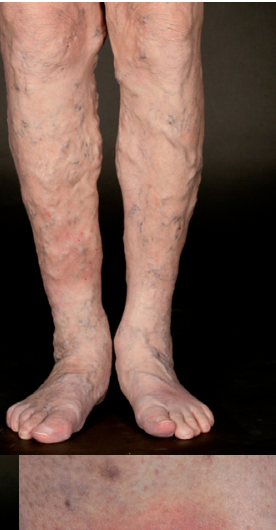

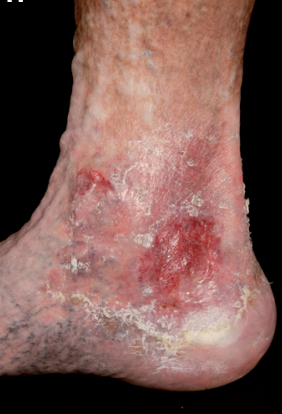

Figure 3. Clinical characteristics of chronic venous disease. A. Teleangiectases. B. Reticular veins. C. Varicose veins. D. Edema. E. Lipodermatosclerosis. F. Pigmentation. G. Ulceration and inflammation. H. Ulceration, pigmentation and varicose dilatations.

symptoms appear when the mechanisms that compensate for insufficient venous return fails. The clinical signs of CVD are varicose dilatations, spider veins or telangiectasias, oedema, induration, pigmentation, lipodermatosclerosis, white atrophy, eczema and skin discoloration (Figure 3) Complications eventually occur, such as venous ulceration, which is considered the final stage of CVD. The Venous Clinical Severity Score (VCSS) can be used to evaluate symptom severity. The VCSS was introduced by Rutherford and has been successfully used in several studies to evaluate changes in the signs and symptoms of CVD over time and to quantify the outcome. ${ }^{43,44}$ The keystone of the management of CVD is the proper diagnosis and accurate classification of the underlying venous problem. The CEAP classification allows for the precise catalogisation of each individual and provides an orderly system for the descriptive clinical (C) signs of venous disease, its aetiology $(E)$, anatomy $(A)$ and pathophysiology (P) (Table 1). It provides a basis for objective identification of each CVD problem and thereby allows for interinstitutional studies. The American Venous Forum established the CEAP classification system in $1994 .{ }^{88,90}$ 
Table 1. Revision of CEAP-classification of chronic venous disease: summary. ${ }^{89}$

\begin{tabular}{|c|c|}
\hline \multicolumn{2}{|c|}{ Clinical classification } \\
\hline $\mathrm{CO}$ & No visible or palpable signs of venous disease \\
\hline $\mathrm{C} 1$ & Telangiectases or reticular veins \\
\hline $\mathrm{C} 2$ & Varicose veins \\
\hline $\mathrm{C} 3$ & Edema \\
\hline $\mathrm{C} 4 \mathrm{a}$ & Pigmentation and/or eczema \\
\hline $\mathrm{C} 4 \mathrm{~b}$ & Lipodermatosclerosis and/or atrophie blanche \\
\hline C5 & Healed venous ulcer \\
\hline C6 & Active venous ulcer \\
\hline S & $\begin{array}{l}\text { Symptomatic, including ache, pain, tightness, skin } \\
\text { irritation, heaviness, muscle cramps, as well as } \\
\text { other complaints attributable to venous dyfunction }\end{array}$ \\
\hline A & Asymptomatic \\
\hline \multicolumn{2}{|c|}{ Etiologic classification } \\
\hline Ec & Congenital \\
\hline Ep & Primary \\
\hline Es & Secondary (postthrombotic) \\
\hline En & No venous etiology identified \\
\hline \multicolumn{2}{|c|}{ Anatomic classification } \\
\hline As & Superficial veins \\
\hline Ap & Perforator veins \\
\hline Ad & Deep veins \\
\hline An & No venous location identified \\
\hline \multicolumn{2}{|c|}{ Pathophysiologic classification } \\
\hline $\operatorname{Pr}$ & Reflux \\
\hline Po & Obstruction \\
\hline $\mathrm{Pr}, \mathrm{O}$ & Reflux and obstruction \\
\hline $\mathrm{Pn}$ & Reflux and obsruction \\
\hline Advanced CEAP & $\begin{array}{l}\text { Same as basic CEAP, with addition that any of } 18 \\
\text { named venous segments can be used as locators } \\
\text { for venous pathology }\end{array}$ \\
\hline
\end{tabular}

\section{Diagnosis}

Ultrasound duplex scanning is the first diagnostic test for all patients with suspected CVD. ${ }^{45}$ This test is safe, non-invasive, cost-effective, and reliable. With the patient in upright position, the diameter and patency of the superficial, deep and perforating veins, as well as reflux in the deep and superficial veins, can be evaluated. Detailed information on the methodology for making complete assessments is described in two recent consensus documents of the UIP (Union Internationale de Phlébologie). ${ }^{46-48}$ If the duplex scanning results are unclear or do not correspond with the clinical signs, additional phlebography, MR and CT venography can be performed to visualise difficult anatomy (e.g., in recurrent varicose veins, congenital malformations, venous pathology of pelvic or abdominal veins). In patients with complex hemodynamic pathology leading to venous hypertension, ambulatory venous pressure measurement or plethysmography can be added as a diagnostic and prognostic tool. 


\section{Treatment}

The early treatment of varicose veins aims at preventing venous hypertension, reflux and inflammation. Both CVD symptoms and ulcers reduce the quality of life and are expensive to treat but can be respectively alleviated and prevented by early treatment. Less frequently, varicose veins are of cosmetic concern only. The treatment of varicose veins is generally divided into four categories: compression therapy, open surgery, endovenous thermal ablation and sclerotherapy.

\section{Compression}

Compression is the longest existing form of CVD therapy. The rationale is to compensate for the ambulatory venous hypertension. Compression therapy is a basic and most frequently used conservative mono-treatment of CVD and has additional advantages over other treatments. ${ }^{49,50}$ We present a detailed discussion of the role of compression therapy following FS in chapter 5 .

\section{Open surgery}

The second primary category of therapy is open surgery. Open surgical treatment of varicose veins with ligation and stripping of the GSV or SSV combined with phlebectomy has been the gold standard of varicose vein treatment for many years. ${ }^{51,52}$ Several variations of the stripping method have been developed, such as the use of the invagination stripper by Keller ${ }^{53}$ in 1905 , an external stripper by Mayo $^{54}$ in 1906 and an intraluminal stripper from the ankle to the groin by Babcock ${ }^{55}$ in 1907. High ligation and stripping has become the technique of choice to remove the saphenous vein. The recognition of frequent saphenous nerve injury during groin-to-ankle stripping changed the technique to a limited, groin-to-knee stripping. ${ }^{56} \mathrm{~A}$ major disadvantage of stripping is the high recurrence rate (up to $30-60 \%$ long-term). ${ }^{57-62}$ The primary reasons for recurrence were technical and tactical errors, neovascularisation at the groin, and progression of the underlying disease..$^{57}$ Adequate preoperative anatomical mapping of the SFJ and SPJ with ultrasound appears to improve the recurrence rates. Surgery may occasionally be associated with significant postoperative morbidity, including bleeding, groin infections, thrombophlebitis and saphenous nerve damage, although major complications are rare..$^{63}$ Conventional surgery is most often performed in hospitals with the use of general or local anaesthesia, potentially increasing costs. Surgical treatment with ligation and GSV stripping in comparison to FS will be discussed in detail in chapters 2 and 9. 


\section{Endovenous thermal ablation}

The third major therapy to treat saphenous veins is endovenous thermal ablation (EVTA), which was developed only a decade ago. EVTA has several advantages over standard open surgery. EVTA requires local tumescent anaesthesia and is an outpatient procedure that can be performed in an office setting. The recurrence rate following thermal techniques is lower than that of surgery. Patients complain of less pain and discomfort and return to work earlier than following stripping. ${ }^{64}$ EVTA techniques include endovascular laser ablation (EVLA), with the wavelength varying from 800 to $1500 \mathrm{~nm}$, radiofrequency ablation (RFA) with VNUS Closure Fast (segmental RFA) and radiofrequency-induced thermotherapy (RFITT); these will be discussed in chapter 9 . The most recently developed ablation technique includes the use of steam at $120^{\circ} \mathrm{C}$, which destroys the endothelial layer and causes shrinkage of the collagen. ${ }^{65}$ EVLA and RFA are equivalent techniques, although EVLA exhibits a slightly better outcome. ${ }^{66}$ Further research is required to compare the effects, side effects and patient preferences of steam ablation and EVLA.

\section{Sclerotherapy}

The fourth primary type of treatment is sclerotherapy. An injection of a chemical agent into the vein to achieve endoluminal fibrosis and obstruction of the vein has been used since the $19^{\text {th }}$ century. The telangiectatic and reticular veins were first injected with ferric chloride and later with sodium carbonate, sodium salicylate, quinine, sodium chloride, urethane and povidone iodine. In 1965, Fegan added compression to sclerotherapy to improve the clinical outcome. ${ }^{67,68}$ Since this time, compression following sclerotherapy has been considered standard. Liquid sclerotherapy has been primarily used for the obliteration of spider and reticular veins. However, interest in the use of sclerotherapy for larger varicose veins gained interest after Cabrera reported in 1995 that foam prepared by mixing a'physiologic' gas with the detergent polidocanol (POL) was effective in obliterating larger veins. ${ }^{69}$ With the introduction of ultrasound (US) machines in phlebology, ultrasound-guided foam sclerotherapy has rapidly begun to be used to treat primary and recurrent varicose veins, including the GSV, SSV, perforating veins and venous malformations. ${ }^{70-79}$ The mechanisms of action of sclerosing detergents are the destruction of venous endothelial cells, leading to thrombus formation and, ultimately, the formation of fibrotic obstruction of the vein. ${ }^{80}$ The use of foaming solutions prolongs the contact time, amplifying the effect of the detergent by a factor of four. ${ }^{81,82}$ Today, liquid and foam sclerotherapy are commonly used with sclerosing solutions, such as POL and sodium tetradecyl sulphate (STS). The most popular technique used today to prepare foam was developed by Tessari, who used a three-way stopcock connected with two syringes. The Double Syringe System (DSS) is also commonly used (Figure 4). ${ }^{83}$ In both techniques, liquid and air are pushed from one syringe into another to create 


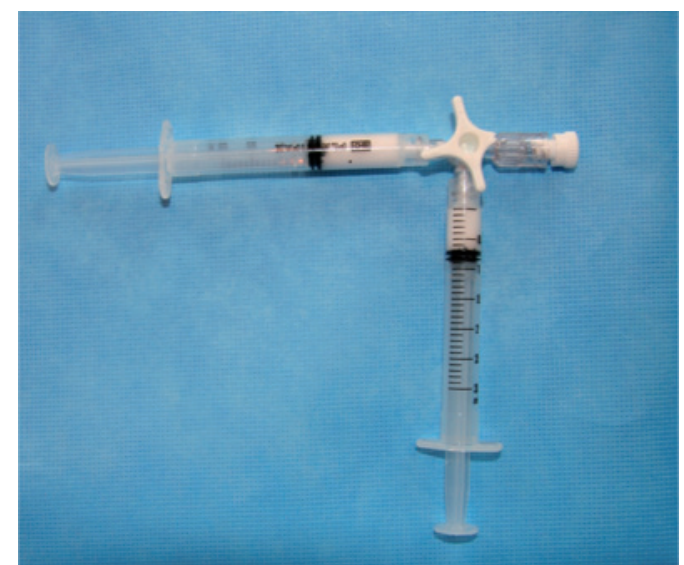

Figure 4. The Double Syringe System (DSS).

the foam. It is recommended to mix one part STS or POL solution with four or five parts air. $^{84,85}$

Different nomenclature is used in the literature to refer to ultrasound-guided foam sclerotherapy. All of these terms imply the injection of foam under the guidance of duplex ultrasound. To improve the readability and clarity of this thesis, we will refer to this process using the term 'foam sclerotherapy (FS)'.

\section{Aims / Questions of the thesis}

\section{Is FS a cost-effective alternative to high ligation and stripping?}

For many years, the gold standard of varicose vein treatment was surgical stripping. This standard was based on a publication by Hobbs, which reported that surgery was more effective than liquid sclerotherapy. ${ }^{86}$ Long-term results, however, demonstrated recurrences in as many as $60 \%$ of patients after 34 years of follow-up. ${ }^{87}$ In the last decade, the demand for minimally invasive and less expensive techniques has resulted in the development of FS. FS is an attractive alternative to surgery given that foam is four times more effective than liquid sclerosants, is less invasive than surgery, is performed in an outpatient setting and is associated with a shorter recovery time than surgery. We therefore performed a multicentre randomised controlled non-inferiority trial with long-term follow-up to compare FS with surgery for the treatment of GSV incompetence (Chapter 2).

Which variables during the preparation of the foam influence its stability?

Since foam was first mentioned in the literature in 1939, many techniques for its preparation have been described. The protocol for making the foam varies and is not standardised, which is confusing for physicians and may affect the clinical outcome of FS. To determine the 
best technique for preparing stable POL foam, we performed an experimental analysis to determine whether different variables, such as the POL concentration, syringe size, the liquid to air ratio and the number of pump cycles affect the properties of the foam (Chapter 3 ).

Does 3\% POL foam have a better clinical outcome than 1\% POL foam in the treatment of varicose GSVs?

The treatment of truncal varicose veins with liquid sclerotherapy gave reasonable short-term results but disappointing long-term results. With the introduction of foam, a stronger obstructive effect can be achieved than with liquid sclerosing solutions. For liquid sclerosants, the higher the concentration of the solution is and the smaller the vein, the greater the endothelial damage. To evaluate whether this trend is also true for foam, we designed a randomised controlled trial to investigate the efficacy and side effects of $1 \%$ and $3 \% \mathrm{POL}$ foam (Chapter 4).

For what period should compression therapy be prescribed following FS for varicose GSVs to increase the success rate and minimise the side effects?

In 1965, Fegan added compression to liquid sclerotherapy to obtain better results. It is generally believed that immediate compression following FS causes direct apposition of the treated vein wall, leading to more effective sclerosis and a minimisation of thrombosis and phlebitic reactions. Moreover, the minor complications that are associated with treatment, including matting, pigmentation and pain, are less severe. Since this time, sclerotherapy has always been combined with compression therapy. Stronger foaming sclerosants have now replaced liquid solutions, and GSVs of larger diameters are frequently treated with FS. We believe that foam results in stronger treatment effects but that it also leads to more severe side effects. We ask, in the context of the increasing diameters of treated veins, whether compression is important to improve success rates and to diminish side effects. A randomised controlled trial was performed to investigate the optimal duration of compression following FS for GSVs, distinguishing between large $(\geq 0.5 \mathrm{~cm})$ and small $(<0.5 \mathrm{~cm})$ vein diameters (Chapter 5 ).

What happens following the foam injection - is it safe?

Patients who are treated with FS occasionally develop transient neurologic adverse effects, such as visual disturbance and migraine-like headache. These symptoms are likely caused by the systemic distribution of the foam (Chapter 6). Although fundamental research demonstrated that sclerosants are neutralised by blood proteins as soon as a few seconds following the injection, many physicians manually compress the SFJ during FS as a safety-measure to prevent the foam entering the systemic circulation. To evaluate whether blocking the SFJ during FS by manual compression or high ligation is an adequate procedure to prevent the foam from entering the deep venous system, we used radioactive foam and scintigraphic techniques (Chapter 7). 
Does FS speed the healing of chronic venous leg ulcerations?

The final stage of CVD includes venous leg ulceration, which has been treated by bandaging and topical applications for hundreds of years. The incidence of venous ulceration is the highest among the elderly, who often suffer greater co-morbidity. Venous ulcers are primarily located in the gaiter area. Underlying incompetence of the superficial venous system is not always limited to the upper leg. In most cases, reflux is also present in the GSV or the SSV in the lower leg or in perforating veins. Therefore, stripping of the superficial saphenous trunks to the level of the knee does not appear to speed ulcer healing but could prevent subsequent recurrence. We believe that FS may be a good alternative for surgery because it can be performed in an outpatient setting and, in terms of comorbidity, has virtually no contraindications. Therefore, we treated patients who were suffering from an active venous ulceration with FS to investigate its effect on wound healing (Chapter 8).

How does FS compare with other treatment modalities for the treatment of varicosis caused by SSV insufficiency?

In $15 \%$ of patients with CVD, the cause is SSV insufficiency. Until recently, surgery on the SPJ was the first treatment of choice. In recent years, however, minimally invasive techniques have generally replaced ligation and stripping techniques. The success rates of endovenous techniques for the treatment of the GSV have been widely investigated; however, much less is known regarding the treatment of SSV incompetence. We systematically reviewed and performed a comparative meta-analysis, examining the outcomes of surgery, EVLA, RFA and FS with respect to the treatment of small saphenous veins (Chapter 9).

In summary, we first compared the effectiveness and costs of FS and surgery in treating varicose GSV. We then investigated multiple aspects of the technical and procedural details of FS with respect to the properties of the produced foam and the occurrence and prevention of the local and systemic side effects. Finally, we sought to understand the current status of FS, in relation to other treatment modalities, as a treatment for SSV incompetence-induced CVD. 


\section{References}

1. Evans CJ, Fowkes FG, Hajivassiliou CA, et al. Epidemiology of varicose veins. A review. Int Angiol. 1994;13:263-70.

2. Beebe-Dimmer JL, Pfeifer JR, Engle JS, Schottenfeld D. The epidemiology of chronic venous insufficiency and varicose veins. Ann Epidemiol. 2005;15:175-84.

3. Evans CJ, Fowkes FG, Ruckley CV, Lee AJ. Prevalence of varicose veins and chronic venous insufficiency in men and women in the general population: Edinburgh Vein Study. J Epidemiol Community Health. 1999;53:149-53.

4. Fowkes FG, Evans CJ, Lee AJ. Prevalence and risk factors of chronic venous insufficiency. Angiology. 2001;52 Suppl 1:S5-15.

5. Heit JA, Rooke TW, Silverstein MD, et al. Trends in the incidence of venous stasis syndrome and venous ulcer: a 25-year population-based study. J Vasc Surg. 2001;33:1022-7.

6. Ruckley CV, Evans CJ, Allan PL, et al. Chronic venous insufficiency: clinical and duplex correlations. The Edinburgh Vein Study of venous disorders in the general population. J Vasc Surg. 2002;36: 520-5.

7. Callam MJ, Harper DR, Dale JJ, Ruckley CV. Chronic ulcer of the leg: clinical history. Br Med J (Clin Res Ed). 1987;294:1389-91.

8. Dwerryhouse S, Davies B, Harradine K, Earnshaw JJ. Stripping the long saphenous vein reduces the rate of reoperation for recurrent varicose veins: five-year results of a randomized trial. J Vasc Surg. 1999;29:589-92.

9. Oostenbrink JB, Rutten FFH. Handleiding voor kostenonderzoek; methoden en richtprijzen voor economische evaluatie in de gezondheidszorg. iMTA/CvZ Amstelveen. 2000.

10. Brand FN, Dannenberg AL, Abbott RD, Kannel WB. The epidemiology of varicose veins: the Framingham Study. Am J Prev Med. 1988;4:96-101.

11. Beebe HG, Bergan JJ, Bergqvist D, et al. Classification and grading of chronic venous disease in the lower limbs. A consensus statement. Int Angiol. 1995;14:197-201.

12. Maurins $\mathrm{U}$, Hoffmann BH, Losch C, et al. Distribution and prevalence of reflux in the superficial and deep venous system in the general population--results from the Bonn Vein Study, Germany. J Vasc Surg. 2008;48:680-7.

13. Rabe E, Pannier-Fischer F, Bromen K, et al. Bonner Venenstudie der Deutschen Gesellschaft für Phlebologie. Epidemiologische Untersuchung zur Frage der Häufigkeit und Auspägung von chronischen Venenkrankheiten in der städtischen und ländlichen Wohnbevölkerung. Phlebologie. 2003;32:1-14.

14. Ruckley CV, Evans CJ, Allan PL, et al. Telangiectasia in the Edinburgh Vein Study: epidemiology and association with trunk varices and symptoms. Eur J Vasc Endovasc Surg. 2008;36:719-24.

15. Widmer LK, Plechl SC, Leu HJ, Boner H. Venous diseases in 1800 employees. Basel Studies II. Schweiz Med Wochenschr. 1967;97:107-10.

16. Criqui MH, Jamosmos $M$, Fronek $A$, et al. Chronic venous disease in an ethnically diverse population: the San Diego Population Study. Am J Epidemiol. 2003;158:448-56.

17. Cornu-Thenard A, Boivin P, Baud JM, et al. Importance of the familial factor in varicose disease. Clinical study of 134 families. J Dermatol Surg Oncol. 1994;20:318-26.

18. Delis KT, Knaggs AL, Khodabakhsh P. Prevalence, anatomic patterns, valvular competence, and clinical significance of the Giacomini vein. J Vasc Surg. 2004;40:1174-83.

19. Mozes G, Gloviczki P, Menawat SS, et al. Surgical anatomy for endoscopic subfascial division of perforating veins. J Vasc Surg. 1996;24:800-8. 
20. Pang AS. Location of valves and competence of the great saphenous vein above the knee. Ann Acad Med Singapore. 1991;20:248-50.

21. Gloviczki P, Mozes G. Handbook of venous disorders: guidelines of the American venous forum. 3rd ed. Gloviczki P, editor. London: Hodder Arnold; 2009.

22. Labropoulos N, Giannoukas AD, Delis K, et al. Where does venous reflux start? J Vasc Surg. 1997; 26:736-42.

23. Sansilvestri-Morel P, Nonotte I, Fournet-Bourguignon MP, et al. Abnormal deposition of extracellular matrix proteins by cultured smooth muscle cells from human varicose veins. J Vasc Res. 1998;35:115-23.

24. Michiels C, Arnould T, Janssens D, et al. Interactions between endothelial cells and smooth muscle cells after their activation by hypoxia. A possible etiology for venous disease. Int Angiol. 1996;15: 124-30.

25. Yamada T, Tomita S, Mori M, et al. Increased mast cell infiltration in varicose veins of the lower limbs: a possible role in the development of varices. Surgery. 1996;119:494-7.

26. Michiels C, Arnould T, Thibaut-Vercruyssen R, et al. Perfused human saphenous veins for the study of the origin of varicose veins: role of the endothelium and of hypoxia. Int Angiol. 1997;16:134-41.

27. Boisseau MR. Venous valves in the legs: hemodynamic and biological problems and relationship to physiopathology. J Mal Vasc. 1997;22:122-7.

28. Thiery L. Physiopathology of leg pain. Phlebologie. 1988;41:624-34.

29. Thibault PK. Duplex examination. Dermatol Surg. 1995;21:77-82.

30. Raffetto JD, Khalil RA. Mechanisms of varicose vein formation: valve dysfunction and wall dilation. Phlebology. 2008;23:85-98.

31. Somers P, Knaapen M. The histopathology of varicose vein disease. Angiology. 2006;57:546-55.

32. Wali MA, Eid RA. Changes of elastic and collagen fibers in varicose veins. Int Angiol. 2002;21: 337-43.

33. Payne SP, London NJ, Newland CJ, et al. Ambulatory venous pressure: correlation with skin condition and role in identifying surgically correctible disease. Eur J Vasc Endovasc Surg. 1996;11: 195-200.

34. Bates DO, Curry FE. Vascular endothelial growth factor increases hydraulic conductivity of isolated perfused microvessels. Am J Physiol. 1996;271:H2520-8.

35. Herouy $Y$, May AE, Pornschlegel G, et al. Lipodermatosclerosis is characterized by elevated expression and activation of matrix metalloproteinases: implications for venous ulcer formation. J Invest Dermatol. 1998;111:822-7.

36. Norgauer J, Hildenbrand T, Idzko M, et al. Elevated expression of extracellular matrix metalloproteinase inducer (CD147) and membrane-type matrix metalloproteinases in venous leg ulcers. $\mathrm{Br}$ J Dermatol. 2002;147:1180-6.

37. Mwaura B, Mahendran B, Hynes N, et al. The impact of differential expression of extracellular matrix metalloproteinase inducer, matrix metalloproteinase-2, tissue inhibitor of matrix metalloproteinase-2 and PDGF-AA on the chronicity of venous leg ulcers. Eur J Vasc Endovasc Surg. 2006;31:306-10.

38. Pappas PJ, You R, Rameshwar P, et al. Dermal tissue fibrosis in patients with chronic venous insufficiency is associated with increased transforming growth factor-beta1 gene expression and protein production. J Vasc Surg. 1999;30:1129-45.

39. Ackerman Z, Seidenbaum M, Loewenthal E, Rubinow A. Overload of iron in the skin of patients with varicose ulcers. Possible contributing role of iron accumulation in progression of the disease. Arch Dermatol. 1988;124:1376-8. 
40. Junger M, Steins A, Hahn M, Hafner HM. Microcirculatory dysfunction in chronic venous insufficiency (CVI). Microcirculation. 2000;7:S3-12.

41. Smith JJ, Garratt AM, Guest M, et al. Evaluating and improving health-related quality of life in patients with varicose veins. J Vasc Surg. 1999;30:710-9.

42. Launois R, Reboul-Marty J, Henry B. Construction and validation of a quality of life questionnaire in chronic lower limb venous insufficiency (CIVIQ). Qual Life Res. 1996;5:539-54.

43. Kakkos SK, Rivera MA, Matsagas MI, et al. Validation of the new venous severity scoring system in varicose vein surgery. J Vasc Surg. 2003;38:224-8.

44. Rutherford RB, Padberg FT, Jr., Comerota AJ, et al. Venous severity scoring: An adjunct to venous outcome assessment. J Vasc Surg. 2000;31:1307-12.

45. Coleridge-Smith P, Labropoulos N, Partsch H, et al. Duplex ultrasound investigation of the veins in chronic venous disease of the lower limbs--UIP consensus document. Part I. Basic principles. Eur J Vasc Endovasc Surg. 2006;31:83-92.

46. Cavezzi A, Labropoulos N, Partsch H, et al. Duplex ultrasound investigation of the veins in chronic venous disease of the lower limbs--UIP consensus document. Part II. Anatomy. Vasa. 2007;36: 62-71.

47. Coleridge-Smith P, Labropoulos N, Partsch H, et al. Duplex ultrasound investigation of the veins in chronic venous disease of the lower limbs--UIP consensus document. Part I. Basic principles. Vasa. 2007;36:53-61.

48. De Maeseneer M, Pichot O, Cavezzi A, et al. Duplex ultrasound investigation of the veins of the lower limbs after treatment for varicose veins - UIP consensus document. Eur J Vasc Endovasc Surg. 2011;42:89-102.

49. Ibegbuna V, Delis KT, Nicolaides AN, Aina O. Effect of elastic compression stockings on venous hemodynamics during walking. J Vasc Surg. 2003;37:420-5.

50. Mayberry JC, Moneta GL, DeFrang RD, Porter JM. The influence of elastic compression stockings on deep venous hemodynamics. J Vasc Surg. 1991;13:91-9; discussion 9-100.

51. Durkin MT, Turton EP, Wijesinghe LD, et al. Long saphenous vein stripping and quality of life--a randomised trial. Eur J Vasc Endovasc Surg. 2001;21:545-9.

52. MacKenzie RK, Paisley A, Allan PL, et al. The effect of long saphenous vein stripping on quality of life. J Vasc Surg. 2002;35:1197-203.

53. Keller WL. A new method of extirpating the internal saphenous and similar veins in varicose conditions: a preliminary report. NY Med J. 1905;82:385.

54. Mayo CH. Treatment of varicose veins. Surg Obstet Gynecol. 1906;2:385-8.

55. Babcock WW. A new operation for the extirpation of varicose veins of the leg. NY Med J. 1907;86: 153-6.

56. Holme JB, Skajaa K, Holme K. Incidence of lesions of the saphenous nerve after partial or complete stripping of the long saphenous vein. Acta Chir Scand. 1990;156:145-8.

57. Perrin MR, Guex JJ, Ruckley CV, dePalma RG, et al. Recurrent varices after surgery (REVAS), a consensus document. REVAS group. Cardiovasc Surg. 2000;8:233-45.

58. Fischer R, Chandler JG, De Maeseneer MG, et al. The unresolved problem of recurrent saphenofemoral reflux. J Am Coll Surg. 2002;195:80-94.

59. Allegra $C$, Antignani PL, Carlizza A. Recurrent varicose veins following surgical treatment: our experience with five years follow-up. Eur J Vasc Endovasc Surg. 2007;33:751-6.

60. Perrin MR, Labropoulos N, Leon LR, Jr. Presentation of the patient with recurrent varices after surgery (REVAS). J Vasc Surg. 2006;43:327-34; discussion 34. 
61. Fischer R, Linde $\mathrm{N}$, Duff $\mathrm{C}$, et al. Late recurrent saphenofemoral junction reflux after ligation and stripping of the greater saphenous vein. J Vasc Surg. 2001;34:236-40.

62. Campbell WB, Vijay Kumar A, Collin TW, et al. The outcome of varicose vein surgery at 10 years: clinical findings, symptoms and patient satisfaction. Ann R Coll Surg Engl. 2003;85:52-7.

63. Perkins JM. Standard varicose vein surgery. Phlebology. 2009;24 Suppl 1:34-41.

64. Kabnick LS. Varicose veins: endovenous treatment. In: Cronenwett JL, Johnston KW, editors. Rutherford's vascular surgery. 7th ed. Philadelphia: Saunders; 2010. p. 871-88.

65. van den Bos RR, Milleret R, Neumann M, Nijsten T. Proof-of-principle study of steam ablation as novel thermal therapy for saphenous varicose veins. J Vasc Surg. 2011;53:181-6.

66. van den Bos $\mathrm{R}$, Arends $\mathrm{L}$, Kockaert $\mathrm{M}$, et al. Endovenous therapies of lower extremity varicosities: a meta-analysis. J Vasc Surg. 2009;49:230-9.

67. Fegan WG, Fitzgerald DE, Beesley WH. A Modern Approach to the Injection Treatment of Varicose Veins and Its Applications in Pregnant Patients. Am Heart J. 1964;68:757-64.

68. Fegan WG. Continuous compression technique of injecting varicose veins. Lancet. 1963;2:109-12.

69. Cabrera Garido JR, Cabrera Garcia Olmedo JR, Olmedo DG. Nuevo metododel de esclerosis en las varices tronculares. Patol Vasculares. 1995;4:55-73.

70. Cabrera J, Redondo P, Becerra A, Garrido C, et al. Ultrasound-guided injection of polidocanol microfoam in the management of venous leg ulcers. Arch Dermatol. 2004;140:667-73.

71. Cabrera J, Cabrera J, Jr., Garcia-Olmedo MA, Redondo P. Treatment of venous malformations with sclerosant in microfoam form. Arch Dermatol. 2003;139:1409-16.

72. Cavezzi A, Tessari L. Foam sclerotherapy techniques: different gases and methods of preparation, catheter versus direct injection. Phlebology. 2009;24:247-51.

73. Frullini A, Cavezzi A. Sclerosing foam in the treatment of varicose veins and telangiectases: history and analysis of safety and complications. Dermatol Surg. 2002;28:11-5.

74. Smith PC. Chronic venous disease treated by ultrasound guided foam sclerotherapy. Eur J Vasc Endovasc Surg. 2006;32:577-83.

75. Barrett JM, Allen B, Ockelford A, Goldman MP. Microfoam ultrasound-guided sclerotherapy of varicose veins in 100 legs. Dermatol Surg. 2004;30:6-12.

76. Breu FX, Guggenbichler S, Wollmann JC. 2nd European Consensus Meeting on Foam Sclerotherapy 2006, Tegernsee, Germany. Vasa. 2008;37 Suppl 71:1-29.

77. Breu FX, Guggenbichler S, Wollmann JC. Duplex ultrasound and efficacy criteria in foam sclerotherapy from the 2nd European Consensus Meeting on Foam Sclerotherapy 2006, Tegernsee, Germany. Vasa. 2008;37:90-5.

78. Bountouroglou DG, Azzam M, Kakkos SK, et al. Ultrasound-guided foam sclerotherapy combined with sapheno-femoral ligation compared to surgical treatment of varicose veins: early results of a randomised controlled trial. Eur J Vasc Endovasc Surg. 2006;31:93-100.

79. Kakkos SK, Bountouroglou DG, Azzam M, et al. Effectiveness and safety of ultrasound-guided foam sclerotherapy for recurrent varicose veins: immediate results. J Endovasc Ther. 2006;13: 357-64.

80. Parsi K, Exner T, Connor DE, et al. In vitro effects of detergent sclerosants on coagulation, platelets and microparticles. Eur J Vasc Endovasc Surg. 2007;34:731-40.

81. Rabe E, Otto J, Schliephake D, Pannier F. Efficacy and safety of great saphenous vein sclerotherapy using standardised polidocanol foam (ESAF): a randomised controlled multicentre clinical trial. Eur J Vasc Endovasc Surg. 2008;35:238-45. 
82. Yamaki T, Nozaki M, Iwasaka S. Comparative study of duplex-guided foam sclerotherapy and duplex-guided liquid sclerotherapy for the treatment of superficial venous insufficiency. Dermatol Surg. 2004;30:718-22; discussion 22.

83. Nijsten T, van den Bos RR, Goldman MP, et al. Minimally invasive techniques in the treatment of saphenous varicose veins. J Am Acad Dermatol. 2009;60:110-9.

84. Tessari L, Cavezzi A, Frullini A. Preliminary experience with a new sclerosing foam in the treatment of varicose veins. Dermatol Surg. 2001;27:58-60.

85. Bergan J. Sclerotherapy: a truly minimally invasive technique. Perspect Vasc Surg Endovasc Ther. 2008;20:70-2.

86. Hobbs JT. Surgery and sclerotherapy in the treatment of varicose veins. A random trial. Arch Surg. 1974;109:793-6.

87. Dumas BE, Spronk S, Boelhouwer RU, den Hoed PT. Subfascial ligation at three different levels versus partial exeresis of the incompetent short saphenous vein: a randomized clinical trial. JVasc Nurs. 2007;25:12-8.

88. Porter JM, Moneta GL. Reporting standards in venous disease: an update. International Consensus Committee on Chronic Venous Disease. J Vasc Surg 1995;21:635-45.

89. Eklof B, Rutherford RB, Bergan JJ, et al. Revision of the CEAP classification for chronic venous disorders: consensus statement. J Vasc Surg 2004;40:1248-52.

90. Nicolaides AN, Cardiovascular Disease Educational and Research T, European Society of Vascular S, Organization TIASAC, International Union of A, Union Internationale de Phlebologie at the Abbaye des Vaux de C. Investigation of chronic venous insufficiency: a consensus statement (France, march 5-9, 1997). Circulation 2000;102:E126-63. 


\title{
CHAPTER 2
}

\section{Foam sclerotherapy versus surgery for incompetent great saphenous veins.}

\author{
N. Shadid \\ R.P. Ceulen \\ P.J. Nelemans \\ C.D. Dirksen \\ J.C. Veraart \\ G.W. Schurink \\ P.A. van Neer \\ J. van der Kley \\ E. de Haan \\ A. Sommer
}

Funding: Netherlands Organisation for Health Research and development (ZonMw) Br J Surg. 2012 May 25. [Epub ahead of print] 


\section{Abstract}

Background Although surgery is the standard treatment for GSV incompetence, new minimally invasive treatment modalities, such as FS are becoming more popular. In a multicentre randomised controlled non-inferiority trial, we compared the effectiveness and costs of FS and surgery in treating GSV incompetence.

Methods Patients with primary GSV varicosity were randomly assigned to either FS or surgical stripping with high ligation. The primary outcome measure was the 2-year probability of the combination of reflux and symptoms. Reflux was determined based on colour duplex scans at baseline and at 3 months, 1 year, and 2 years following the initial treatment. The secondary outcome measures were presence of recurrent reflux (irrespective of symptoms), reduction of symptoms, health-related quality of life $\left(E Q-5 D^{\mathrm{TM}}\right)$, adverse events and direct hospital costs.

Results Two hundred thirty-patients were treated by FS, and 200 patients underwent GSV stripping. The 2-year probability of the combination of reflux and venous symptoms was similar between the FS and surgery groups: $11.3 \%$ (24/213) and 9.0\% (16/177), respectively $(p=0.30)$. At 2 years, reflux, irrespective of venous symptoms, occurred significantly more frequently in the FS group (35\%) than in the surgery group (21\%) $(p=0.002)$. The mean hospital costs per patient over 2 years were EUR 774 (SD: EUR 344.08) per patient for FS and EUR 1824 (SD: EUR 140.90) for stripping.

Conclusion At 2-year follow-up, FS was not inferior to surgery when reflux associated with venous symptoms was the clinical outcome of interest. FS has the potential to be a costeffective approach to a common health problem. 


\section{Introduction}

Lower extremity venous insufficiency is a common health problem in Western countries, and its prevalence increases with age. The results of epidemiological studies demonstrate that a quarter of the adult population have some degree of varicose veins. This condition occurs more frequently in women than in men. ${ }^{1}$ More than $25 \%$ of individuals with varicose veins exhibit insufficiency of the truncal veins of the legs. The disease has a substantial impact on the patients' quality of life and on the resources and budgets of the health care systems. ${ }^{2}$ For many years, the standard treatment for this condition was surgical stripping of the GSV. This standard was based on the results of a large randomised trial by Hobbs et al. This previous study compared surgery with liquid sclerotherapy for the treatment of GSV incompetence and demonstrated that surgery was more effective. ${ }^{3}$ Long-term results showed recurrence rates between $21 \%$ and $26 \%$ after 3 years of follow-up and $60 \%$ after 34 years of follow-up. ${ }^{4-6}$ In recent years, however, the demand for minimally invasive and less expensive procedures has increased. ${ }^{7}$ One such technique is FS, which is performed in an outpatient setting. FS is a variant of liquid sclerotherapy, in which the liquid/air mixture (foam) is injected into varicose veins under ultrasound guidance. Compared with liquid sclerotherapy, FS is approximately four times as effective. ${ }^{8,9}$ Successfully treated veins are transformed into fibrous cords, and the functional result corresponds to surgical removal of a varicose vein..$^{10,11} \mathrm{FS}$ is a successful therapy, with reported occlusion rates of $75-85 \%$ after one year and $69 \%$ after 2 years of follow-up. ${ }^{12-14}$ The advantages of this treatment are that it is less invasive, reduces health care costs, and is associated with a shorter recovery time than surgery. ${ }^{15-17}$ All of these advantages make FS an attractive alternative to surgery for the treatment of reflux of saphenous veins.

To our knowledge, there has been no large randomised controlled trial comparing surgery with FS for the treatment of varicose veins. The aim of the present multicentre randomised controlled trial was to compare the effectiveness and hospital costs of FS with those of surgery in treating GSV incompetence. Although success rates following one FS session may be lower than that following surgery, FS can be a cost-effective alternative to surgery because of the simple and relatively low-cost of treatment and retreatment.

\section{Methods}

\section{Patients}

Patients were recruited at the outpatient dermatology and surgery departments of three hospitals in the Netherlands: Maastricht University Medical Centre, Atrium Medical Centre Heerlen, and Laurentius Hospital Roermond. Patients were eligible if they 1. exhibited primary incompetence of the SFJ and the GSV (measured over a distance of at least $20 \mathrm{~cm}$ in 
the upper leg) with a reflux time greater than 0.5 seconds; and 2. presented a normal deep venous system as determined by colour duplex scanning. The patients with an incompetent deep venous system or an active ulcer and those who were allergic to the sclerosing liquid POL were excluded. The trial was approved by the medical ethics committee of Maastricht University Medical Centre. All of the patients provided written informed consent prior to participating in the study, according to the principles of the Declaration of Helsinki. The trial was registered on the websites www.trialregister.nl (NTR654) and https://register.clinicaltrials.gov (NCT01103258).

\section{Procedures}

Eligible patients with primary incompetence of the GSV were included and randomly assigned to FS or surgery using a computer-generated randomisation scheme with random permuted blocks of 8 .

\section{Outcome measures}

The primary outcome measure of this study was the cumulative probability of recurrent varicose veins 2 years following treatment. The recurrence of varicose veins was defined as the presence of one or more venous symptoms, such as pain, cramps, restless legs, and a tired/ heavy feeling in the treated leg, in combination with the presence of reflux longer than 0.5 seconds. This primary outcome measure was chosen for pragmatic reasons given that in clinical practice, only patients with both venous reflux and symptoms are candidates for retreatment. Recurrent reflux was defined as reflux for more than $2 \mathrm{~cm}$ in length in the treated vein segment (proximal GSV) as measured by colour flow Doppler ultrasound. Duplex findings of the treated GSV were categorised as follows: $1=$ absence of reflux, 2=reflux, 3=occlusion, $4=$ partial occlusion or $5=$ absence of vein. Patients in categories 2 and 4 were considered to have reflux. Duplex findings in the distal GSV and other veins were also recorded. Secondary outcomes were presence of recurrent reflux (irrespective of symptoms), health-related quality of life (EQ-5D ${ }^{\mathrm{Tm}}$; EuroQol Group, Rotterdam, The Netherlands), adverse events and direct hospital costs. The secondary outcome measures were complaints, quality of life, adverse events and hospital costs. The outcomes were evaluated at baseline, 3 months, 1 year and 2 years following the treatment. The patients were asked about the presence of venous complaints, such as pain, cramps, a tired/heavy feeling and restless legs. Symptom frequency was classified into the following four categories: 1 =absent, 2 =occasionally, 3 =frequently or $4=$ continuously. The patients were also asked to indicate whether the treatment met their expectations in terms of the aesthetic and functional outcome (reduced complaints), with the following answer options: $1=$ not meeting expectations, $2=$ partially meeting expectations and $3=$ fully meeting expectations. The clinical, Etiology, Anatomy, Pathology (CEAP) 
classification was performed, all the varicose veins were mapped and a Venous Clinical Severity Score (VCSS) was assigned by the research physician.

Patients'health-related quality of life was measured by means of the EQ-5D ${ }^{\mathrm{TM}}$. The EQ-5D ${ }^{\mathrm{TM}}$ consists of five dimensions (mobility, self-care, usual activities, pain and mood) which each can be rated at three levels (no problems, some problems, severe problems), which yields 243 potential combinations of health states. Each health state is associated with a utility score by means of an additive function derived from the Dutch general population. ${ }^{32}$ Furthermore, the EQ-5D ${ }^{\mathrm{TM}}$ consists of a visual analogue scale (VAS) on which patients can rate their health state from worst possible health state (0) to best possible health state (100).

\section{Colour duplex}

The duplex examination was performed at baseline, 3 months, 1 year, and 2 years following treatment by an independent ultrasound technician using a colour duplex scanner (MyLab25 ${ }^{\mathrm{TM}}$; Esaote Benelux, Maastricht, The Netherlands). The scanner was equipped with a $10 \mathrm{MHz}$ transducer to detect venous reflux in the GSV. Venous mapping of the entire deep and superficial venous system was performed. The reflux time of the GSV was measured using colour-flow Doppler ultrasound. Treated veins were screened for venous occlusion, flow and compressibility.

\section{Foam sclerotherapy}

The GSV was identified via duplex imaging in the standing position and was marked from the SFJ following the path of reflux in the GSV. Sclerosing foam was prepared with the DSS technique, applying a 1:4 sclerosant-to-air ratio. One syringe was filled with $1 \mathrm{~mL} 3 \% \mathrm{POL}$ (Aethoxysklerol ${ }^{\oplus}$, Kreussler Pharma, Wiesbaden, Germany) and the other syringe with $4 \mathrm{~mL}$ air. The patients were treated in the supine position with an 18-G intravenous cannula (B. Braun, Melsungen, Germany). The treatment was considered successful if the proximal GSV was completely filled with foam and maximal venospasm was achieved. Neither elevation of the leg nor compression of the SFJ was performed. Compression was applied with a foam pad over the treated area and an anti-embolism (Brevet TX $10 \mathrm{mmHg}$, Klinion Medeco, Oud Beijerland, The Netherlands) stocking for one week, day and night. A Class II elastic stocking (Mediven Plus $23 \mathrm{mmHg}$, Medi, Bayreuth, Germany) was prescribed to be worn during the day for six weeks. Following the treatment, the patients were instructed to walk for at least 30 minutes, after which they could resume their daily activities, including professional activities. If necessary, patients received additional treatment at the subsequent visits for other varicose veins with FS or phlebectomies.

\section{Surgery}

Saphenofemoral ligation and GSV stripping to the knee level was performed as a day-case procedure under general or spinal anaesthesia. Following a groin incision, the sapheno- 
femoral GSV was prepared. Following ligation of the side branches of the GSV, the SFJ was ligated and the GSV was cut. The GSV was fixed just below the knee to the stripper (Multistrip, Prodimed, Washington DC, USA) and then the proximal GSV was removed. The incision in the groin was closed subcutaneously with Vicryl 3-0 and intracutaneously with Monocryl 4-0. The decision te perform phlebectomies was left to the decision of the surgeon. The leg was bandaged from distal to proximal. The patient was mobilised immediately postoperatively. After 48 hours, the bandages were replaced by a Class II elastic stocking (Mediven Plus 23 $\mathrm{mmHg}$, Medi, Bayreuth, Germany) for 6 weeks. The patients were advised to resume their daily activities, including professional activities, after 1 week.

\section{Cost analysis}

The cost analysis was performed from a hospital perspective with a 2-year time horizon. The data regarding resource use were obtained for each patient from case report forms (CRFs). The cost data included the costs of outpatient visits, study treatment (FS or stripping), retreatment and the complementary treatment of the GSV and other varicose veins during follow-up. The unit prices, comprising personnel, materials, capacity and overhead costs were obtained from the financial department of the Maastricht University Medical Centre. All of the prices were expressed in 2008 euros. The hospital costs over 2 years were calculated by multiplying resource use by cost price per unit of resource use. The costs occurring after one year were discounted.

\section{Statistical analyses}

The study was designed as a non-inferiority trial. Based on the literature, we assumed that the 2-year probability of recurrent varicose veins following standard treatment by surgery was $30 \%$. A power calculation demonstrated that a total sample size of 460 patients was required to detect a $10 \%$ difference in the failure percentage between surgery and FS with a power of $80 \%$ (one-sided type I error of 0.05 ).

The differences between the treatment groups with respect to the proportions of patients with a specific outcome at 3 months, 1 year and 2 years following treatment were tested for statistical significance using the Chi-squared test. Ninety-five per cent confidence intervals around the difference in proportions were calculated. $\mathrm{P}<0.05$ was considered statistically significant. Only patients who underwent the allocated intervention were included in the analysis.

All of the data were analysed with SPSS version 16.0 (SPSS, Chicago, Illinois, USA) and Stata version 11.1 (SAS Institute, Cary, North Carolina, USA). 


\section{Role of the funding source}

The sponsor of the study had no role in the study design; the writing of the report; or the collection, analysis or interpretation of data. The corresponding author had full access to all of the data in the study and had final responsibility for its submission for publication.

\section{Results}

From October 2005 to December 2007, 530 patients were eligible for this study. Seventy patients with GSV incompetence refused to participate, primarily because they had a preference for one of the two treatments. In total, 460 patients with primary GSV incompetence were randomised into one of the two groups. Of the 233 patients assigned to FS, 230 were treated by this modality; 3 patients withdrew from the study following randomisation. Of the 227 patients assigned to surgery, 200 were treated, and 27 withdrew from the study. Twenty-four of these patients refused treatment by surgery. Baseline data were available for 460 patients. According to the Clinical Etiologic Anatomic Pathophysiologic (CEAP) classification, assessed by the coordinating researcher, all patients had C2-C5EpAsPr. Complete follow-up data up to 2 years following treatment were obtained for 93\% (213/230) of the patients in the FS group and for $89 \%(177 / 200)$ of the patients in the surgery group (Figure 1). Table 1a lists the baseline characteristics of the 460 enrolled participants. The baseline characteristics were similar in both groups. Table $1 \mathrm{~b}$ lists the baseline characteristics of the patients who underwent the treatment to which they had been assigned. Due to logistic problems, baseline VAS values were lacking for $11.6 \%$ of the patients.

The probabilities of the primary outcome and anatomical failure are presented in Figure 2.

Two years following the treatment, the probability of recurrence in the FS group was $11.3 \%$, compared to $9.0 \%$ in the surgery group. The difference in the proportions was $2.2 \%$, with a $95 \%$ confidence interval of $-3.8 \%$ to $7.7 \%(p=0.30)$. During follow-up, differences between the treatments emerged with respect to the anatomical results (i.e., the presence of reflux irrespective of venous complaints). Although there were no significant differences at 3 months or 1 year following the treatment, the proportion of patients exhibiting reflux irrespective of venous symptoms 2 years following the treatment was significantly higher in the FS group than in the surgery group ( $p=0.002$ ). The difference between these proportions was $14 \%$, with a $95 \%$ confidence interval ranging from $5.4 \%$ to $22.5 \%$. However, the percentage of reflux in the surgery group may have been underestimated; in this group, 9 of 10 patients with reflux at 1 year did not attend the final consultation at 2 years, compared to only 1 patient who did not attend the 2-year follow-up in the FS group. Assuming that recurrent varicosity in these patients was still present at 2 years, the percentages of those exhibiting 


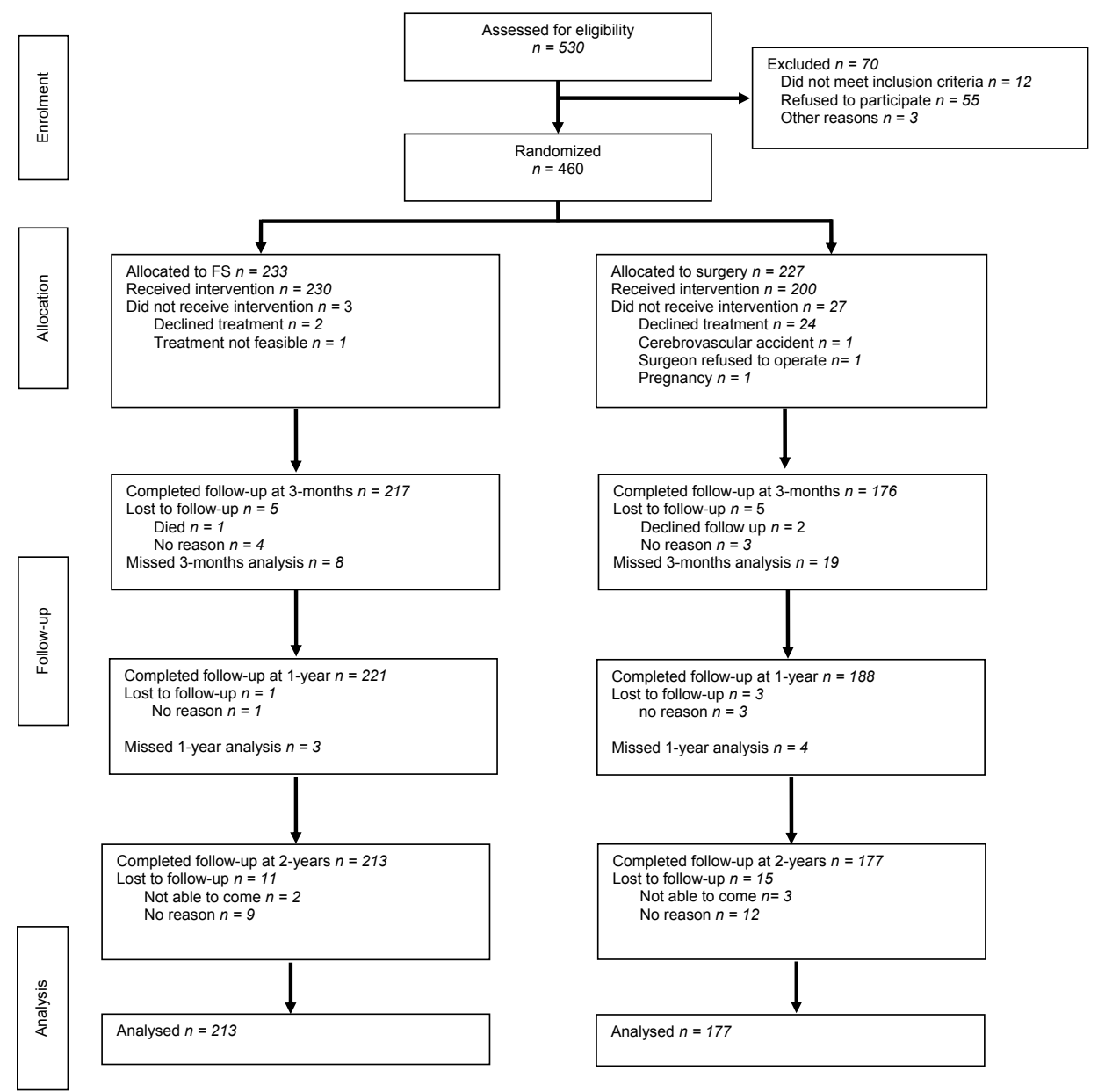

Figure 1. CONSORT diagram showing flow of patients through the study. Note that due to missed visits, there are differences between the numbers of patients available for analysis and the number actually seen in the follow-up measurements.

reflux would have been $35.5 \%$ and $24.7 \%$ in the FS and surgery group, respectively, with a difference of $10.8 \%$ and a $95 \%$ confidence interval of $1.7 \%$ to $19.3 \%(p=0.03)$.

Reflux in the distal GSV below the knee at 2 years was present in $41.3 \%$ and $42.9 \%$ of patients in the FS and surgery group, respectively $(p=0.75)$.

Of the 230 patients treated with FS, 61 patients were additionally treated. Two patients underwent FS of the SSV and 14 FS of tributaries of the GSV, 26 patients underwent phlebectomy of tributaries of the GSV and 19 patients were treated with sclerotherapy for teleangiectatic veins. In the surgery group, phlebectomy was performed in $44 \%$ (87/200) of the patients during the initial stripping procedure. In subsequent visits, another 28 patients 
Table 1. (a) Distribution of baseline characteristics of the 460 randomised patients assigned to FS or surgery. (b) Distribution of baseline characteristics of the 430 treated patients assigned to FS or surgery. The figures represent absolute numbers and percentages for nominal variables, mean values, and standard deviations (SD) for continuous variables.

\section{(a) Randomised 460 patients}

\begin{tabular}{|c|c|c|}
\hline & $\mathrm{FS}(\mathrm{n}=233)$ & Surgery $(n=227)$ \\
\hline Age(years) & 55.8 (SD 13.4) (range 27-87) & 54.6 (SD 13.4) (range 24-86) \\
\hline Female & $175(75.1 \%)$ & $162(71.4 \%)$ \\
\hline \multicolumn{3}{|l|}{ Clinical presentation } \\
\hline C2 & $203(87.1 \%)$ & $188(82.8 \%)$ \\
\hline C3 & $21 \quad(9.0 \%)$ & $24 \quad(10.6 \%)$ \\
\hline C4 & $21 \quad(9.0 \%)$ & $16 \quad(7.0 \%)$ \\
\hline C5 & $5 \quad(2.1 \%)$ & $(2.6 \%)$ \\
\hline Diameter GSV upper thigh (mm) & 6.1 (SD 2.0) (range 2.3-15.4) & 6.6 (SD 2.4) (range 2.2-18.6) \\
\hline Diameter GSV mid thigh(mm) & 5.5 (SD 1.8) (range 1.5-13.6) & 5.8 (SD 2.0) (range 2.3-12.0) \\
\hline Diameter GSV lower thigh(mm) & 5.2 (SD 1.9) (range 1.2-12.8) & 5.5 (SD 2.0) (range 1.4-15.0) \\
\hline Reflux time GSV(s) & 2.4 (SD 1.6) (range 0.5-8.0) & 2.5 (SD 1.7) (range 0.5-9.0) \\
\hline Volume of foam (ml) & 5.4 (SD 2.0) (range 2-20) & \\
\hline
\end{tabular}

\section{(b) Treated 430 patients}

\section{Age(years)}

Female

Clinical presentation

C2

C3

C4

C5

Diameter GSV upper thigh(mm)

Diameter GSV mid thigh $(\mathrm{mm})$

Diameter GSV lower thigh (mm)

Reflux time GSV(s)

$$
\mathrm{FS}(\mathrm{n}=230)
$$

51.6 (SD 13.3) (range 22-83)

$173(75.2 \%)$

$$
\begin{array}{ll}
199 & (86.5 \%) \\
21 & (9.1 \%) \\
21 & (9.1 \%) \\
5 & (2.2 \%)
\end{array}
$$

$6 \cdot 1$ (SD 2.0) (range 2.3-15.4)

5.5 (SD 1.8) (range 1.5-13.6)

5.2 (SD 1.9) (range 1.2-12.8)

2.4 (SD 1.6) (range 0.5-8.0)
Surgery $(n=200)$

50.7 (SD 13.4) (range 20-81)

141 (70.5\%)

$160(80.0 \%)$

$23(11.5 \%)$

$16(8.0 \%)$

$6 \quad(3.0 \%)$

6.8 (SD 2.4) (range 2.2-18.6)

5.9 (SD 2.0) (range 2.3-12.0)

5.7 (SD 2.0) (range 1.4-15.0)

2.6 (SD 1.9) (range 0.6-9.0)

\footnotetext{
${ }^{*} \mathrm{FS}=$ foam sclerotherapy tGSV = great saphenous vein $\neq \mathrm{C} 2$ = varicosis as clinical sign $\S C 3=$ oedema as clinical sign $\| C 4=$ skin changes as clinical sign ПC5 = healed ulcer as clinical sign
} 

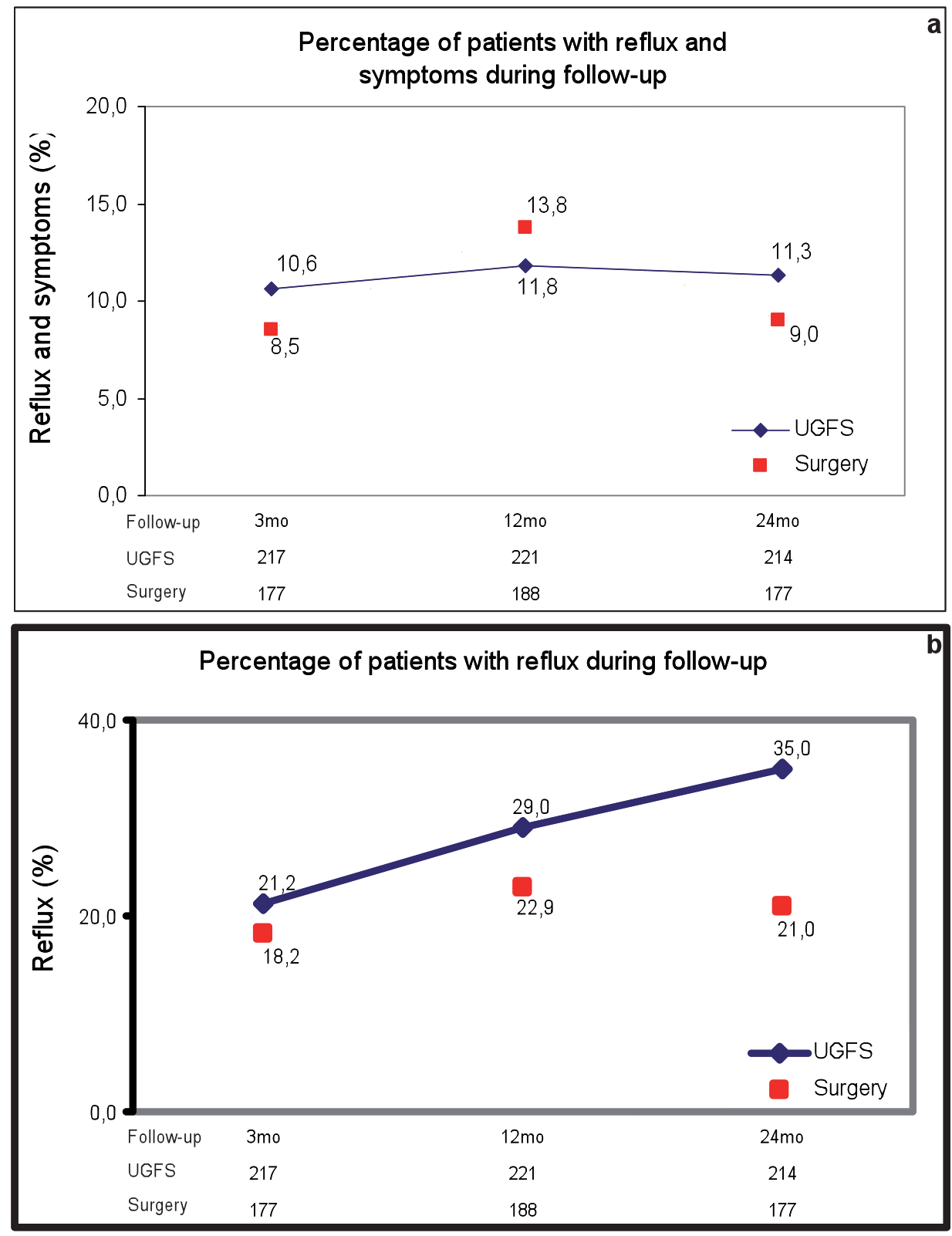

Figure 2. (a) percentage of patients with reflux in combination with venous symptoms and (b) percentage of patients with reflux irrespective of venous symptoms at 3-,12-, and 24-month follow-up. UGFS = foam sclerotherapy

had an additional treatment. One patient received FS of the SSV, 11 patients underwent treatment of tributaries: 7 with phlebectomy, 4 with FS. Sixteen patients underwent sclerotherapy for teleangiectatic veins. 
At 2 years the mean change in the VCSS score from baseline was similar in both groups -1.49 in the FS group versus -1.75 in the surgery group $(p=0.23)$. Change in health-related quality of life did not differ between both groups. The mean change in the EQ-5D ${ }^{\text {TM }}$ utility score (score at 2 years follow up minus score at baseline) was 0.064 and 0.061 in the FS and surgery group respectively $(p=0.89)$. The mean changes for the VAS scores were -0.36 in the FS and -1.8 in the surgery group ( $p=0.58$ ). After 2 years, no significant differences in symptom relief were observed between the treatment groups. The greatest impact of both treatments

Table 2. Effect of FS and surgery on venous symptoms and patient satisfaction of patients with aesthetic and functional outcomes at 3,12, and 24 months.

\begin{tabular}{|c|c|c|c|c|c|c|c|c|c|c|c|c|c|c|c|}
\hline & \multicolumn{4}{|c|}{3 months } & \multicolumn{5}{|c|}{12 months } & \multicolumn{6}{|c|}{24 months } \\
\hline & \multicolumn{2}{|c|}{$\begin{array}{c}\text { FS } \\
(n=217)\end{array}$} & \multicolumn{2}{|c|}{$\begin{array}{c}\text { Surgery } \\
(n=176)\end{array}$} & \multirow[t]{2}{*}{ p value } & \multicolumn{2}{|c|}{$\begin{array}{c}\text { FS } \\
(n=221)\end{array}$} & \multicolumn{2}{|c|}{$\begin{array}{l}\text { Surgery } \\
(n=188)\end{array}$} & \multirow[t]{2}{*}{ p value } & \multicolumn{2}{|c|}{$\begin{array}{c}\text { FS } \\
(n=213)\end{array}$} & \multicolumn{2}{|c|}{$\begin{array}{l}\text { Surgery } \\
(n=177)\end{array}$} & \multirow[t]{2}{*}{ p value } \\
\hline \multicolumn{13}{|l|}{ Venous Symptoms } & & & \\
\hline \multicolumn{16}{|l|}{ Pain } \\
\hline More & 12 & $(5.5 \%)$ & 10 & $(5.7 \%)$ & 0.80 & 20 & $(9.0 \%)$ & 14 & $(7.4 \%)$ & 0.83 & 14 & $(6.6 \%)$ & 6 & $(3.4 \%)$ & 0.34 \\
\hline Stable & 111 & $(51.2 \%)$ & 84 & $(47.4 \%)$ & & 109 & $(49.3 \%)$ & 93 & $(49.5 \%)$ & & 104 & $(48.8 \%)$ & 86 & $(48.6 \%)$ & \\
\hline Less & 94 & $(43.3 \%)$ & 82 & $(46.6 \%)$ & & 92 & $(41.6 \%)$ & 81 & $(43.1 \%)$ & & 95 & $(44.6 \%)$ & 85 & $(48.0 \%)$ & \\
\hline \multicolumn{16}{|l|}{ Tired/heavy feeling } \\
\hline More & 8 & $(3.7 \%)$ & 2 & $(1.1 \%)$ & 0.27 & 5 & $(2.3 \%)$ & 9 & $(4.8 \%)$ & 0.29 & 6 & $(2.8 \%)$ & 4 & $(2.3 \%)$ & 0.36 \\
\hline Stable & 71 & $(32.7 \%)$ & 61 & $(34.7 \%)$ & & 85 & $(38.5 \%)$ & 64 & $(34.0 \%)$ & & 74 & $(34.7 \%)$ & 50 & $(28.2 \%)$ & \\
\hline Less & 138 & $(63.6 \%)$ & 113 & $(64.2 \%)$ & & 131 & $(59.3 \%)$ & 115 & $(61.2 \%)$ & & 133 & $(62.4 \%)$ & 123 & $(69.5 \%)$ & \\
\hline \multicolumn{16}{|l|}{ Cramps } \\
\hline More & 9 & $(4.1 \%)$ & 6 & $(3.4 \%)$ & 0.60 & 10 & $(4.5 \%)$ & 9 & $(4.8 \%)$ & 0.75 & 8 & $(3.8 \%)$ & 7 & $(4.0 \%)$ & 0.42 \\
\hline Stable & 79 & $(36.4 \%)$ & 72 & $(40.9 \%)$ & & 84 & $(38.0 \%)$ & 78 & $(41.5 \%)$ & & 79 & $(37.1 \%)$ & 77 & $(43.5 \%)$ & \\
\hline Less & 129 & $(59.4 \%)$ & 98 & $(55.7 \%)$ & & 127 & $(57.5 \%)$ & 101 & $(53.7 \%)$ & & 126 & $(59.2 \%)$ & 93 & $(52.5 \%)$ & \\
\hline \multicolumn{16}{|l|}{ Restless legs } \\
\hline More & 27 & $(12.4 \%)$ & 16 & $(9.1 \%)$ & 0.52 & 34 & $(15.4 \%)$ & 26 & $(13.8 \%)$ & 0.87 & 29 & $(13.6 \%)$ & 21 & $(11.9 \%)$ & 0.63 \\
\hline Stable & 153 & $(70.5 \%)$ & 126 & $(71.6 \%)$ & & 150 & $(67.9 \%)$ & 132 & $(70.2 \%)$ & & 145 & $(68.1 \%)$ & 124 & $(70.1 \%)$ & \\
\hline Less & 37 & $(17.1 \%)$ & 34 & $(19.3 \%)$ & & 37 & $(16.7 \%)$ & 30 & $(16.0 \%)$ & & 39 & $(18.3 \%)$ & 32 & $(18.1 \%)$ & \\
\hline \multicolumn{16}{|l|}{ Patient satisfaction } \\
\hline \multicolumn{16}{|l|}{ Aesthetic } \\
\hline Not satisfied & 39 & $(18.0 \%)$ & 19 & $(10.8 \%)$ & 0.13 & 33 & $(14.9 \%)$ & 32 & $(17 \%)$ & 0.76 & 31 & $(14.6 \%)$ & 23 & $(13 \%)$ & 0.03 \\
\hline Reasonably satisfied & 95 & $(43.8 \%)$ & 82 & $(46.6 \%)$ & & 89 & $(40.3 \%)$ & 70 & $(32.2 \%)$ & & 97 & $(45.5 \%)$ & 60 & $(33.9 \%)$ & \\
\hline Fully satisfied & 83 & $(38.2 \%)$ & 75 & $(42.6 \%)$ & & 99 & $(44.8 \%)$ & 86 & $(45.7 \%)$ & & 85 & $(39.9 \%)$ & 94 & $(53.1 \%)$ & \\
\hline \multicolumn{16}{|l|}{ Functional } \\
\hline Not satisfied & 20 & $(9.2 \%)$ & 15 & $(8.5 \%)$ & 0.06 & 22 & $(10 \%)$ & 28 & $(14.9 \%)$ & 0.1 & 17 & $(8.0 \%)$ & 17 & $(9.6 \%)$ & 0.21 \\
\hline Reasonably satisfied & 76 & $(35 \%)$ & 43 & $(24.4 \%)$ & & 70 & $(31.7 \%)$ & 44 & $(23.4 \%)$ & & 69 & $(32.4 \%)$ & 43 & $(24.3 \%)$ & \\
\hline Fully satisfied & 121 & $(55.8 \%)$ & 118 & $(67.0 \%)$ & & 129 & $(58.4 \%)$ & 116 & $(61.7 \%)$ & & 127 & $(59.6 \%)$ & 117 & (66.1\%) & \\
\hline
\end{tabular}


was observed for cramps and heavy/tired feeling, whereas pain and restless legs were less affected by treatment (Table 2). Complete satisfaction with a reduction of venous complaints was reported by $59.6 \%$ of the patients in the FS group and by $66.1 \%$ in the surgery group.

In the FS group, $82.6 \%(190 / 230)$ of the patients had only one treatment session. Forty patients had a repeat session of FS, 5 of whom had more than two sessions. Two patients in the surgery group underwent re-exploration of the groin. Eight patients were referred for FS by their surgeon because a re-operation was technically infeasible. Certain patients with recurrence in both treatment groups were not retreated because these patients considered their complaints not sufficiently serious or because the surgeon recommended conservative treatment with elastic stockings.

Thrombophlebitis as an adverse event of FS occurred in 17 of the 230 patients (7.5\%). Seven patients required NSAIDs (Diclofenac ${ }^{\oplus} 50 \mathrm{mg} 3$ times daily) and compression. After surgery, 4 patients developed a groin infection, 2 of whom required surgical evacuation. Paraesthesia following surgery persisted in 6 patients, who experienced a numb feeling in the upper or lower leg, although no severe nerve injuries were observed. Two patients in the FS group experienced a serious adverse event: one DVT and one pulmonary embolism one week following the treatment (Table 3). Both of these patients were treated according to protocol with oral anticoagulant therapy.

Table 3. Complications and side-effects after treatment of the incompetent GSV with FS or Surgery.

\begin{tabular}{|c|c|c|c|c|c|}
\hline & \multicolumn{2}{|c|}{$\mathrm{FS}(n=230)$} & \multicolumn{2}{|c|}{ Surgery $(n=200)$} & $p$ value \\
\hline Groin infection & 0 & $(0 \%)$ & 4 & $(2 \%)$ & 0.03 \\
\hline Haematoma & 0 & $(0 \%)$ & 3 & $(1.5 \%)$ & 0.06 \\
\hline Paraesthesia & 0 & $(0 \%)$ & 6 & $(3.0 \%)$ & 0.008 \\
\hline Pain at injection site & 6 & $(2.6 \%)$ & 0 & $(0 \%)$ & 0.02 \\
\hline Thrombophlebitis & 17 & $(7.5 \%)$ & 0 & $(0 \%)$ & $<0.001$ \\
\hline Headache/Migraine & 3 & $(1.3 \%)$ & 0 & $(0 \%)$ & 0.11 \\
\hline Deep venous thrombosis & 1 & $(0.4 \%)$ & 0 & $(0 \%)$ & 0.35 \\
\hline \multirow[t]{2}{*}{ Pulmonary embolism } & & $(0.4 \%)$ & 0 & $(0 \%)$ & 0.35 \\
\hline & \multicolumn{2}{|c|}{ FS ( $n=213)$} & \multicolumn{2}{|c|}{ Surgery $(n=177)$} & \\
\hline \multicolumn{6}{|c|}{ Late complications (at two years) } \\
\hline Hyperpigmentation & 12 & $(5.6 \%)$ & 2 & $(1.1 \%)$ & 0.026 \\
\hline Teleangiectatic matting & 6 & $(2.6 \%)$ & 2 & $(1.1 \%)$ & 0.30 \\
\hline
\end{tabular}

The cost analysis showed the mean total hospital costs to be EUR 774 per patient for FS and EUR 1824 per patient for surgery (Table 4). This cost difference is primarily explained by the costs of treatment and the preceding visits to the outpatient departments which add 
Table 4. Mean hospital costs for patients treated by FS $(n=230)$ or stripping $(n=200)$. Mean hospital costs were EUR 731.12 (SD: 330.97) for FS and EUR 1811.82 (SD: 162.30) for surgery.

\begin{tabular}{|c|c|c|c|c|c|c|c|}
\hline & \multirow[b]{2}{*}{ Unit price (EUR) } & \multicolumn{3}{|c|}{ FS $(n=230)$} & \multicolumn{3}{|c|}{ Surgery $(n=200)$} \\
\hline & & $\begin{array}{c}\text { Resource } \\
\text { use }\end{array}$ & Mean (EUR) & SD & $\begin{array}{c}\text { Resource } \\
\text { use }\end{array}$ & $\begin{array}{l}\text { Mean } \\
\text { (EUR) }\end{array}$ & SD \\
\hline \multicolumn{8}{|l|}{ First visit at department of } \\
\hline dermatology & 98.41 & 230 & 98.41 & 0.00 & - & - & - \\
\hline surgery & 143.69 & - & - & - & 200 & 143.69 & 0.00 \\
\hline anaesthetics & 380.99 & - & - & - & 200 & 380.99 & 0.00 \\
\hline \multicolumn{8}{|l|}{ Initial treatment } \\
\hline FS & 244.94 & 230 & 244.94 & 0.00 & - & - & - \\
\hline stripping & 979.79 & - & - & - & 200 & 979.79 & 0.00 \\
\hline \multicolumn{8}{|l|}{ Follow-up at department of dermatology } \\
\hline 3 months after initial treatment & 98.41 & 217 & 92.85 & 22.78 & 176 & 86.60 & 32.06 \\
\hline 12 months after initial treatment & 98.41 & 221 & 94.56 & 19.12 & 188 & 92.51 & 23.43 \\
\hline 24 months after initial treatment & 98.41 & 213 & 91.14 & 25.80 & 177 & 87.09 & 31.47 \\
\hline \multicolumn{8}{|l|}{ Retreatment } \\
\hline FS & 244.94 & 43 & 52.18 & 117.35 & 10 & 13.47 & 61.13 \\
\hline stripping & 979.79 & 0 & - & - & 2 & 9.80 & 97.75 \\
\hline follow-up & 98.41 & 30 & 12.84 & 35.67 & 6 & 2.95 & 16.83 \\
\hline \multicolumn{8}{|l|}{ Complementary treatment } \\
\hline FS & 244.94 & 16 & 17.03 & 66.5 & 5 & 6.12 & 38.34 \\
\hline phlebectomy & 228.89 & 26 & 26.0 & 78.84 & 7 & 8.01 & 42.2 \\
\hline sclerotherapy & 65.31 & 19 & 5.4 & 18.02 & 16 & 5.22 & 18.93 \\
\hline \multicolumn{8}{|l|}{ Complications } \\
\hline deep venous thrombosis & 1322.00 & 1 & 5.75 & 87.17 & 0 & - & - \\
\hline pulmonary embolism & 4210.00 & 1 & 18.30 & 277.60 & 0 & - & - \\
\hline groin infection & 378.97 & 0 & - & - & 4 & 7.58 & 53.19 \\
\hline thrombophlebitis & 200.74 & 17 & 14.84 & 52.63 & 0 & - & - \\
\hline Total & & 230 & 774.11 & 344.08 & 200 & 1823.82 & 140.90 \\
\hline
\end{tabular}

$\mathrm{SD}=$ standard deviation

up to EUR 343 per patient for FS and EUR 1504 for surgery. The costs of retreatment and complications were slightly higher for FS. Although complications were recorded in the CRF, the consequences in terms of hospital resource use were not, so these costs were estimated. Thrombophlebitis was assumed to require two outpatient visits and one week of Diclofenac ${ }^{\oplus}$ (EUR 0.56 per DDD). The patients with a groin infection were assumed to have visited the outpatient department twice (3 times for those requiring surgical evacuation) and to require 1 week of Floxapen ${ }^{\oplus}$ (EUR 2.82 per DDD). The costs of DVT and pulmonary embolism were based on a paper by ten Cate et al. ${ }^{20}$ 


\section{Discussion}

The principal finding of this randomised clinical trial with a 2-year follow-up is that FS is not inferior to surgery when reflux associated with venous symptoms is considered to be the clinical outcome of interest. FS reduces hospital costs by approximately EUR 1050 per patient for the treatment of GSV varicosis. This study is the first randomised controlled trial providing evidence of the effectiveness of FS compared with stripping of the incompetent GSV. A comparison with data from the literature regarding the effectiveness of FS and surgery is difficult because of differences in the primary outcomes measured. The proportion of patients exhibiting reflux in our study is in agreement with that reported by other studies. Following surgery, recurrence rates after 2-5 years vary between 20 and 50\% $4,21,22$, and recurrence following FS reflux was reported in $31 \%$ of the patients after 2 years. ${ }^{23}$ The conclusion that FS is not inferior to surgery strongly depends on the choice of the outcome measure. From a cost-effectiveness perspective, we considered reflux combined with symptoms as the most relevant measure because it best reflects clinical practice, where patients are treated only if they exhibit a combination of venous reflux and symptoms. However, if we had used only the presence of reflux in the GSV as the outcome measure and the only requirement for retreatment, regardless of venous symptoms, as other studies ${ }^{24,25}$ have, surgery would have been significantly more effective than FS. With respect to the possible inferiority of FS, however, this result is inconclusive. ${ }^{26}$

In our study, side effects, such as hyperpigmentation and thrombophlebitis, were the most common complications in the FS group. One case of DVT and one of pulmonary embolism occurred in the FS group. Neither of these patients exhibited an increased risk of thromboembolic events or any sign of post-thrombotic syndrome, such as deep venous occlusion or reflux within 2 years of follow-up. The $0.4 \%$ frequency of thromboembolic events in our study corresponds to reported thromboembolic event rates between $0.02 \%$ and $1.25 \%$ in other studies of FS. ${ }^{27,28}$

FS is substantially less expensive than surgery. The 2.5-fold lower cost of FS compared to stripping is primarily explained by the lower costs of treatment, as FS does not require general anaesthesia and can be performed as a simple outpatient procedure. We recognise that in the cost analysis 'real-world costs' are probably confounded with study-induced costs, which is the case in many studies that apply an active follow-up scheme. This applies especially to the surgery group as, in routine practice, these patients have only one follow-up visit 10 days following surgery. In this study, follow up visits were planned at 3, 12 and 24 months in order to be able to compare the primary outcome measure between both study arms. It cannot be ruled out that these visits have induced costs (due to retreatment and complementary treatment) that in normal practice would not have been made.

In Western countries, the treatment of varicose veins imposes a considerable burden on health care budgets. ${ }^{29,30}$ In the Netherlands, EUR 274 million annually is spent on the treat- 
ment of venous diseases, accounting for $6 \%$ of the total health care costs. ${ }^{31}$ Replacing surgery with FS would result in a cost reduction of over EUR 1000 per patient and could substantially lower the health care costs of varicose veins.

Minimally less invasive techniques like FS and endothermal ablation techniques, such as EVLA and RFA, are becoming increasingly popular in the treatment of varicose veins. At the start of the present study, experience with the latter treatment modalities was still limited in the Netherlands, which was the reason to focus on comparison of surgery with FS for evaluating whether less invasive treatment of varicose veins are cost-effective. The results support the trend towards the use of minimally invasive techniques. An advantage of FS over endothermal ablation techniques is that tumescent anaesthesia is not required. Moreover, FS is easy to learn and makes it an accessible treatment modality for a large group of practitioners such as dermatologists, surgeons and radiologists.

This study had certain limitations. First, following randomisation, 26 patients refused the treatment to which they had been randomised. The fact that 24 patients refused treatment in the surgery group versus 2 in the FS group could indicate that certain patients had hoped to be assigned to FS. The withdrawal of these patients is unlikely to have affected the results of the study because it did not affect the comparability of the two treatment groups (Table 1b).

Second, blinding was not feasible because of the visible scars following the surgical treatment and the obliteration of the GSV following FS. However, the outcomes were objectively assessed using colour duplex scanning by an analyst who was not involved in the study. The duplex technician was affiliated with neither the dermatology nor the surgery department.

Third, loss to follow-up resulted in a sample size that was less than the intended $\mathbf{4 6 0}$ patients. However, with 200 patients in the surgery group and 230 patients in the FS group, the post-hoc power of this analysis to detect a minimal clinically relevant increase in the risk of recurrence by $10 \%$ or more following FS was $92.6 \%$ (alpha $=5 \%$ ).

In conclusion, this large trial comparing FS with surgery for the treatment of GSV incompetence demonstrated that the 2-year probability of a combination of reflux and symptoms following treatment by FS is similar to that following treatment by surgery. A major advantage of FS is that it results in a 2.4-fold reduction in costs at the hospital level. Our findings indicate that FS is a non-invasive treatment of GSV incompetence and represents a cost-effective approach to a common health problem. These results should be taken into account in the development of future guidelines for the treatment of trunk varicosis, for which FS may deserve a more prominent consideration. 


\section{References}

1. Evans CJ, Fowkes FG, Ruckley CV, Lee AJ. Prevalence of varicose veins and chronic venous insufficiency in men and women in the general population: Edinburgh Vein Study. J Epidemiol Community Health. 1999;53:149-53.

2. Eberhardt RT, Raffetto JD. Chronic venous insufficiency. Circulation. 2005;111:2398-409.

3. Hobbs JT. Surgery and sclerotherapy in the treatment of varicose veins. A random trial. Arch Surg. 1974;109:793-6.

4. van Rij AM, Jiang P, Solomon C, et al. Recurrence after varicose vein surgery: a prospective longterm clinical study with duplex ultrasound scanning and air plethysmography. J Vasc Surg. 2003; 38:935-43.

5. Fischer R, Linde N, Duff C, et al. Late recurrent saphenofemoral junction reflux after ligation and stripping of the greater saphenous vein. J Vasc Surg. 2001;34:236-40.

6. Neglen P. Long saphenous stripping is favored in treating varicose veins. Dermatol Surg. 2001;10: 901-2.

7. Kanwar A, Hansrani M, Lees T, Stansby G. Trends in varicose vein therapy in England: radical changes in the last decade. Annals of the Royal College of Surgeons of England. 2010;92:341-6.

8. Rabe E, Otto J, Schliephake D, Pannier F. Efficacy and Safety of Great Saphenous Vein Sclerotherapy Using Standardised Polidocanol Foam (ESAF): A Randomised Controlled Multicentre Clinical Trial. Eur J Vasc Endovasc Surg. 2008;35:238-45.

9. Yamaki T, Nozaki M, Iwasaka S. Comparative study of duplex-guided foam sclerotherapy and duplex-guided liquid sclerotherapy for the treatment of superficial venous insufficiency. Dermatol Surg. 2004;30:718-22.

10. Kern P. Sclerotherapy of varicose leg veins. Technique, indications and complications. Int Angiol. 2002;21:40-5.

11. Rabe E, Pannier-Fischer F, Gerlach H. Leitlinien zur Verodungsbehandlung der Varikose (ICD 10: 183.0, 183.1, 183.2, 183.9) entwicklungsstufe 1. Phlebologie. 2001;30:154-8.

12. Hamel-Desnos C, Ouvry P, Benigni JP, Boitelle G, Schadeck M, Desnos P, et al. Comparison of $1 \%$ and $3 \%$ polidocanol foam in ultrasound guided sclerotherapy of the great saphenous vein: a randomised, double-blind trial with 2 year-follow-up. "The 3/1 Study". Eur J Vasc Endovasc Surg. 2007;34:723-9.

13. Belcaro G, Cesarone MR, Di Renzo A, et al. Foam-sclerotherapy, surgery, sclerotherapy, and combined treatment for varicose veins: a 10-year, prospective, randomized, controlled, trial (VEDICO trial). Angiology. 2003;54:307-15.

14. Barrett JM, Allen B, Ockelford A, Goldman MP. Microfoam ultrasound-guided sclerotherapy treatment for varicose veins in a subgroup with diameters at the junction of $10 \mathrm{~mm}$ or greater compared with a subgroup of less than $10 \mathrm{~mm}$. Dermatol Surg. 2004;30:1386-90.

15. Beale RJ, Gough MJ. Treatment options for primary varicose veins--a review. Eur J Vasc Endovasc Surg. 2005;30:83-95.

16. Teruya TH, Ballard JL. New approaches for the treatment of varicose veins. Surg Clin North Am. 2004;84:1397-417.

17. Darvall KA, Bate GR, Adam DJ, Bradbury AW. Recovery after ultrasound-guided foam sclerotherapy compared with conventional surgery for varicose veins. Br. J Surg. 2009;96:1262-7.

18. Kakkos SK, Rivera MA, Matsagas MI, et al. Validation of the new venous severity scoring system in varicose vein surgery. J Vasc Surg. 2003;38:224-8. 
19. Rutherford RB, Padberg FT, Jr., Comerota AJ, et al. Venous severity scoring: An adjunct to venous outcome assessment. J Vasc Surg. 2000;31:1307-12.

20. Ten Cate-Hoek AJ, Toll DB, Buller HR, et al. Cost-effectiveness of ruling out deep venous thrombosis in primary care versus care as usual. J Thromb Haemost. 2009;7:2042-9.

21. Lurie F, Creton D, Eklof B, et al. Prospective randomised study of endovenous radiofrequency obliteration (closure) versus ligation and vein stripping (EVOLVeS): two-year follow-up. Eur J Vasc Endovasc Surg. 2005;29:67-73.

22. Jones L, Braithwaite BD, Selwyn D, et al. Neovascularisation is the principal cause of varicose vein recurrence: results of a randomised trial of stripping the long saphenous vein. Eur J Vasc Endovasc Surg. 1996;12:442-5.

23. van den Bos R, Arends L, Kockaert M, et al. Endovenous therapies of lower extremity varicosities: a meta-analysis. J Vasc Surg. 2009;49:230-9.

24. Blaise S, Bosson JL, Diamand JM. Ultrasound-Guided Sclerotherapy of the Great Saphenous Vein with $1 \%$ vs. $3 \%$ Polidocanol Foam: A Multicentre Double-Blind Randomised Trial with 3-Year Follow-Up. Eur J Vasc Endovasc Surg. 2010;39:779-86.

25. Darke SG, Baker SJ. Ultrasound-guided foam sclerotherapy for the treatment of varicose veins. $\mathrm{Br}$ J Surg. 2006;93:969-74.

26. Piaggio G, Elbourne DR, Altman DG, et al. Reporting of noninferiority and equivalence randomized trials: an extension of the CONSORT statement. Jama. 2006;295:1152-60.

27. Ceulen RP, Bullens-Goessens YI, Pi-Van de Venne SJ, et al. Outcomes and side effects of duplexguided sclerotherapy in the treatment of great saphenous veins with $1 \%$ versus $3 \%$ polidocanol foam: results of a randomized controlled trial with 1-year follow-up. Dermatol Surg. 2007;33: 276-81.

28. Guex JJ, Allaert FA, Gillet JL, Chleir F. Immediate and midterm complications of sclerotherapy: report of a prospective multicenter registry of 12,173 sclerotherapy sessions. Dermatol Surg. 2005;31:123-8.

29. Subramonia S, Lees T. Radiofrequency ablation vs conventional surgery for varicose veins - a comparison of treatment costs in a randomised trial. Eur J Vasc Endovasc Surg. 2010;39:104-11.

30. Allegra C. Chronic venous insufficiency: the effects of health-care reforms on the cost of treatment and hospitalisation--an Italian perspective. Curr Med Res Opin 2003;19:761-9.

31. Oostenbrink JB, Rutten FFH. Handleiding voor kostenonderzoek; methoden en richtprijzen voor economische evaluatie in de gezondheidszorg. iMTA/CvZ Amstelveen. 2000.

32. Lamers LM, McDonnell J, Stalmeier PF, et al. The Dutch tariff: results and arguments for an effective design for national EQ-5D valuation studies. Health Econ. 2006;15:1121-32. 



\title{
CHAPTER 3
}

\section{Foam characteristics.}

\author{
B. van Deurzen \\ R.P. Ceulen \\ S.S. Tellings \\ C. van der Geld \\ T.E. Nijsten
}

Dermatol Surg. 2011;37:1448-55. 


\section{Abstract}

Background The manner in which foam is created for sclerotherapy varies and is not standardised. Moreover, the effects of several factors on the quality of the foam have not been well studied.

Objective To investigate the effects of different parameters on foam stability and bubble size. Methods As a measure of foam stability, foam half time (FHT) and bubble size distribution were determined for various parameters ( $\mathrm{POL}$ concentration, the freshness of the $\mathrm{POL}$, the syringe size, the liquid-to-air ratio, the number of pump cycles and the needle size) in the foam creation process.

Results The FHT was 115 to 157 seconds for $1 \%$ POL and was 143 to 192 seconds for 3\% POL. The other parameters had a limited effect on FHT. One percent POL foam ( $t=0$ seconds) had a mean bubble size of $71 \pm 9 \mu \mathrm{m}$, which increased when the foam was horizontally maintained in the syringe to $102 \pm 12 \mu \mathrm{m}$ at 30 seconds and to $121 \pm 20 \mu \mathrm{m}$ at 60 seconds. The other parameters had no significant influence on bubble size distribution.

Conclusion A higher concentration of POL and rapid injection optimise foam stability and bubble size distribution; however, other important foam characteristics are largely independent of variations in the generation and injection of the foam.

The authors have indicated no significant interest with commercial supporters. 


\section{Introduction}

FS is a widely accepted and frequently applied minimal invasive technique to treat varicose veins. ${ }^{1,2}$ Not only is FS effective, inexpensive and simple to (re)apply, but it also can be used to treat a wide range of incompetent veins, from small reticular and spider veins to primary and recurrent saphenous veins. The mechanism of action of sclerosing solutions is endothelial damage, which causes inflammation and ultimately endofibrosis. The extent of damage to the blood vessel wall determines the effectiveness of the solution. ${ }^{3}$ The FS foam is less likely to be 'washed out' than liquid because it mixes and dilutes less with and in blood, resulting in a more pronounced effect on the venous endothelium. ${ }^{4}$

The use of foam in sclerotherapy was first mentioned in the literature in $1939 .{ }^{5}$ Since then, a wide variety of methods have been used to create and to inject the foam into varicose veins. Currently, the Tessari technique and the so-called double syringe system (DSS) are the most commonly used methods. In both methods, liquid and air are pushed from one syringe into another through a small connector piece to create the foam. ${ }^{6}$ However, the creation of the foam varies and is not standardised, which is confusing for physicians, affects comparisons of study findings and may affect the clinical effectiveness of FS. For this reason, few studies have been performed on specific foam characteristics in recent years. The effect of different gasses and a range of liquid to air ratios on foam stability have been investigated. ${ }^{7}$ The use of the double syringe system results in the highest foam stability, and the type of connector used is not important. ${ }^{7,8}$ If the foam is deteriorated, it can be re-foamed several times using the double syringe technique without loss of foam quality. ${ }^{7,9}$ We designed this study to determine whether other variables affect foam quality. We investigated the effect of multiple variables in foam preparation, such as the concentration POL, the syringe size, the liquid-toair ratio and the number of pump cycles, that may affect important the foam's properties. We focused in detail on the stability and bubble size of POL foam because it is likely that these two properties influence the function of the foam and its administration and are therefore clinically relevant.

\section{Methods}

\section{Foam creation}

Aethoxysclerol (Kreussler Pharma, Wiesbaden, Germany) was used for the production of the POL foam. Aethoxysclerol contains water and POL and small amounts of $96 \%$ ethanol, sodium monohydrogen phosphate dihydrate, and potassium dihydrogen phosphate. The Tessari method was used to generate the foam. ${ }^{6}$ Two syringes are connected using a three- 
way stopcock (BD Bioscience, Franklin Lakes, NJ, USA). One syringe is filled with POL, and the other is filled with air. The syringe containing air is emptied into the other syringe, and the content of the second syringe is pushed back again (this is defined as one pump cycle) until a homogenous foam is established. For the experiments measuring foam deterioration and bubble size distribution, the following parameters were varied: POL concentration, syringe size, liquid-to-air ratio (e.g., 1 part liquid vs. 3 parts gas for 1:3), the number of pump cycles and the freshness of the POL.

\section{Measurement of foam stability}

Foam stability can be quantified by the time it takes for the foam to deteriorate. Basically, three primary processes exist that lead to foam deterioration.

First, because of the mass density difference between the liquid and the air in foam, the liquid drains downward through the spaces between the bubbles, and the liquid film between the bubbles thins. Second, the thin liquid films can subsequently rupture, leading to coalescence of the bubbles. Third, surface tension causes the pressure in the smaller bubbles to be higher than the pressure in larger bubbles. Because of this pressure difference, the gas in the foam will diffuse from the small bubbles to the larger ones through the liquid film separating them, causing the larger bubbles to grow by consuming the smaller ones. The speed of this process increases when the separating liquid film becomes thinner. ${ }^{10}$ Because of these principles, the mean bubble size will grow, and the homogeneity of the foam will be lost (Figure 1).

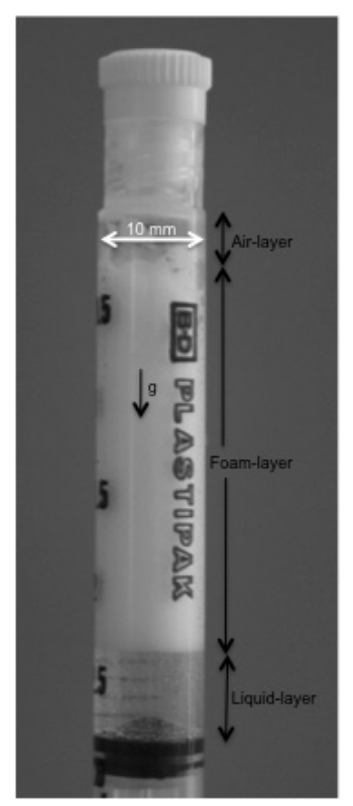

Figure 1. Photograph of a foam column in a $3 \mathrm{~mL}$ syringe; the foam is made using a 1:4 liquid to air ratio. The result of foam deterioration is visible; at the bottom a liquid layer is formed, at the top an air layer has emerged and bubble size variation over the height of the column is exhibited. 
A frequently used measure of foam stability is $\mathrm{FHT}$, which is the time (in seconds) it takes to form a liquid layer at the bottom of the foam column that is half of the volume of the original liquid. After the last pump cycle, the freshly generated foam is contained in one syringe, and its piston is set in such a way that the volume matches the volume of the initial air + liquid. The syringe containing the foam is placed precisely vertically (the syringe is not disconnected from the stopcock), and a timer is set. The effect of POL concentration (1\% vs. $3 \%$ ), the freshness of the POL solution (new vs. re-used foam), syringe size ( 3 vs. $5 \mathrm{~mL}$ ), the liquid to air ratio (1:3 vs. 1:4) and the number of pump cycles (10 vs. 30 ) on FHT were assessed separately. The results were presented as the mean of 10 measurements with corresponding 95\% confidence intervals (Cls).

\section{Bubble size measurement}

The foam was sprayed in a test device, which consisted of a 7-mm Perspex plate with a $15-\mathrm{mm}$ hole in the middle and a glass plate that was glued to the bottom (Figure 2). An additional cover glass plate was placed on top of the Perspex plate to maintain a constant foam volume. The layer of foam in this test device was quickly examined under an inverted microscope (Zeiss Axio Observer. Z1, Carl Zeiss B.V., Sliedrecht, the Netherlands) to visualise the bottom of the sample. The time required to place the foam under the microscope and to adjust the microscope was approximately 10 seconds for all of the measurements. The foam bubbles were immediately photographed using a 5-magnification lens and processed using Matlab software to measure the bubble size. A close-up of a microscopic image (Figure 3 ) illustrates the outer diameter of the bubble, $d$. Because the outer border of the bubble was not always clearly visible, to assess bubble size distribution, $\sqrt{0.5} d$ was measured in each microscopic image for at least 300 bubbles. At the distance of precisely $\sqrt{0.5} d$, a clearly visible ring can be observed. This ring originates from the diffraction and refraction of the light at the air-water interface of the bubble.

The effect of POL concentration ( $1 \%$ vs. $3 \%$ ), the freshness of the POL solution (new vs. reused foam), the syringe size ( 3 vs. $5 \mathrm{~mL}$ ), the liquid to air ratio (1:3 vs. 1:4) and the number of pump cycles (10 vs. 30 ) on the bubble size distribution were assessed separately. The foam

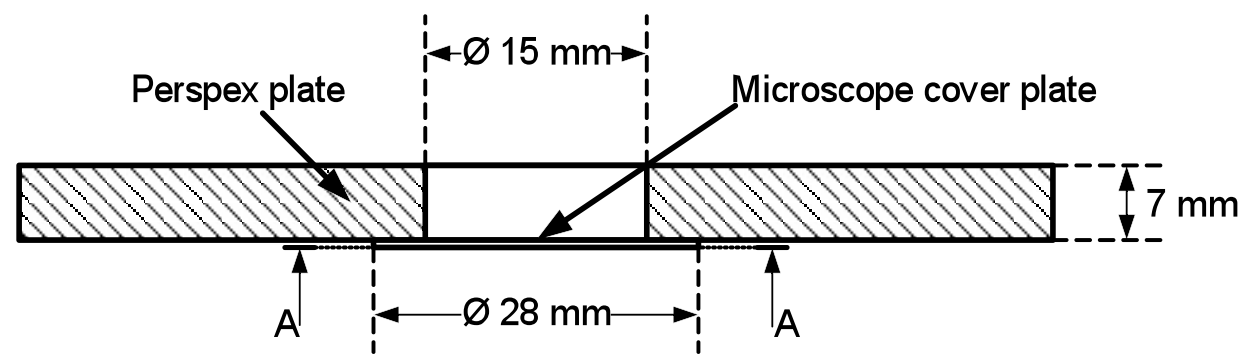

Figure 2. Schematic drawing of the test device used to create microscopic images of the foam. 


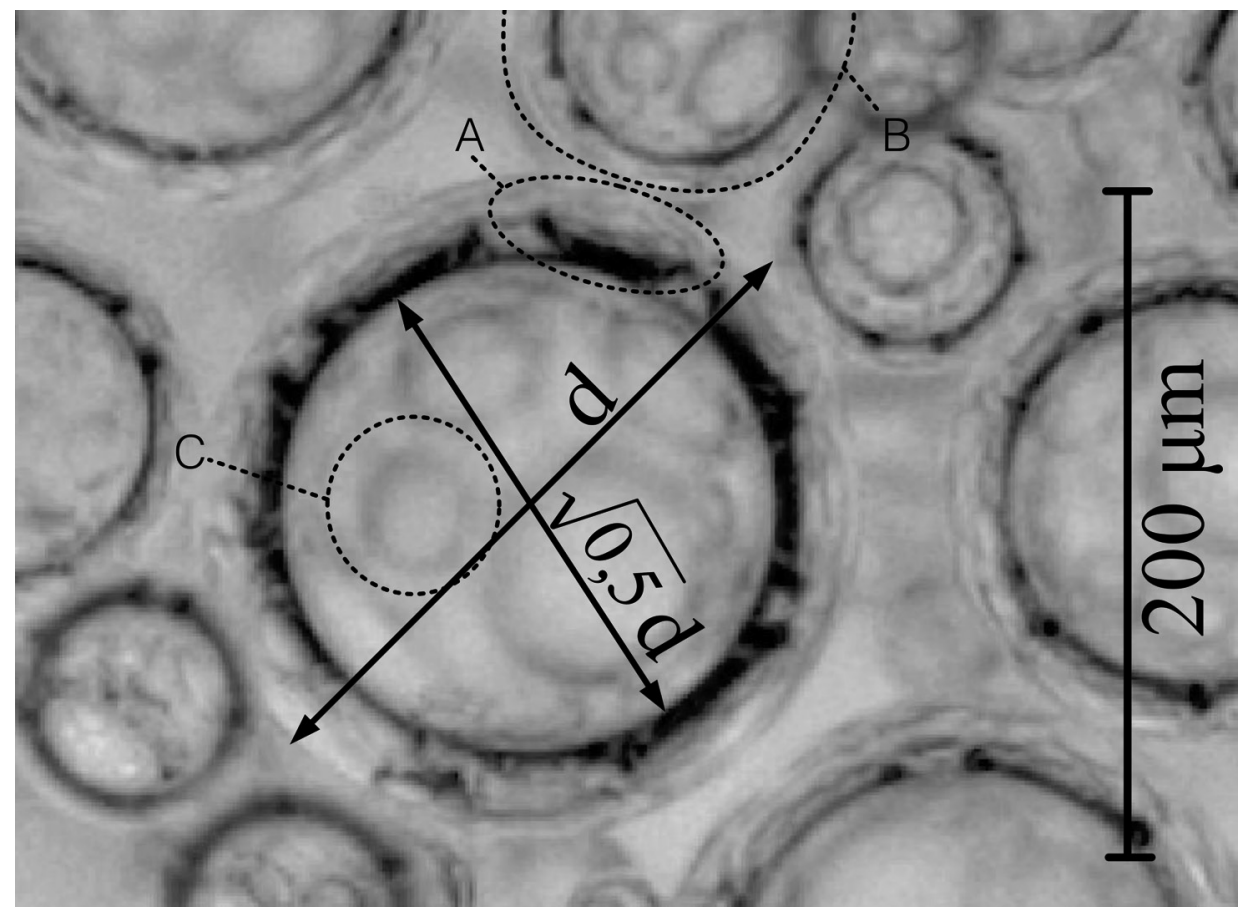

Figure 3. Close up of a microscopic image, in which the diameter of a bubble is shown (d) together with the easy recognizable length scale $\sqrt{0.5} \mathrm{~d}$. A indicates the reflection of bubble $\mathrm{B}$ in the bubble with diameter $\mathrm{d}$. $\mathrm{C}$ indicates the distorted image of a bubble positioned behind this bubble.

was injected into the test device, and the bubble size distribution was measured (5 to 10 times for each of the variations). The results were presented as the average of the mean bubble size with corresponding $95 \% \mathrm{Cls}$.

The changes of the mean bubble size distribution over time were investigated as follows. Prior to injecting the foam (used 1\% POL with a 1:4 liquid-to-air ratio, 10 pump cycles in 3 $\mathrm{mL}$ syringes) into the test device, the syringe containing the foam was placed horizontally without disconnecting the syringe from the three-way connector hub for 0,30 or 60 seconds. Thereafter, the foam was injected into the test device, and the bubble size distribution was measured ( 5 times for each of the waiting times).

The effect of time on bubble size was also studied by generating bubble size distribution for the same foam sample (1\% POL with a 1:4 liquid-to-air ratio, 10 pump cycles in $3 \mathrm{~mL}$ syringes). The foam remained in the test device. A picture was taken every 30 seconds using a microscope, allowing for visualisation of the time effect, specifically at the bottom of a foam column. 
The difference in the bubble size distribution following injection of the foam (1\% POL with a 1:4 liquid-to-air ratio, 10 pump cycles in $3 \mathrm{~mL}$ syringes) through different needles (BD Bioscience, Franklin Lakes, NJ, USA) and a Venflon (B. Braun Medical, Inc., Bethlehem, PA, USA) was also assessed. The foam was injected in the test device using a $21 \mathrm{G}$ needle (length $50 \mathrm{~mm}$, internal diameter: $514 \pm 19 \mu \mathrm{m}$ ), a $23 \mathrm{G}$ needle (length $25 \mathrm{~mm}$, internal diameter: $337 \pm 19 \mu \mathrm{m}$ ) and an $18 \mathrm{G}$ Venflon (length $45 \mathrm{~mm}$, internal diameter: $838 \pm 38 \mu \mathrm{m}$ ).

\section{Results}

\section{Foam stability}

Figure 4 shows the FHT for the different parameters in the foam generation process. Of the variables assessed, only a higher concentration of POL resulted in considerably greater FHT (115-157 sec for $1 \%$ POL and 143-192 sec for 3\% POL). The freshness of the POL (new vs. re-used), syringe size, liquid-to-air ratio and the number of pump cycles had a limited effect on FHT.

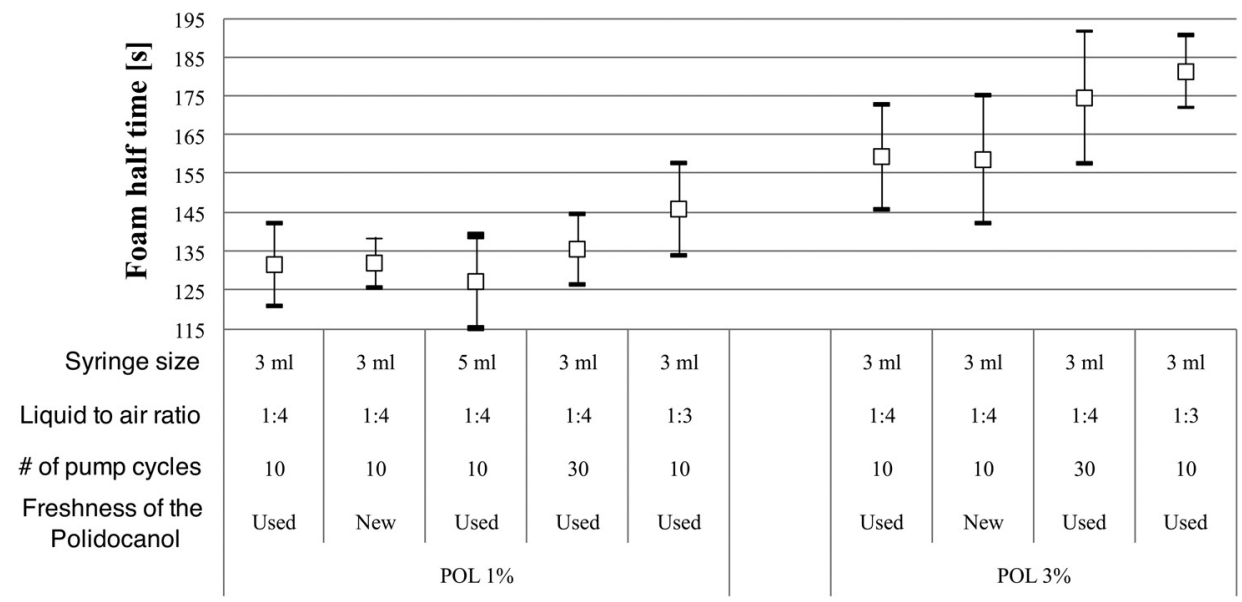

Figure 4. FHT for various variables in foam generation. Displayed is the average of 10 measurements \pm 2 SD.

\section{Bubble size}

For freshly generated foam (1\% POL with a 1:4 liquid-to-air ratio, 10 pump cycles in $3 \mathrm{~mL}$ syringes, $t=0$ seconds), the mean bubble size was $71 \mu \mathrm{m}$ (SD $9 \mu \mathrm{m}$ ) (Figure 5). The bubble size increased when the foam was horizontal in the syringe for some time before injecting it into the test device; the average bubble size increased to $102 \mu \mathrm{m}$ (SD $12 \mu \mathrm{m}$ ) at 30 seconds 


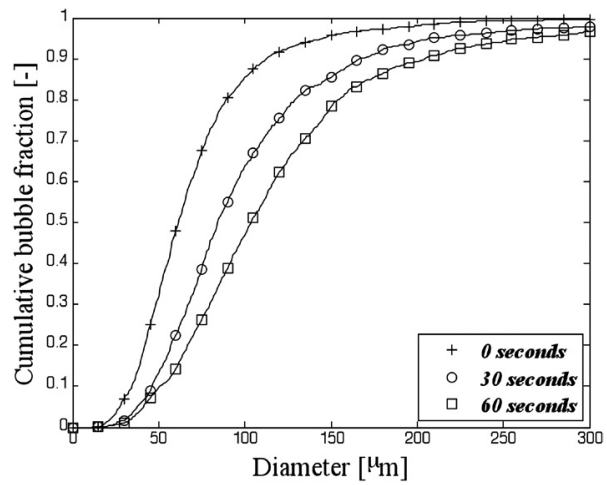

Figure 5. History of the bubble size cumulative distribution in the syringe. Foam is generated and kept in a horizontal syringe for the time indicated before injecting the foam in the test device. Each line shows the average of 5 measurements. POL 1\% is used with 1:4 liquid to air ratio, 10 pump cycles and $3 \mathrm{~mL}$ syringes.

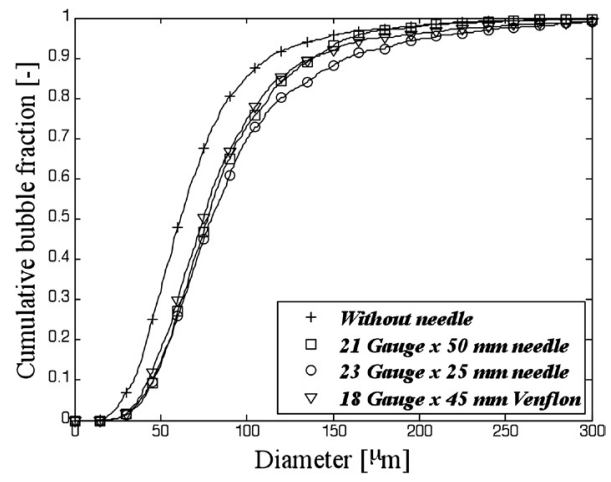

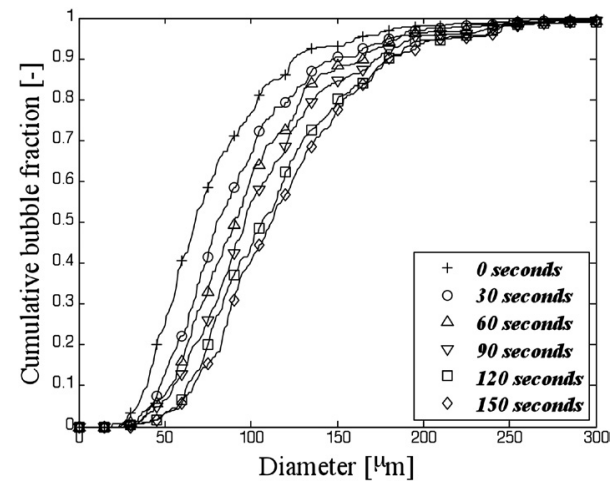

Figure 6. History of the bubble size cumulative distribution in the microscopic test device. Foam is generated and injected in the test device. Measurements at given times. POL $1 \%$ is used with 1:4 liquid to air ratio, 10 pump cycles and $3 \mathrm{~mL}$ syringes.

Figure 7. Effect of different needles on the bubble size cumulative distribution. Foam is generated and injected in the test device using the needles. Each line shows the average of 5 different measurements. POL 1\% is used with 1:4 liquid to air ratio, 10 pump cycles and $3 \mathrm{~mL}$ syringes.

and $121 \mu \mathrm{m}$ (SD $20 \mu \mathrm{m}$ ) at 60 seconds (Figure 5). The increase in bubble size over time at the bottom of the foam sample was decreased but was still visible (Figure 6).

Injecting freshly generated foam (1\% POL with a 1:4 liquid-to-air ratio, 10 pump cycles in 3 $\mathrm{mL}$ syringes) through needles with different diameters or a Venflon did not influence cumulative bubble fraction distribution, except that the mean bubble diameter was slightly smaller when the foam was directly injected from the syringe in the test device without a needle or a Venflon (Figure 7).

Changing the POL concentration (1\% vs. 3\%), freshness of the POL solution (new vs. re-used), syringe size ( 3 vs. $5 \mathrm{~mL}$ ), liquid-to-air ratio (1:3 vs. 1:4) and number of pump cycles (10 vs. 30) did not result in any significant differences in bubble size (Figure 8 ). In addition, any observed 


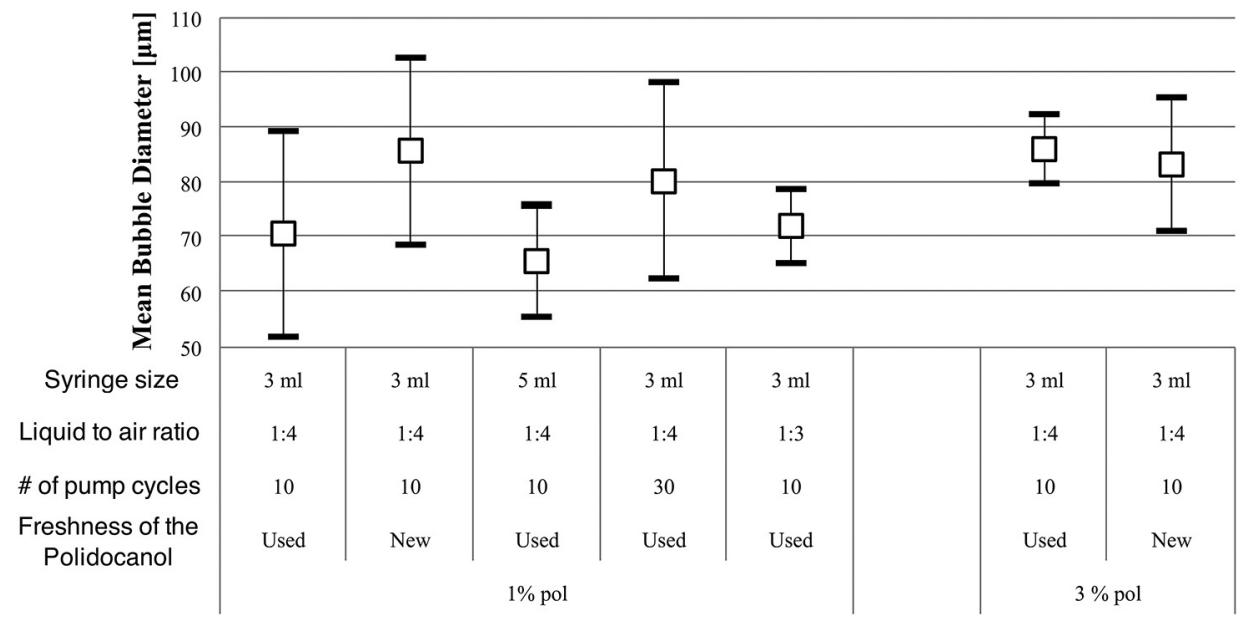

Figure 8. Mean bubble size for various variables in foam generation. Displayed is the average of 5 to 10 measurements $\pm 2 \mathrm{SD}$.

differences in the mean bubble size may be due to the duration of the bubble visualisation process, which could have varied slightly between measurements.

\section{Discussion}

FS is an effective, inexpensive, and commonly used technique for the treatment of a variety of varicose veins. Unfortunately, FS is not well standardised within or across nations, making it difficult to compare the results of different studies. ${ }^{1,2,11}$ Important FS-related issues, such as the optimal generation of the foam, the method of administration, the type of sclerosant, the injected foam volume and the dynamics of endovenous foam, remain controversial. One of the leading principles of foam deterioration in a syringe is the drainage of liquid out of the cavities between the bubbles under the influence of gravity. In this study, we quantified this drainage in POL foam by measuring the FHT and the bubble size distribution for different parameters. We demonstrated that the use of $3 \% \mathrm{POL}$ resulted in a greater $\mathrm{FHT}$ than did $1 \%$ POL. Furthermore, we demonstrated that the rapid injection of the foam was associated with smaller bubbles. Whether POL foam is created rapidly or slowly, whether it is created in a large or small syringe, whether it has been used before to generate foam or not, and whether it is injected through a needle a or Venflon did not affect the investigated foam characteristics in this experimental setting. The study findings suggest that the generation process and the injection of foam are 'forgiving' and that the different methods of foam creation do not affect the generated foam considerably. Except for the POL concentration and the swift injection of the foam, none of the other variables appear to have a large effect on foam stability and bubble size. Our findings are in accordance with a recent study by Wollmann that focused of 
foam stability, although there are several important differences in the methodology between this study and Wollmann's study; for example, in the preparation techniques used (the Tessari technique vs. DSS) and the volume of the syringes used (10 mL vs. 3 and $5 \mathrm{~mL}){ }^{7}$ The finding that the concentration of the sclerosant affected the FHT when room air was used is in accord with a recent study. ${ }^{12}$

In clinical practice, the greater stability of $3 \%$ POL foam than that of $1 \%$ POL foam does not appear to translate into greater effectiveness, as demonstrated in several clinical studies. ${ }^{13,14}$ In these studies, 3\% POL foam was associated with more adverse events, such as phlebitis and hyperpigmentation, but was equally effective. Although there is no clinical study to confirm the importance of swift administration of the foam generated, this is obvious given that the foam deteriorates rapidly in the syringe. The clinical relevance of this observation is that the treated vein should be easily accessible (visualised on ultrasound) and that the treating physician should select the most convenient method of injecting the foam (the direct needle approach or the indirect Venflon method). The measurements demonstrate that the bubble growth rate is slower at the bottom of a foam sample than it is at the top (Figure 1). The explanation for this difference is that an increase on bubble size is dependent on the liquid-to-air ratio and the thickness of the liquid film between the bubbles, both of which depend on height of the column. Therefore, the bubble size increases at a slower rate at the lower part of the foam column than at higher parts. A practical implication of the observation that time affects bubble size is that the syringe with foam should be held in a vertical position as much as possible, with the opening facing downward because the upper proportion of the syringe will contain larger bubbles and may be less effective.

Whether the foam was injected through a needle of varying gauges or through a Venflon did not affect the bubble size distribution, suggesting that the smallest opening through which the foam is pushed has a limited effect. The omission of the time it took to connect the syringe to a needle of Venflon may explain why the bubble size of the foam that was injected without a needle or Venflon was slightly smaller.

For the preparation of foam, the findings indicate that there is no disadvantage of refoaming deteriorated foam in daily practice. From a physical perspective, this result is not surprising given that the POL mixture does not undergo any chemical changes during the foam preparation process; this finding is in accordance with that of a previous study. ${ }^{9}$

It would be interesting to investigate other methods of increasing foam stability. For example, the use of micro-filters, syringes made of glass, non-silicon pistons, and preparing foam at different temperatures (the viscosity is greater at lower temperatures). Greater viscosity will retard drainage and thus increase stability. To determine the influence of viscosity on stability, we investigated the effect of adding varying percentages of glycerol $(0,10,20,33 \mathrm{wt} \%)$ on FHT and demonstrated that FHT is up to 2.5 times greater 33 wt $\%$ glycerol (data not shown). 
Although the FHT of the foam mixture increases with the glycerol concentration, the generated foam was not homogeneous and contained large bubbles that remained, regardless of the number of pump cycles. We agree with Peterson and Goldman that these large, stable bubbles may have distant adverse effects when injected..$^{15}$ Therefore, we do not recommend the addition of glycerol to POL foam in daily practice.

Although the experiments were standardised as much as possible, were repeated at least five times and were performed by the same researcher (BvD), variations may have occurred given that all of the experiments were performed by hand. However, most of the variations were likely due to normal repeatability inaccuracies. There are several ways to assess foam stability, and we, as have others, selected FHT to quantify foam stability. ${ }^{7,8,16}$ Alternative measures could have been the change in the height of the foam column over time, foam drainage time (i.e., the time taken for a layer of water to become visible at the bottom of the syringe) or foam coalescence time (i.e., the time taken for bubbles of a given size to appear in the foam) ${ }^{17}$ These parameters were not measured because in FS, only small volumes of foam are created, and measuring these parameters involves large observer-dependant variability.

Due to the conical shape of the piston, slightly less than half of the liquid leaks out of the foam. Because this small error affected all of the measures, it was a non-differential bias.

Although bubble size depends on the type of detergent used, only POL was used in this study. Therefore, generalisations of the findings to other sclerosants should be made with caution.

In conclusion, a higher concentration of POL and rapid injection optimise foam stability and bubble size distribution, but other important foam characteristics are largely independent of the differences in the generation and injection of the foam. 


\section{References}

1. Nijsten T, van den Bos RR, Goldman MP, et al. Minimally invasive techniques in the treatment of saphenous varicose veins. J Am Acad Dermatol. 2009;60:110-9.

2. van den Bos R, Arends L, Kockaert M, et al. Endovenous therapies of lower extremity varicosities: a meta-analysis. J Vasc Surg. 2009;49:230-9.

3. Parsi K, Exner T, Connor DE, et al. In vitro effects of detergent sclerosants on coagulation, platelets and microparticles. Eur J Vasc Endovasc Surg. 2007;34:731-40.

4. Monfreux A. Traitement sclerosant des troncs sapheniens et leurs collaterales par la methode MUS. Phlebologie. 1997;50:351.

5. McAusland S. The modern treatment of varicose veins. Med Press Circular. 1939;201:404-10.

6. Tessari L. Nouvelle technique d'obtention de la sclero-mousse. Phlebologie. 2000;53:129.

7. Wollmann JC. Sclerosant foams, stabilities, physical properties and rheological behavior. Phlebologie. 2010;4:208-17.

8. Rao J, Goldman MP. Stability of foam in sclerotherapy: differences between sodium tetradecyl sulfate and polidocanol and the type of connector used in the double-syringe system technique. Dermatol Surg. 2005;31:19-22.

9. Gallenkemper G. Schaumveroedung: lange Wiederaufschaeum-barkeit von Polidocanol-Schaeumen. Phlebologie. 2008;1:10-5.

10. Schramm L. Emulsions, foams and suspensions. Weinheim: Willey-VCH verlag GmbH \& Co; 2005.

11. Cavezzi A, Tessari L. Foam sclerotherapy techniques: different gases and methods of preparation, catheter versus direct injection. Phlebology. 2009;24:247-51.

12. Peterson JD, Goldman MP. An investigation into the influence of various gases and concentrations of sclerosants on foam stability. Dermatol Surg. 2011;37:12-7.

13. Ceulen RP, Bullens-Goessens YI, Pi van de Venne SJ, et al. Outcomes and side effects of duplexguided sclerotherapy in the treatment of great saphenous veins with $1 \%$ versus $3 \%$ polidocanol foam: results of a randomized controlled trial with 1-year follow-up. Dermatol Surg. 2007;33: 276-81.

14. Hamel-Desnos C, Ouvry P, Benigni JP, et al. Comparison of $1 \%$ and $3 \%$ polidocanol foam in ultrasound guided sclerotherapy of the great saphenous vein: a randomised, double-blind trial with 2 year-follow-up. "The 3/1 Study". Eur J Vasc Endovasc Surg. 2007;34:723-9; discussion 30.

15. Peterson JD, Goldman MP. An investigation on the influence of glycerin on sclerosant foam stability. Phlebology. 2011;26:232-4.

16. Ceulen RP, Jagtman EA, Sommer A, et al. Blocking the Saphenofemoral Junction During Ultrasound-Guided Foam Sclerotherapy - Assessment of a Presumed Safety-measure Procedure. Eur J Vasc Endovasc Surg. 2010;40:772-6.

17. Isenberg C. The science of soap and soap bubbles. Somerset: Woodspring Press Ltd.; 1978. 


\section{CHAPTER 4}

\section{Clinical outcome of foam sclerotherapy with $1 \%$ versus $3 \%$ POL foam.}

R.P. Ceulen

Y.I. Bullens-Goessens

S.J. Pi - van de Venne

P.J. Nelemans

J.C. Veraart

A. Sommer

Dermatol Surg. 2007;33:276-81. 


\section{Abstract}

Background Eighty subjects were treated with either $1 \%$ or $3 \%$ POL foam to compare the efficacy and adverse sequelae of each concentration.

Objective The objective was to compare the effects of the two different concentrations of POL foam.

Material \& Methods During a 6-month period, we treated 80 consecutive patients with primary GSV incompetence in combination with SFJ incompetence. These patients were treated with either $1 \%$ or $3 \%$ POL foam. Duplex-analyses were made prior to treatment and in follow-up visits to determine the presence or absence of reflux.

Results After 1 year, there was a clinically relevant difference in the percentage of patients with occlusion of the treated GSV between both groups: $69.5 \%$ in the $1 \%$ foam group versus $80.1 \%$ in the $3 \%$ foam group. This difference, however, was not statistically significant $(p=0.249)$. After 1 year of follow-up, the patients in the 3\% POL group exhibited a larger cosmetic improvement than did the patients in the $1 \%$ group.

Conclusion In the treatment of primary incompetent GSVs, 3\% POL foam appears to be more effective than $1 \%$ POL foam. The side effects were similar in both groups. 


\section{Introduction}

Varicose veins are a common phenomenon in the general population, and their treatment places a great demand on medical resources. Until a few years ago, the primary treatment of GSV varicosity was ligation of the SFJ in combination with GSV stripping. With respect to the SSV, the primary option is ligation of the SPJ. Treatment with sclerotherapy using liquid sclerosing agents produced reasonable results in the short-term but disappointing results in the long-term when compared to surgery. ${ }^{1}$ For the past few years, foam agents have gained popularity, and it has been shown that their effect is stronger than that of liquid sclerosing agents. ${ }^{2}$ Until now, there have been very few publications of clinical trials in which different characteristics, such as bubble size, sclerosant concentrations, and different preparation techniques of the foam, have been compared. ${ }^{3}$ To evaluate the efficacy and the side effects of different foam concentrations, we designed this study to investigate the sclerosing agent POL using concentrations of $1 \%$ and $3 \%$. Furthermore, we were interested in potentially serious adverse effects, the cosmetic results and the number of treatments necessary to achieve obstruction of the treated vessel.

\section{Materials and Methods}

\section{Patients}

From June to December 2004, 80 limbs of 80 consecutive patients who presented at our outpatient clinic with primary isolated GSV incompetence were randomly assigned into one of two groups; Group 1 was treated with 1\% POL foam, and Group 2 was treated with 3\% POL foam. The randomisation of the study group assignment was based on a computergenerated list.

The limbs were categorised according to the CEAP classification (according to the North American Chapter of the Society for Vascular Surgery and the International Society). ${ }^{4}$ The patients were included if they exhibited primary incompetence of the GSV and SFJ insufficiency, with a reflux time $\geq 0.5 \mathrm{sec}$ measured over $20 \mathrm{~cm}$ of the upper leg.

The exclusion criteria were pregnancy, active thrombophlebitis, clotting disturbances, coagulation disorders, or a history of deep vein thrombosis or malignancies. Ethics committee approval and written informed consent were obtained. The study protocol conformed to the guidelines of the 1975 Declaration of Helsinki. 


\section{Colour Duplex Scanning}

A pretreatment examination was performed using a colour duplex scanner ( $\mathrm{HDI} 3000$, Advanced Technology Laboratories, Bothell, WA, USA) with a 5-12 $\mathrm{MHz}$ transducer. This examination was performed to detect venous reflux in the GSV and to exclude other venous pathologies, such as deep venous insufficiency, obstruction and venous malformations. The post-treatment duplex examination was performed at 1 month and at 1 year following the treatment to check for reflux (when still present), venous occlusion, the compressibility and the diameter of the treated vein. The patients were also screened for deep venous thrombosis. A physical examination was performed to determine the efficacy of the treatment and the side effects, such as thrombophlebitis, fibrosis and hyperpigmentation.

\section{Foam sclerotherapy}

Both of the sclerosing foams were prepared using the DSS technique and a sclerosant to air ratio of 1:5. The FS treatment consisted of a single injection of $1 \%$ or $3 \%$ POL foam, with the patient in a supine position. We used the catheter technique with an $18 \mathrm{G}$ Venflon cannula. The cannula was placed in the insufficient GSV, preferably just above the knee. When necessary, a retrograde injection was given through the same injection site toward the distal part of the GSV up to the ankle region. The end point of treatment was closure of the incompetent GSV. Following FS session, the patients were treated with a local compression pad and an antiembolism stocking (18mmHg) (Mediven Thrombexin, Medi, Bayreuth, Germany), worn both day and night for the first week. For the first 6 weeks, the patients were advised to wear Class II (30 mmHg) elastic stockings (Mediven Plus, Medi, Bayreuth, Germany) during the day. The patients were instructed to stay in the hospital for at least 30 minutes following the treatment in case an acute allergic reaction appeared.

\section{Follow-up and assessment of the outcome measures}

At baseline and at 1 month and 1 year following inclusion into the study, a history of clinical and cosmetic complaints was taken. The primary outcome measure was the presence of reflux as measured with duplex imaging. Treatment success was defined as complete occlusion of the treated vein. The current definition of incompetent saphenous veins is a 0.5 -second reflux. ${ }^{5}$ The secondary outcome measures were hyperpigmentation, deep vein thrombosis, thrombophlebitis, fibrosis and the persistence of venous complaints. Venous complaints were defined as the presence of at least 1 of the following complaints: cramps, pain or restless legs. During the scheduled visits, the patients were asked to report if their venous complaints and the cosmetic appearance of their legs improved following the treatment. 


\section{Statistics}

Treatment success was defined as the absence of reflux in the treated vein 1 year following the treatment. The Chi-squared test was used to evaluate the difference in the percentage of success between the $1 \%$ and the $3 \%$ foam group. Statistical significance was defined as a $p<0.05$. This test was also used to compare the difference in percentages of the patients that reported side effects following the treatment. All of the data were analysed with computer software (SPSS, Version 12.0, SPSS, Inc., Chicago, IL, USA).

\section{Results}

Eighty consecutive legs with 80 incompetent GSVs in 80 patients awaiting FS for clinical grade (CEAP classification) C1 $(n=10), C 2(n=52)$ or $C 3$ to $C 5(n=18)$ disease were examined. No patients were graded as $\mathrm{C} 6$. Males represented $28 \%$ of the population, and women represented $72 \%$. The mean age was 52 years (Table 1 ). Complete occlusion of the GSV required an average of 1.2 sessions in both the $1 \%$ and the $3 \%$ group. The mean total volume of injected sclerosing foam per treatment session was $5.3 \mathrm{~mL}$ in the $1 \%$ foam group and $5.1 \mathrm{~mL}$ in the $3 \%$ foam group (range, 1-10 mL).

After 1 year, complete occlusion of the treated vein in the $1 \%$ foam group was $69.5 \%$ versus $82.1 \%$ in the $3 \%$ foam group $(p=0.249)$ (Table 2 ).

Table 1 Baseline characteristics..

\begin{tabular}{ccc}
\hline & foam 1\% group & foam 3\% group \\
\hline Number of patients & 40 & 40 \\
$\mathrm{M}: \mathrm{F}(\mathrm{n})$ & $6: 34$ & $16: 24$ \\
Mean age (yrs) & 50.7 & 53.6 \\
Mean diameter & 5.4 & 6.4 \\
GSV measured 5 cm below SFJ $(\mathrm{mm})$ & & \\
\hline
\end{tabular}

Table 2 Primary and secondary outcomes

\begin{tabular}{|c|c|c|c|c|c|c|c|c|}
\hline & Baseline 1\% & Baseline 3\% & $\begin{array}{c}1 \% \\
1 \text { month }\end{array}$ & $\begin{array}{c}3 \% \\
1 \text { month }\end{array}$ & p-value & $\begin{array}{c}1 \% \\
1 \text { year }\end{array}$ & $\begin{array}{c}3 \% \\
1 \text { year }\end{array}$ & $p$-value \\
\hline Cosmetic improvement & & & $40 \%$ & $52.5 \%$ & 0.312 & $67.5 \%$ & $77.5 \%$ & 0.569 \\
\hline Venous complaints & $66.7 \%$ & $78.9 \%$ & $6.7 \%$ & $11.1 \%$ & 0.513 & $29.7 \%$ & $25.0 \%$ & 0.454 \\
\hline Thrombophlebitis & & & $32.1 \%$ & $50.0 \%$ & 0.162 & $5.4 \%$ & $5.0 \%$ & 0.936 \\
\hline Hyperpigmentation & & & $22.0 \%$ & $28.2 \%$ & 0.477 & $8.1 \%$ & $17.5 \%$ & 0.221 \\
\hline
\end{tabular}


The mean diameter of the treated vein in the $1 \%$ foam group was $5.4 \mathrm{~mm}$ prior to treatment and $3.5 \mathrm{~mm}$ after 1 year. In the $3 \%$ foam group the mean diameter was $6.4 \mathrm{~mm}$ prior to and $2.4 \mathrm{~mm}$ following the treatment.

Complete cosmetic satisfaction at 1 year following the treatment was reported by $67.5 \%$ of the patients in the $1 \%$ group and by $77.5 \%$ in the $3 \%$ group $(p=0.569)$ (Table 2). At 1 year following the treatment, $40 \%$ of the patients in the $1 \%$ foam group and $52.5 \%$ in the $3 \%$ foam group reported complete disappearance of the initial complaints that were due to chronic venous insufficiency $(p=0.454)$.

Thrombophlebitis as a side effect 4 weeks following the treatment was present in $32.1 \%$ of the patients in the $1 \%$ group and in $50.0 \%$ in the $3 \%$ of the patients in the group ( $p=0.162$ ). The thrombophlebitis resolved in most cases without sequelae after 1 year of follow-up. In a small number of patients, thrombophlebitis turned into fibrosis $(5.4 \%$ of the patients in the $1 \%$ group vs. $5.0 \%$ in the $3 \%$ group; $p=0.936$ ) (Table 2 ). The incidence of hyperpigmentation decreased in both groups during the 1 year follow-up; however, a difference was still observed between the groups, although it was not statistically significant. After the 1 year follow-up, hyperpigmentation was observed in $8.1 \%$ of the patients in the $1 \%$ foam group and in $17.5 \%$ of the patients in the $3 \%$ foam group $(p=0.221)$.

No serious adverse events occurred in either group. Specifically, no DVT was observed. In the $3 \%$ group, we observed one patient with a pulmonary embolism at 4 weeks following the sclerosing therapy. The patient was admitted to our hospital and was successfully treated with anticoagulants. An ultrasound investigation was performed by a radiologist and was negative for deep or superficial thrombosis of the leg. No relationship between the pulmonary embolism and the prior treatment with foam was detected.

\section{Discussion}

Since the introduction of the ultrasound technique in the early 1980 s as a diagnostic device in venous insufficiency, ultrasound-guided foam sclerotherapy has been used in the treatment of saphenous veins, now known as FS. Initially FS was performed using liquid sclerosants. This therapy appeared to be efficient, safe, inexpensive and exhibited no major side-effects. ${ }^{6}$ It was in the late 1990s that the first publications of ultrasound-guided sclerotherapy with foaming agents appeared, demonstrating even more promising results than those obtained with liquid agents. In fact, it was half a century ago that various foamed sclerosing agents were first used for the treatment of varicose veins. ${ }^{7}$ The first publication of foam sclerosis was in 1939, from Mc Ausland, followed by the oft-cited 1944 article by Orbach..$^{8,9}$ After the 
publication of this famous article, in which the air block technique was described, many other publications with other foam techniques followed, but no controlled trials have been performed in that time. For unknown reasons, the treatment lost popularity, likely because of the studies by Hobbs in $1974^{10}$ and by Rutgers and Kitslaar in $1994^{11}$, which compared surgical treatment with sclerocompression. Both of these studies preferred surgical treatment based on the results after 10 years. However, following a publication by Cabrera and colleagues ${ }^{7}$, who used foam sclerosants in ultrasound-guided sclerotherapy, foaming agents regained interest. It was in fact only recently that a prospective, double blind placebo-controlled study performed by Kahle and Leng ${ }^{12}$ conclusively demonstrated that sclerotherapy is an effective treatment modality in the treatment of varicose saphenous veins. However, the details of FS treatment, such as the favoured detergent, the concentration of the detergent, and the amount of injected detergent, are not well defined. ${ }^{13-15}$ These factors could play an important role in the long-term results of sclerotherapy and therefore require further investigation.

In our study, we demonstrate that treatment with 3\% POL concentration in FS patients with primary GSV incompetence appears to be more effective than a lower concentration of foam (1\%). At the 1-year follow-up, complete occlusion was achieved in $81.1 \%$ of the $3 \%$ foam group, compared with $69.5 \%$ in the $1 \%$ foam group. It is likely that the lack of statistical significance is due to the relatively small sample size, which is a limitation of this trial. Assuming that the probability of reflux in the $1 \%$ foam group is $30 \%, 120$ patients per group would have been required to demonstrate a halving of the risk of reflux (alpha $=5 \%$ ) with a power of $80 \%$. This patient number was not feasible. The proportion of occluded veins at 12 months in our study population appears to correspond to the data reported by other authors after 2 to 3 years of follow-up. ${ }^{16-18}$ An occlusion rate of $81 \%$ was published by Cabrera and coworkers in the treatment of $500 \mathrm{GSV}$ patients with a follow-up period of 3 years. ${ }^{7}$ It remains difficult to compare study outcomes, however, when the inclusion criteria, the treatment characteristics, and the primary outcome parameters are not well defined. Demagny reported a recanalisation rate of $11 \%$ after 6 months in 300 foam-treated GSV patients. ${ }^{19}$ It has been suggested that his results could have been improved had he achieved greater sclerosis of the saphenous trunk, not just of the junction. ${ }^{20}$ The extension of the vein undergoing treatment also likely influences the outcome of the occlusion. A detailed description of the treatment procedure appears to be necessary.

We found that the use of $3 \%$ POL foam was more effective in terms of the absence both reflux and complaints after 1 year of follow-up, despite an increased incidence of hyperpigmentation in the $3 \%$ foam group. After 4 weeks, fewer venous complaints are reported in the $1 \%$ group than in the $3 \%$ group. A probable explanation for this result may be the higher incidence of thrombophlebitis in the $3 \%$ group. Therefore, patient questionnaires should clearly distinguish between the pain associated with venous insufficiency and pain due to 
the venous treatment. We believe that the occurrence of hyperpigmentation is likely due to the concentration of the foam and not due to the total amount of injected foam, given that the average volume of injected foam was equal in both groups. By using more and longer compression following the treatment, the efficacy of the procedure would likely be the same, but the side effects would diminish because of the reduction in the thrombus size in the treated vein. ${ }^{21}$

In our study population, one pulmonary embolism occurred, yet we could not identify a relationship between the embolism and the prior foam treatment. With respect to this serious adverse event, we searched the literature for reported incidences of deep vein thrombosis and pulmonary embolism occurring following sclerotherapy with POL foam. Three authors (Einarsson in $1993^{22}$, Hobbs in $1974^{10}$, and Jakobsen in $1979^{23}$ ) reported a pulmonary embolism rate that ranged from $0.48 \%$ to $1.25 \%$. Three studies reported a deep vein thrombosis (0.02-1.0\%) without pulmonary embolism. ${ }^{16,24,25}$ Although these reported incidences are small, the need to screen patients for the known side effects should be emphasised.

\section{Conclusion}

We expect that FS will play an important role in the treatment of varicose veins, possibly greater than that of surgical intervention. We demonstrated that foam can be used as an adequate therapeutic option in primary varicose veins. The results of our present study demonstrate a clinically relevant difference in the effectiveness of the different concentrations of POL foam after 1 year.

Recanalisation of the treated saphenous vein 1 year following the treatment appears to be lower in the $3 \%$ POL foam group than in the $1 \%$ POL foam group. With respect to the side effects, we demonstrated that the frequencies of phlebitis and hyperpigmentation are higher in the $3 \%$ group than in the $1 \%$ group after 1 month of follow-up. These effects healed without sequelae after 1 year, however, in both of the groups. Therefore, we recommend the use of $3 \% \mathrm{POL}$ rather than $1 \%$ POL for the production of foam for the application of FS for the treatment of primary saphenous varicose veins. Still, follow-up studies with larger patient groups are required to determine the long-term effects of different concentrations of POL foam. 


\section{References}

1. Rigby KA, Palfreyman SJ, Beverley C, Michaels JA. Surgery versus sclerotherapy for the treatment of varicose veins. Cochrane Database Syst Rev 2004;(4):CD004980.

2. Yamaki T, Nozaki M, Iwasaka S. Comparative study of duplex-guided foam sclerotherapy and duplex-guided liquid sclerotherapy for the treatment of superficial venous insufficiency. Dermatol Surg 2004;30:718-22; discussion 722.

3. Hamel-Desnos C, Desnos P, Wollmann JC, et al. Evaluation of the efficacy of polidocanol in the form of foam compared with liquid form in sclerotherapy of the greater saphenous vein: initial results. Dermatol Surg 2003;29:1170-5; discussion 1175.

4. Beebe HG, Bergan JJ, Bergqvist $D$, et al. Classification and grading of chronic venous disease in the lower limbs. A consensus statement. Eur J Vasc Endovasc Surg 1996;12:487-91; discussion 491-2.

5. Labropoulos N, Delis K, Nicolaides AN, et al. The role of the distribution and anatomic extent of reflux in the development of signs and symptoms in chronic venous insufficiency. J Vasc Surg 1996;23:504-10.

6. Bullens-Goessens $\mathrm{Yl}$, Heij JF, Veraart JC. Favorable results with duplex-guided compression sclerotherapy for varices of the small saphenous vein; a retrospective study. Ned Tijdschr Geneeskd 2003;147:117-20.

7. Cabrera J, Cabrera JJ, Garcia Olemedo M. Treatment of varicose long saphenous veins with sclerosants in microfoam: long term outcomes. Phlebology 2000;15:19-23.

8. McAusland S. The modern treatment of varicose veins. Med Press Circular 1939;201:404-10.

9. Orbach E. Sclerotherapy of varicose veins-utilisation of an intravenous air block. Am J Surg 1944; 3:362-6.

10. Hobbs JT. Surgery and sclerotherapy in the treatment of varicose veins. A random trial. Arch Surg 1974;109:793-6.

11. Rutgers PH, Kitslaar PJ. Randomized trial of stripping versus high ligation combined with sclerotherapy in the treatment of the incompetent greater saphenous vein. Am J Surg 1994;168:311-5.

12. Kahle B, Leng K. Efficacy of sclerotherapy in varicose veins-- prospective, blinded, placebocontrolled study. Dermatol Surg 2004;30:723-8; discussion 728.

13. Wollmann JC. The history of sclerosing foams. Dermatol Surg 2004;30:694-703; discussion 703.

14. Rao J, Wildemore JK, Goldman MP. Double-blind prospective comparative trial between foamed and liquid polidocanol and sodium tetradecyl sulfate in the treatment of varicose and telangiectatic leg veins. Dermatol Surg 2005;31:631-5; discussion 635.

15. Rao J, Goldman MP. Stability of foam in sclerotherapy: differences between sodium tetradecyl sulfate and polidocanol and the type of connector used in the double-syringe system technique. Dermatol Surg 2005;31:19-22.

16. Cavezzi A, Frullini A, Ricci S, Tessari L. Treatment of varicose veins by foam sclerotherapy: two clinical series. Phlebology 2002;17:13-18.

17. Breu F, Marshall M, Gugggenbichler S. Prospektive untersuchungen zur schaumsklerosierung: die erste drei Jahre. Vasomed 2005;17:20.

18. Belcaro G, Nicolaides AN, Ricci A, et al. Endovascular sclerotherapy, surgery, and surgery plus sclerotherapy in superficial venous incompetence: a randomized, 10-year follow-up trial--final results. Angiology 2000;51:529-34.

19. Demagny A. Étude comparative de l'efficacité dún produit sclérosant sous ses formes lipuide ou mousse dans la sclérose echoguidée des crosses de grandes et petites veines saphènes. Phlebologie 2002;55:133-7. 
20. Coleridge Smith P. Saphenous ablation: sclerosant or sclerofoam? Semin Vasc Surg 2005;18:19-24.

21. Breu F, Gugggenbichler S, Marshall M. Konsensus und eigene Erfahrungen zur Schaumverödung. Vasomed 2004;16:25.

22. Einarsson E, Eklof B, Neglen P. Sclerotherapy or surgery as treatment for varicose veins. A prospective randomized study. Phlebology 1993;8:22-6.

23. Jakobsen B. The value of different forms of treatment for varicose veins. Br J Surg 1979;66:182-184.

24. Conrad P, Malouf GM, Stacey MC. The Australian polidocanol (aethoxysklerol) study. Results at 2 years. Dermatol Surg 1995;21:334-6; discussion 337-8.

25. Hobbs JT. Surgery or sclerotherapy for varicose veins. Lancet 1978;1:1149. 


\title{
CHAPTER 5
}

\section{Compression after foam sclerotherapy.}

\author{
R.P. Ceulen \\ S.M. Essers
}

Submitted 


\section{Abstract}

Objective The objective of this study was to determine the effect of compression therapy with elastic stockings for different periods of time $(0,1$ or 4 weeks) following foam sclerotherapy of the great saphenous vein (GSV). The results were compared across two subgroups: a subgroup with diameters of $\leq 0.5 \mathrm{~cm}$ and a subgroup with diameters of $>0.5 \mathrm{~cm}$.

Methods In this randomised controlled trial, 72 patients with a primary insufficient GSV were divided into 2 groups based on GSV diameter (group $1 \leq 0.5 \mathrm{~cm}$ and group $2>0.5 \mathrm{~cm}$ ). Subjects were randomly assigned to groups with compression using the combination of a pelotte, a class 1 (18-21 $\mathrm{mmHg}$ ) and a class $2(23-32 \mathrm{mmHg}$ ) stocking for a period of either 0 , 1 or 4 weeks. Physical examination and duplex evaluation of the treated vein took place at 1 , 4, 8 and 12 weeks post-treatment. Patients were assessed with questionnaires on pain and satisfaction.

Results Clinical symptoms showed similar improvement in all randomisation groups compared with pre-treatment assessment. Follow-up after 12 weeks, in the $\leq 0.5$ group, showed complete occlusion in $84 \%$ ( 0 week compression), 92\% (1 week compression) and $84 \%$ (4 weeks compression) of patients. In the $>0.5$ group, full obliteration was obtained in $84 \%$ ( 0 week compression), 84\% (1 week compression) and 92\% (4 weeks compression) of patients. We found a significant rate of phlebitis arising after 1, 4 and 8 weeks only in those patients without compression, regardless of the size of the vein. Hyperpigmentation related to thrombophlebitis was reported in $82 \%$ of patients in the $>0.5 \mathrm{~cm}$ group $(p<0.01)$.

As a result of phlebitis, patients in the $>0.5$ group, patients in the 0 -wk compression group and patients who stopped compression because of the study protocol reported significantly more pain. No serious adverse events occurred. The reported satisfaction rates were equivalent in all groups.

Conclusion Although compression following foam sclerotherapy did not result in higher rates of obliteration, it did prevent side effects such as thrombophlebitis, hyperpigmentation and feelings of pain, particularly in GSVs with a diameter $>0.5 \mathrm{~cm}$. 


\section{Introduction}

Since sclerotherapy with liquid sclerosants became a routine procedure a few decades ago, experts in the field of phlebology have stressed the effectiveness of compression. It is a general belief that compression increases success rates, reduces thrombosis and reduces skin pigmentation..$^{1-3}$ In sclerotherapy techniques used for truncal varicose veins today, foaming sclerosants have replaced the conventional liquid formulation. ${ }^{4}$ The effect of compression after liquid sclerotherapy might be different from that after FS, and it seems unwise to extrapolate from one to the other. ${ }^{5}$ Foam displaces blood from the vein and may prolong the contact of the sclerosing agent with the vein wall, maximizing endothelial destruction. ${ }^{6}$ More important, foam results in higher rates of obliteration. Immediate compression after FS causes direct apposition of treated vein walls, which produces more effective sclerosis. In addition, limiting thrombosis and phlebitic reactions may minimize excessive inflammation. ${ }^{7}$

Most dermatologists and surgeons utilise some form of compression following FS for a variable duration, but the reason for such variation is not clear and seems to be based on individual practice or prejudice rather than objective evidence. ${ }^{8}$ To improve success rates, there is a need for a detailed description of methods. Although much has been published on the short and midterm effects of FS, there is a striking paucity of articles dealing with the period of compression. Therefore, we designed this randomised controlled trial to investigate the optimal duration of compression following FS for GSVs, distinguishing between small $(\leq 0.5 \mathrm{~cm})$ and large $(>0.5 \mathrm{~cm})$ diameters.

\section{Material and Methods}

\section{Patients}

The study design was a randomised, open, prospective, mono-centre study with 6 arms. The study included 72 patients with a primary isolated reflux of the GSV and the SFJ, with a reflux time $\geq 0.5$ seconds measured over a course of $20 \mathrm{~cm}$. Limbs were categorized according to the CEAP classification (according to the North American Chapter of the Society for Vascular Surgery and the International Society). All subjects were divided into 2 study groups on the basis of the diameter of the lumen of the GSV. The mean diameter was calculated from the diameters measured at $5 \mathrm{~cm}$ under the SFJ and at the level of mid-thigh, knee and mid-calf. Group 1 consisted of 36 patients with a GSV $\leq 0.5 \mathrm{~cm}$ in diameter. Group 2 consisted of 36 patients with a GSV $>0.5 \mathrm{~cm}$ in diameter. Subsequently, patients were randomly assigned either to 1. FS without compression (0 wk group), 2. FS followed by compression for 1 week 
(1 wk group) or 3. FS followed by compression for 4 weeks (4 wk group). Randomisation to the study groups was based on a computer-generated list.

The exclusion criteria include the following: very dark skin tone, which could make the assessment of pigmentation difficult or impossible; pregnancy; age less than 18 years or greater than 75 years; obesity; malignancy; inherited or acquired coagulopathy; physical or geographical impediment to participate in the study; lower extremity arterial insufficiency, as defined by absent foot pulses or ankle-brachial index less than 0.7 ; acute superficial vein thrombosis and history of deep vein thrombosis.

\section{Colour duplex scanning}

Pre-treatment examination was performed using a colour duplex scanner (MyLab25 $5^{\mathrm{TM}}$; Esaote Benelux, Maastricht, The Netherlands), with a $10 \mathrm{MHz}$ transducer, to detect venous reflux in the GSV and to exclude other venous pathology, such as deep venous insufficiency, obstruction and venous malformations. The reflux time of the GSV was measured by colour-flow, Doppler ultrasound. A post-treatment duplex examination was performed at 1, 4, 8 and 12 weeks to determine reflux and venous occlusion. A physical examination was performed to determine the effects and side effects of the treatment, such as thrombophlebitis and hyperpigmentation. Patients were screened for deep venous thrombosis.

\section{Foam sclerotherapy}

The incompetent GSV was diagnosed and marked in standing position. The treatment with FS consisted of a single injection of $1 \%$ POL foam, with the patient in supine position. An 18 $\mathrm{G}$ Venflon was placed in the GSV preferably just above the knee. The foam was produced with the double syringe system. An amount of $1 \mathrm{~mL}$ of $1 \%$ POL was mixed with $4 \mathrm{~mL}$ of room air. The maximum total of $10 \mathrm{~mL}$ of foam was injected in 1 treatment session. When necessary, retrograde injection was administered through the same injection site toward the distal part of the GSV up to the ankle region. Because only the effect of compression therapy following FS was assessed, no adjuvant therapies were allowed during the follow-up period of 12 weeks in order to prevent bias of observational data.

\section{Compression therapy}

After the injection, the treatment was finished for subjects randomized to the 0 wk group. For patients randomized to the $1 \mathrm{wk}$ group or $4 \mathrm{wk}$ group, a pelotte was attached firmly to the skin in the marked course of the treated vein using tapes (Photograph 1). A class 1 compression stocking (Venotrain Micro class 1, Bauerfeind, Zeulenroda Triebes, Germany) 
was used during the day and night. A class 2 compression stocking (Venotrain Micro class 2, Bauerfeind, Zeulenroda Triebes, Germany) was placed on top during the daytime. Measurements to determine the correct size of compression stockings were made with the Bauerfeind-3D-imager (Bauerfeind, Zeulenroda, Triebes, Germany). Because elastic stockings can exert the true pressure only during the working phase of the muscle, the in vivo pressure was measured with the Kikuhime Pressure monitor (MediTrade, Soro, Denmark). Inflatable small sensor cells were placed underneath the pelotte. Pressure was measured in supine and standing positions.

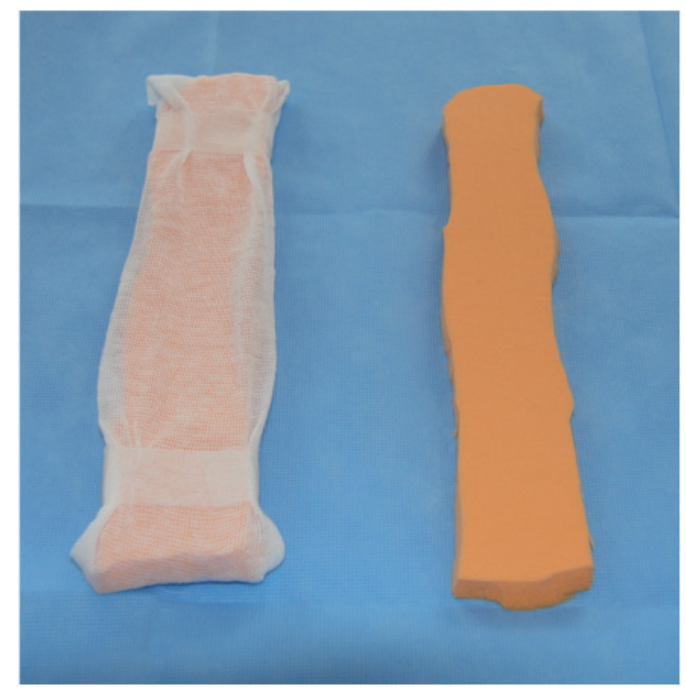

Photograph 1. Self-made pelotte to increase pressure underneath compression stockings.

\section{Follow-up and assessment of outcome measures}

Patients were screened at baseline and during a follow-up at 1, 4, 8 and 12 weeks. The primary outcome was the occlusion of treated GSV, measured by duplex. Success was defined as complete obliteration and no flow. Incompetent saphenous veins are currently defined as reflux for 0.5 seconds. ${ }^{9}$ Secondary outcome measures were thrombophlebitis, post-sclerotic pigmentation, and patient satisfaction. Post-sclerotic pigmentation in the course of the treated vein was defined as no pigmentation $=0, \tan =1$ and hyperpigmentation $=2$.

Thrombophlebitis was defined as the presence of at least one of the following: pain during palpation or warmth and/or redness in the course of the treated vein. Patient satisfaction was measured with a patient satisfaction questionnaire, expressing their degree of satisfaction or dissatisfaction with the treatment: $0=$ not satisfied, $1=$ moderately satisfied, $2=$ complete satisfied. 


\section{Statistical analysis}

We previously demonstrated that despite adequate compression during 4 weeks following FS the incidence of hyperpigmentation is $30 \%{ }^{14} \mathrm{Goldman}$ and Weiss demonstrated less hyperpigmentation if liquid sclerotherapy was followed by compression (100\% hyperpigmentation when no compression is performed, $80 \%$ when compression was given during 3 days)., ${ }^{7,21}$ Based on these data sample size calculations compared proportions for independent samples and the feasibility of recruitment, assuming that the incidence of postsclerotic pigmentation after FS followed by 4 weeks of compression therapy is $30 \%(P 1=0.30)$. Assuming that the incidence of post-sclerotic pigmentation followed by 1 week of compression therapy is $85 \%$ $(\mathrm{P} 2=0.85)$, with alpha $=5 \%$ and power $=80 \%$, the number of patients needed per group is $\mathrm{n}=12$. Thus, with 6 different groups, the total amount of patients necessary is 72 .

The differences between the treatment groups with respect to the proportions of patients with a specific outcome at 1 week, 4 weeks, 8 weeks and 12 weeks following treatment were tested for statistical significance using the Chi-squared test. $A p<0.05$ was considered to indicate statistical significance. All data were analysed with computer software (SPSS, Version 15.0, SPSS, Inc., Chicago, IL, USA).

\section{Results}

During the period from February 2008 to January 2009, eighty consecutive patients with 80 incompetent GSVs were assessed for eligibility. Eight patients were excluded: 2 refused to participate, and 6 did not meet the selection criteria. Seventy-two patients awaiting FS for clinical grade (CEAP classification) C0 ( $n=0)$, C1 $(n=4), C 2(n=45)$, C3 $(n=18), C 4(n=4), C 5$ $(n=0)$ and $C 6(n=1)$ disease were randomized for treatment. Men represented $28 \%(n=20)$ and women represented $72 \%(n=52)$ of the population. The mean age was 58 years (Table 1). All subjects were analysed at baseline and after 1, 4, 8 and 12 weeks; none was lost to follow-up (Figure 1). The mean diameter of the GSV before treatment was $3.7 \mathrm{~mm}$ (range: $2.7-5.0$ ) in the $\leq 0.5$ group and $6.7 \mathrm{~mm}$ (range: $5.0-9.2$ ) in the $>0.5$ group. The mean volume of sclerosant foam per leg required to achieve full obliteration was $5.2 \mathrm{~mL}$ (range: $3.5-6.0$ ) in the $\leq 0.5$ group and $7.9 \mathrm{~mL}$ (range: $5.0-9.5$ ) in the $>0.5$ group.

The in vivo pressure measured at the skin underneath the pelotte in the supine position was $29 \mathrm{mmHg}$ at the groin, $34 \mathrm{mmHg}$ at the knee and $43 \mathrm{mmHg}$ at the level of the calf. In standing position, during the working phase, the mean pressure was $30 \mathrm{mmHg}$ at the groin, $38 \mathrm{mmHg}$ at the knee and $52 \mathrm{mmHg}$ at the calf respectively (Figure 2). 
Table 1. Baseline Characteristics.

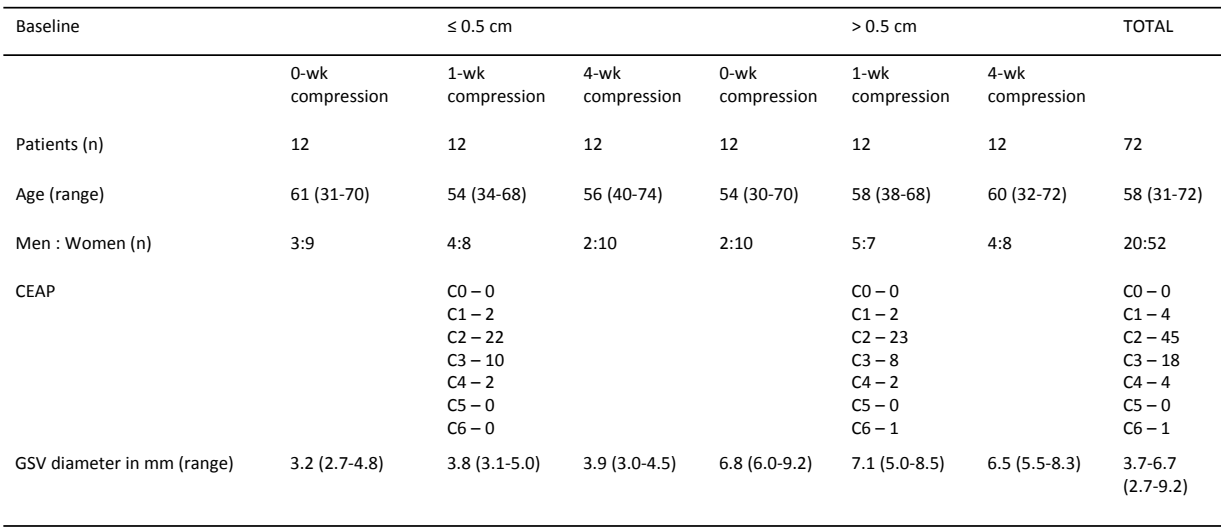

At the 12-week follow-up, we were able to examine all the patients. None was lost to followup. A substantial improvement in clinical venous disease was obtained. Figure 3 shows the CEAP clinical class before and after FS. Duplex examination of the GSVs showed complete occlusion in the $\leq 0.5$ group in $84 \%$ ( 0 wk group), $92 \%$ ( 1 wk group) and $84 \%$ ( 4 wk group) of

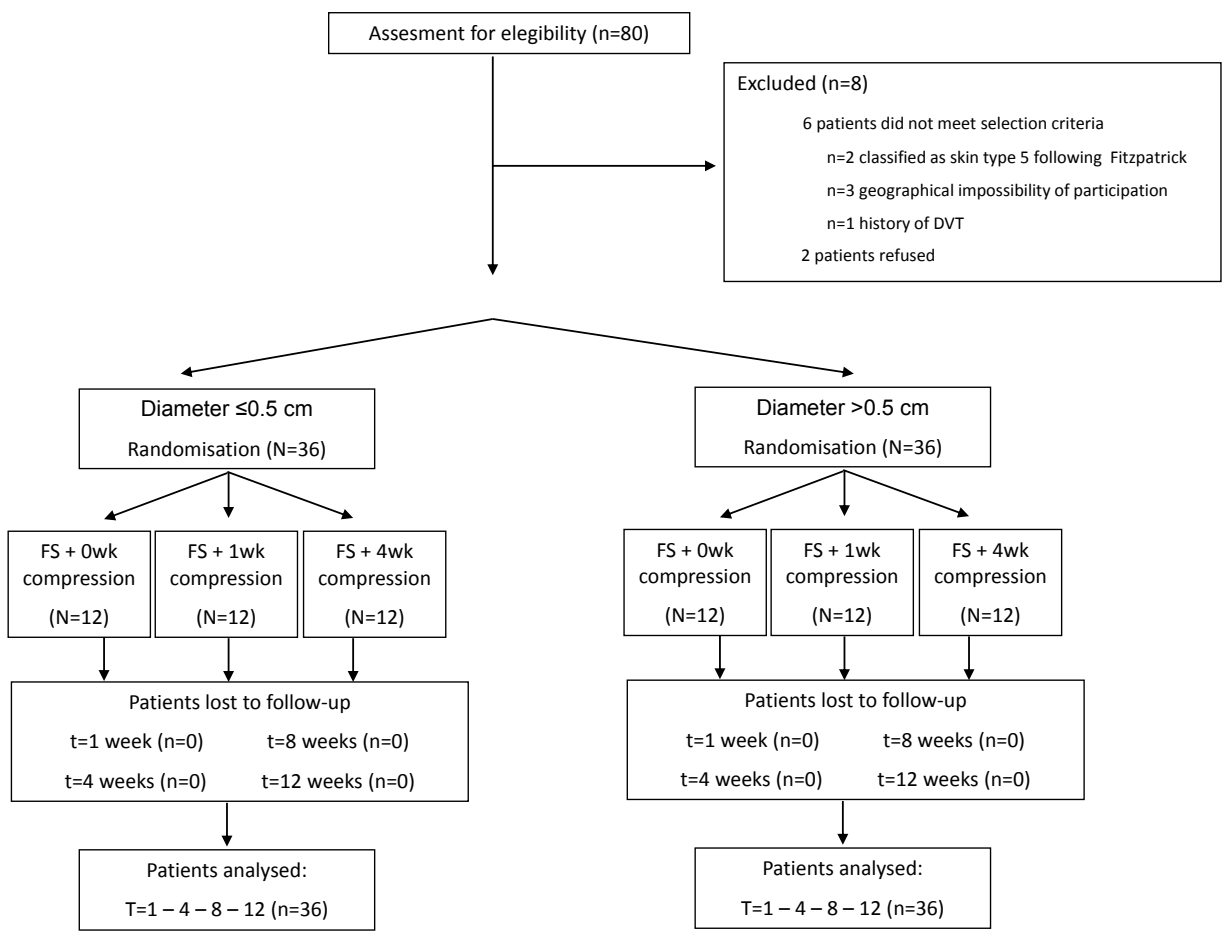

Figure 1. CONSORT diagram showing flow of patients through the study. 


\section{Mean Pressures in $\mathrm{mm} \mathrm{Hg}$}

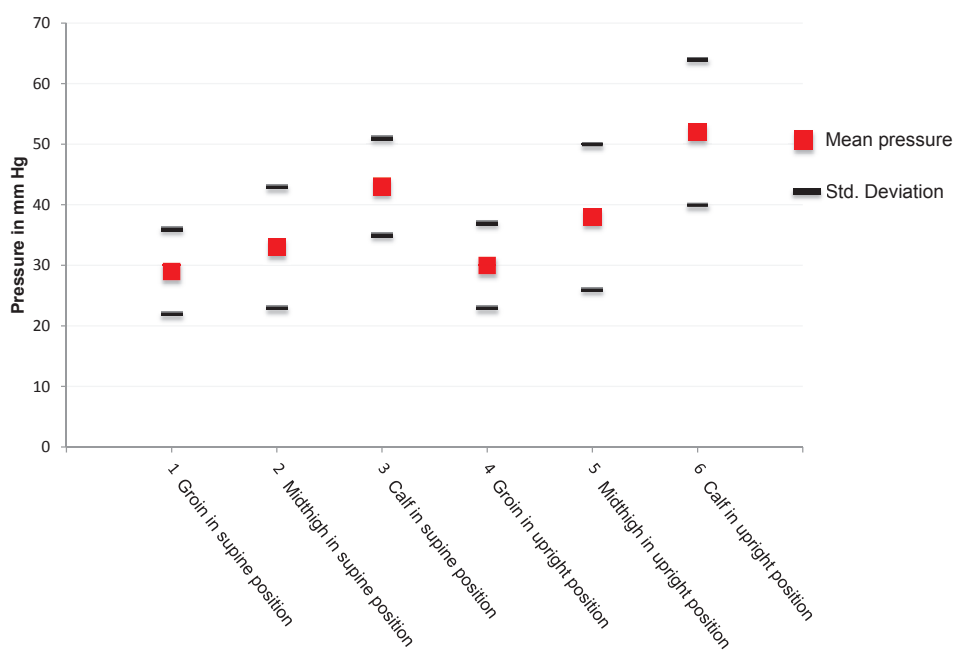

Figure 2. Mean pressures underneath the pelotte measured with Kikuhime sensor cells.

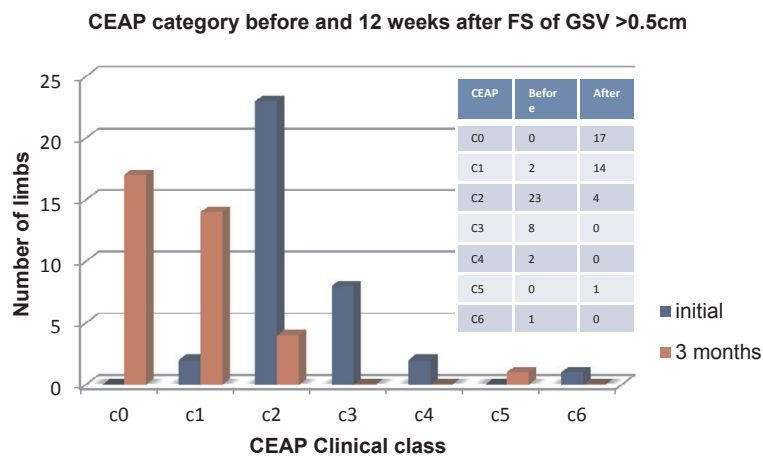

CEAP category before and 12 weeks after FS of GSV $\leq 0.5 \mathrm{~cm}$

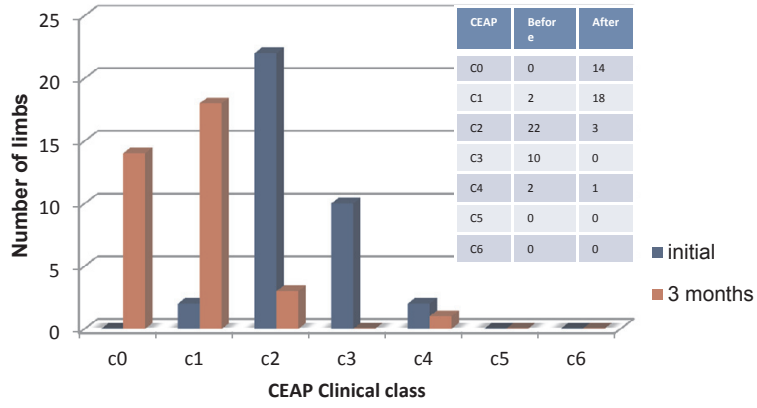

Figure 3. Distribution by CEAP category before and 12 weeks after FS of the GSV. Classes are defined as follows: Class 0, no visible signs of venous disease; Class 1, telangiectasia or reticular veins; Class 2, varicosis without clinical indications of CVl; Class 3, varicosis with oedema; Class 4, varicosis with trophic skin changes; Class 5, varicosis with healed ulcer; Class 6, varicosis with florid ulcer. 
the patients ( $p=0.633$ ). In the $>0.5$ group, full obliteration had been obtained in $84 \%$ ( 0 wk group), $84 \%$ ( 1 wk group) and $92 \%$ ( 4 wk group) of the patients ( $p=0.633$ ) (Table 2 ).

We found compression to significantly prevent the development of thrombophlebitis. At the 1-week follow-up, phlebitis developed only in patients without compression. In the $\leq 0.5$ group, phlebitis developed in $33 \%$ of the patients $(p=0.008)$, and in the $>0.5$ group, phlebitis developed in $42 \%$ of the patients $(p=0.045)$. At the 4 -week follow-up, phlebitis was also significantly raised in the subjects randomized to 1 week of compression. Phlebitis developed in $50 \%$ of patients in the $\leq 0.5$ group ( $p=0.022)$ and $58 \%$ of patients in the $>0.5$ group $(p=0.009)$. In contrast, phlebitis only developed in $8 \%$ of patients randomized to 4 weeks of compression, regardless of the size of the diameter (large or small) of the treated vein. After 8 weeks, the difference in phlebitis between the different randomization groups disappeared (Table 2; Figure 4). Patients in the $>0.5$ group, patients in the 0 -wk compression group and patients who stopped compression because of the study protocol reported significantly more pain than the other groups (Table 2).

Table 2. Obliteration rates; Side effects; Patient satisfaction score.

\begin{tabular}{|c|c|c|c|c|c|c|c|c|c|}
\hline & & & $\leq 0.5 \mathrm{~cm}$ & & & & $>0.5 \mathrm{~cm}$ & & \\
\hline & & $\begin{array}{c}\text { 0-wk } \\
\text { compression }\end{array}$ & $\begin{array}{c}1 \text {-wk } \\
\text { compression }\end{array}$ & $\begin{array}{c}\text { 4-wk } \\
\text { compression }\end{array}$ & $\mathrm{P}$ & 0-wk compression & $\begin{array}{c}1 \text {-wk } \\
\text { compression }\end{array}$ & $\begin{array}{c}\text { 4-wk } \\
\text { compressio } \\
n\end{array}$ & $P$ \\
\hline $\begin{array}{l}\text { Occlusion on } \\
\text { duplex }\end{array}$ & $12 \mathrm{wk}$ & $84 \%$ & $92 \%$ & $84 \%$ & NS & $84 \%$ & $84 \%$ & $92 \%$ & NS \\
\hline $\begin{array}{l}\text { Post-sclerotic } \\
\text { pigmentation }\end{array}$ & $12 \mathrm{wk}$ & $25 \%$ & $33 \%$ & $25 \%$ & NS & $33 \%$ & $33 \%$ & $50 \%$ & NS \\
\hline \multirow[t]{4}{*}{ Phlebitis } & $1 \mathrm{wk}$ & $33 \%$ & 0 & 0 & 0.008 & $50 \%$ & $17 \%$ & $8 \%$ & 0.045 \\
\hline & $4 \mathrm{wk}$ & $42 \%$ & $50 \%$ & $8 \%$ & 0.022 & $50 \%$ & $58 \%$ & $8 \%$ & 0.009 \\
\hline & $8 w k$ & $17 \%$ & $29 \%$ & $33 \%$ & NS & $42 \%$ & $42 \%$ & $42 \%$ & NS \\
\hline & $12 \mathrm{wk}$ & $8 \%$ & $29 \%$ & $25 \%$ & NS & $33 \%$ & $33 \%$ & $25 \%$ & NS \\
\hline \multirow{3}{*}{$\begin{array}{l}\text { Pain as a } \\
\text { symptom of } \\
\text { phlebitis }\end{array}$} & $1 \mathrm{wk}$ & $50 \%$ & 0 & 0 & 0.028 & $80 \%$ & 0 & 0 & 0.001 \\
\hline & 4 wk & $60 \%$ & $14 \%$ & $8 \%$ & 0.002 & $100 \%$ & $50 \%$ & $8 \%$ & 0.046 \\
\hline & $12 \mathrm{wk}$ & $100 \%$ & $50 \%$ & $67 \%$ & 0.01 & $75 \%$ & $100 \%$ & $100 \%$ & NS \\
\hline \multirow{4}{*}{$\begin{array}{l}\text { Pigmentation } \\
\text { as a symptom } \\
\text { of phlebitis }\end{array}$} & $1 \mathrm{wk}$ & & 0 & & & & 0 & & - \\
\hline & $4 \mathrm{wk}$ & & $31 \%$ & & & & $82 \%$ & & 0.000 \\
\hline & $8 w k$ & & $40 \%$ & & & & $73 \%$ & & 0.030 \\
\hline & $12 \mathrm{wk}$ & & $38 \%$ & & & & $60 \%$ & & 0.010 \\
\hline \multirow{3}{*}{$\begin{array}{l}\text { Patient } \\
\text { satisfaction }\end{array}$} & $1 \mathrm{wk}$ & $87 \%$ & $88 \%$ & $89 \%$ & NS & $85 \%$ & $89 \%$ & $87 \%$ & NS \\
\hline & $4 \mathrm{wk}$ & $83 \%$ & $69 \%$ & $83 \%$ & NS & $84 \%$ & $72 \%$ & $81 \%$ & NS \\
\hline & $12 \mathrm{wk}$ & $83 \%$ & $79 \%$ & $92 \%$ & NS & $86 \%$ & $82 \%$ & $86 \%$ & NS \\
\hline
\end{tabular}

Post-sclerotic pigmentation after 3 months of follow-up was present in the $\leq 0.5$ group in $25 \%$ ( 0 wk group), 33\% ( $1 \mathrm{wk}$ group) and $25 \%$ ( $4 \mathrm{wk}$ group) of patients ( $p=0.198)$. In the $>0.5$ group, post-sclerotic pigmentation was present in 33\% (0 wk group), 33\% (1 wk group) and 50\% (4 wk group) of patients ( $p=0.248$ ). After 12 weeks of follow-up, we found a large difference 
between the incidence of hyperpigmentation in the presence of phlebitis, comparing GSVs with large diameters to GSVs with small diameters: $82 \%$ of the patients in the $>0.5$ group as compared with $38 \%$ of the patients in the $<0.5$ group $(p<0.001)$. While registering the CEAP classification during the clinical examinations at the 12-week follow-up, we did not classify the post-sclerotic skin pigmentations as C4 because discoloration is iatrogenic and not a symptom of chronic venous disease.

In both groups, no serious adverse events occurred. Sometimes small palpable lumps were detectable in the course of the treated vein and comprised residual elements of treated veins. We did not find deep vein thrombosis, neurological damage or lymphatic injuries.

At the 12-week follow-up, the reported patient satisfaction rates were similar in both the $\leq 0.5$ group and the $>0.5$ group, regardless of the period of compression. In the $\leq 0.5$ group, $83 \%$ of the patients in the 0 wk group, $79 \%$ of the patients in the $1 \mathrm{wk}$ group and $92 \%$ of the patients in the $4 \mathrm{wk}$ group reported having a successful treatment of varicose veins and their related symptoms ( $p=0.223$ ). In the $>0.5$ group, $87 \%$ of the patients ( 0 wk group), $81 \%$ of the patients ( 1 wk group) and $86 \%$ of the patients ( 4 wk group) were completely satisfied ( $p=0.336)$. None of the studied subjects in either group rated the treatment as a failure (Table 2).

\section{Discussion}

This is the first time that different compression regimens following FS for the treatment of GSVs have been investigated with a distinction between large $(>0.5 \mathrm{~cm})$ and small $(\leq 0.5 \mathrm{~cm})$ diameters. The principal findings are first, that full occlusion of the treated GSV was achieved in more than $84 \%$ of patients over all randomisation groups. Second, compression therapy significantly prevents the development of thrombophlebitis. Third, the severity of the symptoms caused by phlebitis is increased with a larger diameter of the lumen of the treated vein.

Previous studies comparing compression following sclerotherapy of telangiectatic and reticular veins showed that compression enhances clinical vessel disappearance and leads to a statistically significant reduction of hyperpigmentation. The results are directly correlated with the duration of compression. ${ }^{7,10,11}$ However, these results cannot be extrapolated to our data because we focused on the GSV, which is anatomically deeper and therefore more difficult to compress, and we used the more powerful POL foam instead of liquid sclerosant, thus making a reliable comparison difficult.

Recently, many studies on compression therapy after FS for saphenous veins have obtained fairly similar success rates and side effects. ${ }^{12-14}$ These studies have resulted in diverse inter- 


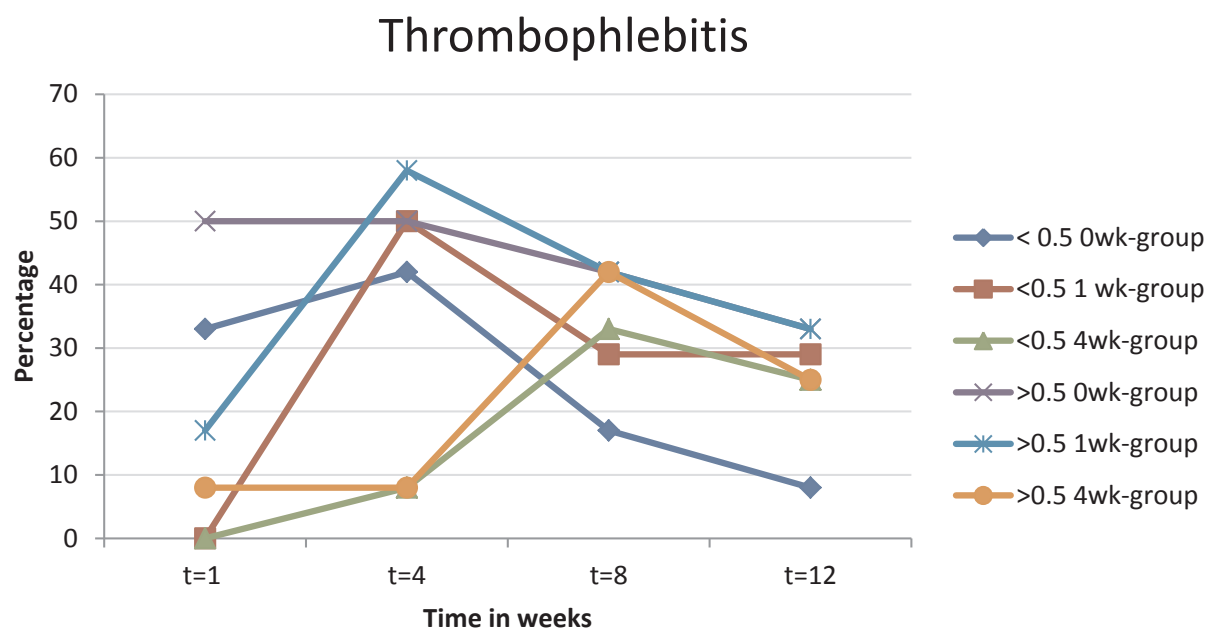

Figure 4. Thrombophlebitis developed mainly in those patients who were not randomised to compression and in those patients where compression was stopped because of the study protocol.

national opinions about proper the length and strength of compression. In the absence of randomised controlled trials comparing the different compression strategies, the European FS consensus that was established in 2003 did not make recommendations concerning compression. ${ }^{15}$

Very recently, Hamel-Desnos published the results of the first randomised controlled trial comparing FS for saphenous veins with or without compression. For the compression treatment, $15-20 \mathrm{mmHg}$ stockings were used during the daytime for three weeks. A significant improvement in QOL and negligible side effects were reported in both groups. Additionally, the authors concluded that compression did not demonstrate the expected superiority in thrombophlebitis, inflammation, pain, pigmentation and matting. The small administered doses of foam were speculated to account for the low incidence of side effects observed. ${ }^{16} \mathrm{~A}$ limitation of Hamel-Desnos trial is that the applied compression $(15-20 \mathrm{mmHg})$ is believed not to provide sufficient pressure to modify the GSV vein wall and is believed not to affect the diameter of the vein.

In our study, we demonstrated that the rate of occlusion after 3 months is not dependent on the diameter of the GSV. In contrast, Smith showed in his case-series that the main factor influencing recurrence was the size of the vein prior to treatment, measured after a mean follow-up time of 11 months. GSVs of $6 \mathrm{~mm}$ diameter or greater were more likely to recur (19\%) than those of $5 \mathrm{~mm}$ diameter and below (7\%). ${ }^{17}$ After 24 months of follow-up, Barrett demonstrated a small increase in the failure to close the SFJ with an increasing size of the junction diameter, but this association did not significantly alter the results with respect to 
the clearance of visible varicosities and patient satisfaction..$^{18}$ In our study, focusing on the effect of compression on outcome, we applied a maximum follow-up time of three months. In the discussed papers, the success percentages after 3 months were not described. Therefore, we believe that the short follow-time explains the difference in outcomes.

To prevent the formation of an endoluminal thrombus following FS, a significant narrowing of the GSV in the upright position needs to be achieved with compression therapy. A local pressure of more than $40 \mathrm{mmHg}$ is necessary. ${ }^{19}$ This level of pressure can be achieved with the eccentric compression technique. We used a combination of a class 1 and class 2 hosiery on top of a self-made foam pad. ${ }^{20}$ During and because of this eccentric compression, phlebitis was only incidentally noticed in all randomisation groups. However, a significant formation of phlebitis was observed when compression was not applied at all and immediately when compression was stopped after 1 or 4 weeks. We demonstrated that rigorous compression avoids thrombophlebitis.

Post-sclerotic pigmentation in the course of the treated vein is a common finding. ${ }^{13,14}$ We demonstrated that if thrombophlebitis arises in GSVs with a diameter $>0.5 \mathrm{~cm}$, this will lead to more discoloration and pain than with GSVs with small diameters. The period of compression, however, did not influence the incidence of hyperpigmentation. In contrast, the report of feelings of discomfort and pain were significantly less when compression was applied. Therefore, we suggest that it may be wise, in order to diminish both the incidence of phlebitis and the feeling of pain and discomfort, to apply compression for a longer than a 4-week period. Clinical trials should be conducted to investigate this hypothesis.

\section{Conclusion}

In conclusion, to our knowledge, this trial is the first prospective study comparing different periods of compression after FS for treating incompetent GSV with variable diameters. We demonstrated that compression following FS is not necessary to achieve successful venous obliteration; however, side effects were less frequently observed if compression was applied. The protective quality of compression diminishes when compression ends, even after four weeks. When thrombophlebitis occurs, the rate of hyperpigmentation will increase mainly in GSVs with a diameter $>0.5 \mathrm{~cm}$, independent to the length of compression applied afterward. Thus, we suggest for the patients' comfort, especially for those with GSVs $>0.5 \mathrm{~cm}$, the application of compression after FS. Research should be conducted to investigate whether compression for a period longer than four weeks following FS will further improve patients' comfort. 


\section{Funding}

Because of the study design, the author was awarded the Bauerfeind-Award; therefore, this study was supported by funds from Bauerfeind. The sponsor had no role in the study design, data collection, data analysis, and data interpretation, or writing of the report. The author had full access to all the data in the study and had final responsibility to submit it for publication. The author declares no conflict of interest. 


\section{References}

1. Fegan WG. Continuous compression technique of injecting varicose veins. Lancet. 1963;2:109-12.

2. Shouler PJ, Runchman PC. Varicose veins: optimum compression after surgery and sclerotherapy. Ann R Coll Surg Engl. 1989;71:402-4.

3. Sigg K. The treatment of varicosities and accompanying complications; (the ambulatory treatment of phlebitis with compression bandage). Angiology. 1952;3:355-79.

4. Ouvry P, Allaert FA, Desnos P, Hamel-Desnos C. Efficacy of polidocanol foam versus liquid in sclerotherapy of the great saphenous vein: a multicentre randomised controlled trial with a 2-year follow-up. Eur J Vasc Endovasc Surg. 2008;36:366-70.

5. Hamel-Desnos C, Allaert FA. Liquid versus foam sclerotherapy. Phlebology. 2009;24:240-6.

6. Hamel-Desnos C, Desnos P, Wollmann JC, et al. Evaluation of the efficacy of polidocanol in the form of foam compared with liquid form in sclerotherapy of the greater saphenous vein: initial results. Dermatol Surg. 2003;29:1170-5; discussion 5.

7. Weiss RA, Sadick NS, Goldman MP, Weiss MA. Post-sclerotherapy compression: controlled comparative study of duration of compression and its effects on clinical outcome. Dermatol Surg. 1999;25:105-8.

8. Kurz X, Kahn SR, Abenhaim L, et al. Chronic venous disorders of the leg: epidemiology, outcomes, diagnosis and management. Summary of an evidence-based report of the VEINES task force. Venous Insufficiency Epidemiologic and Economic Studies. Int Angiol. 1999;18:83-102.

9. Labropoulos N, Delis K, Nicolaides AN, et al. The role of the distribution and anatomic extent of reflux in the development of signs and symptoms in chronic venous insufficiency. J Vasc Surg. 1996;23:504-10.

10. Goldman MP. Compression in the treatment of leg telangiectasia: theoretical considerations. J Dermatol Surg Oncol. 1989;15:184-8.

11. Nootheti PK, Cadag KM, Magpantay A, et al. Efficacy of graduated compression stockings for an additional 3 weeks after sclerotherapy treatment of reticular and telangiectatic leg veins. Dermatol Surg. 2009;35:53-7; discussion 7-8.

12. Rabe $E$, Otto J, Schliephake $D$, et al. Efficacy and safety of great saphenous vein sclerotherapy using standardised polidocanol foam (ESAF): a randomised controlled multicentre clinical trial. Eur J Vasc Endovasc Surg. 2008;35:238-45.

13. Hamel-Desnos C, Ouvry P, Benigni JP, et al. Comparison of $1 \%$ and $3 \%$ polidocanol foam in ultrasound guided sclerotherapy of the great saphenous vein: a randomised, double-blind trial with 2 year-follow-up. "The 3/1 Study". Eur J Vasc Endovasc Surg. 2007;34:723-9; discussion 30.

14. Ceulen RP, Bullens-Goessens $\mathrm{YI}, \mathrm{Pi}$ - van de Venne SJ, et al. Outcomes and side effects of duplexguided sclerotherapy in the treatment of great saphenous veins with $1 \%$ versus $3 \%$ polidocanol foam: results of a randomized controlled trial with 1-year follow-up. Dermatol Surg. 2007;33: 276-81.

15. Breu FX, Guggenbichler S. European Consensus Meeting on Foam Sclerotherapy, April, 4-6, 2003, Tegernsee, Germany. Dermatol Surg. 2004;30:709-17; discussion 17.

16. Hamel-Desnos CM, Guias BJ, Desnos PR, et al. Foam sclerotherapy of the saphenous veins: randomised controlled trial with or without compression. Eur J Vasc Endovasc Surg. 2010;39:500-7.

17. Smith PC. Chronic venous disease treated by ultrasound guided foam sclerotherapy. Eur J Vasc Endovasc Surg. 2006;32:577-83. 
18. Barrett JM, Allen B, Ockelford A, et al. Microfoam ultrasound-guided sclerotherapy treatment for varicose veins in a subgroup with diameters at the junction of $10 \mathrm{~mm}$ or greater compared with a subgroup of less than $10 \mathrm{~mm}$. Dermatol Surg. 2004;30:1386-90.

19. Partsch H, Mosti G. Thigh compression. Phlebology. 2008;23:252-8.

20. Tazelaar DJ, Neumann HA, De Roos KP. Long cotton wool rolls as compression enhancers in macrosclerotherapy for varicose veins. Dermatol Surg. 1999;25:38-40.

21. Goldman MP. How to utilize compression after sclerotherapy. Dermatol Surg 2002;28:860-2. 



\section{CHAPTER 6}

\section{Microembolism during foam sclerotherapy.}

R.P. Ceulen

A. Sommer

K. Vernooy

NEJM. 2008;358:1525. 

Chronic venous insufficiency is a common disease in adulthood. One recently developed therapy for varicose veins is FS. ${ }^{1}$

We used FS in a 51-year-old man and a 33-year-old woman who had symptomatic varicose great saphenous veins and were otherwise healthy. Immediately after the initiation of treatment transient scotomas developed in the man, and a migraine attack in the woman.

On the basis of these observations, we decided to monitor by echocardiography the foam distribution during foam sclerotherapy in 33 consecutive patients with CVI. The treatment of each patient was carried out according to European consensus guidelines. ${ }^{2}$ Briefly, patients received a single injection of $5 \mathrm{~mL} 1 \% \mathrm{POL}$ foam (air-to-liquid ratio 4:1). The foam was injected with the patient's leg slightly elevated, while the SFJ was manually compressed until full vasospasm occurred and blood flow velocity in the GSV decreased to zero.

In all patients studied we detected foam microemboli in both the right atrium and ventricle between 45 seconds and 15 minutes after foam injection (Figure 1a). In 5 patients microem-
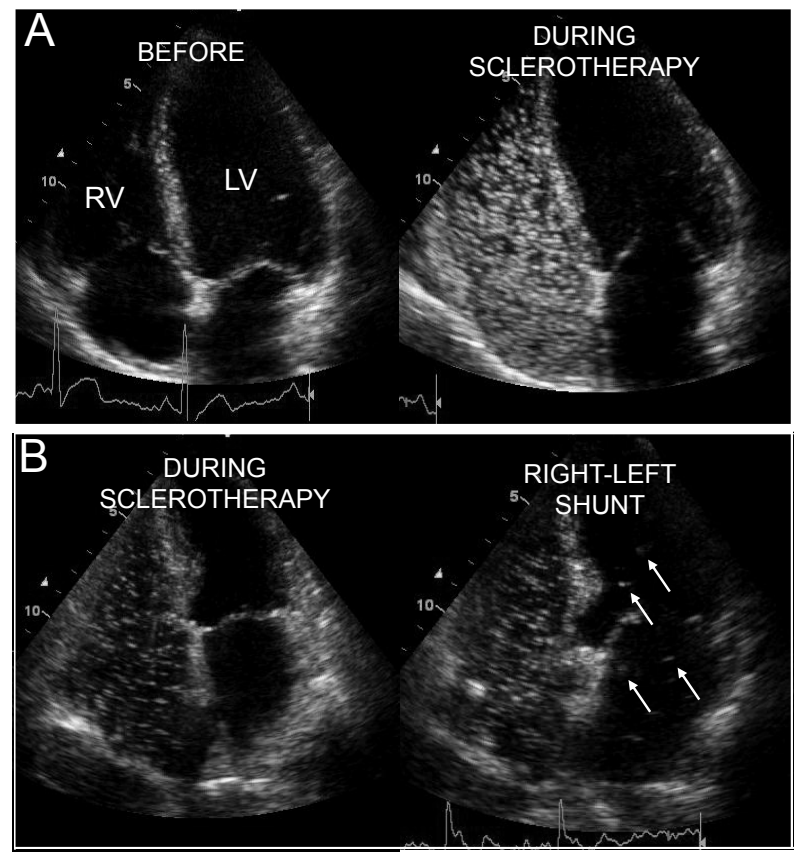

Figure 1. Echocardiographic images obtained during sclerotherapy with foam injection. Panel A shows apical four-chamber images before and during foam sclerotherapy. Foam microemboli are present in the right atrium and ventricle of the heart.

Panel B show paradoxical foam microembolism during foam sclerotherapy. Microemboli in the left atrium and ventricle of the heart (arrows) are due to a right-to-left shunt through a patent foramen ovale. RV denotes right ventricle, and LV left ventricle. 
bolism was also detectable in the left atrium and ventricle (Figure 1b); however, neurologic signs did not develop in any to them. Careful echocardiographic examination of these 5 patients showed a right-to-left shunt through a patent foramen ovale. Because the neurologic symptoms observed in the two index patients could have reflected adverse effects of foam sclerotherapy due to a right-to-left shunt, we subsequently examined both patients by echocardiography and detected a patent foramen ovale in each.

These findings suggest that foam-induced microembolism is a common phenomenon during foam sclerotherapy. The prevalence of patent foramen ovale, which can be a source of paradoxical embolism, is approximately $26 \%$ in the general population. ${ }^{3}$ Still, serious neurologic symptoms after FS, which include scotomas, migraine, and stroke, occur in only $0.27 \%$ or less of patients. ${ }^{4,5}$ Thus, the findings in our cohort show are not in line with previous reports. Although the overall number of neurologic adverse effects during foam sclerotherapy might be underestimated, it appears that neurologic complications develop in relatively few patients with right-to-left shunts and foam microembolism.

Nevertheless, we suggest that caution be exercised when FS is performed in patients with a known patent foramen ovale and that patients with overt neurologic symptoms undergo an additional echocardiographic examination for the presence of a patent foramen ovale. Further prospective studies are needed to evaluate and confirm our observations. 


\section{References}

1. Jia X, Mowatt G, Burr JM, et al. Systematic review of foam sclerotherapy for varicose veins. Br J Surg 2007;94:925-36.

2. Breu FX, Guggenbichler S. European Consensus Meeting on Foam Sclerotherapy, April, 4-6, 2003, Tegernsee, Germany. Dermatol Surg. 2004;30:709-17; discussion 17.

3. Meier B, Lock JE. Contemporary management of patent foramen ovale. Circulation. 2003;107:5-9.

4. Forlee MV, Grouden M, Moore DJ, et al. Stroke after varicose vein foam injection sclerotherapy. J Vasc Surg. 2006;43:162-64.

5. Guex JJ, Allaert FA, Gillet JL, et al. Immediate and midterm complications of sclerotherapy: report of a prospective multicenter registry of 12,173 sclerotherapy sessions. Dermatol Surg. 2005;31: 123-28; discussion 28. 



\title{
CHAPTER 7
}

\section{Blocking the SFJ during foam sclerotherapy - assessment of a presumed safety measure procedure.}

\author{
R.P. Ceulen \\ E.A. Jagtman \\ A. Sommer \\ G.J. Teule \\ G.W. Schurink \\ G.J. Kemerink
}

Eur J Vasc Endovasc Surg. 2010;40:772-6. 


\section{Abstract}

Objectives Ultrasound guided foam sclerotherapy is a technique in which a mixture of sclerosing agent and gas is used to treat varicose veins. Several authors have demonstrated transient systemic effects after FS. These effects are not well understood but probably originate from a systemic distribution of the sclerosing foam. Therefore, safety measures have been developed to prevent foam from flowing into the deep venous system. To evaluate whether blockage of the saphenofemoral junction (SFJ) by either manual compression or surgical ligation prevents microbubbles from leaking into the deep venous circulation.

Methods To detect the distribution of microbubbles, radioactive pertechnetate $\left({ }^{99 \mathrm{~m}} \mathrm{TcO}_{4}^{-}\right)$ was added to the foam solution. Initially, in vitro trials were performed in the laboratory to investigate the effect of ${ }^{99 \mathrm{~m} T \mathrm{C}}$ on foam stability. The duration of time it takes for foam to

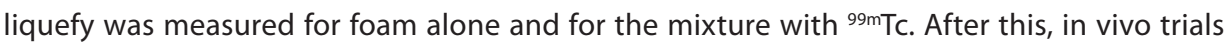
were conducted. Eight varicose GSVs were treated by FS. In 3 patients, this treatment was preceded by surgical ligation of the SFJ. In 3 patients, the groin was manually compressed during FS. In 2 patients FS was performed without compression of the groin.

Results In vitro, ${ }^{99 \mathrm{mTC}}$ did not influence foam stability; after 2.6 minutes all foam had reduced to liquid, regardless of whether ${ }^{99 \mathrm{~m} T c}$ had been added. In vivo trials showed that all patients showed a decrease in the cumulative amount of ${ }^{99 \mathrm{mT}} \mathrm{Tc}$ detected in the GSV following policocanol-99mTc mixture injection. However, the decrease of radioactivity was slight reduced when compression or ligation of the SFJ was performed.

Conclusion Blocking the SFJ during FS using either manual compression or ligation does not prevent, but slightly reduces the flow of foam into the femoral vein. 


\section{Introduction}

Venous insufficiency of the lower limb is a common phenomenon, with varicose veins appearing as a hallmark of this condition. It is estimated that the prevalence of incompetent veins varies from $<1 \%$ to $73 \%$ in females and from $2 \%$ to $56 \%$ in males, with the highest reported rates in Western countries. ${ }^{1,2}$ Venous incompetence has a strong impact on healthrelated quality of life and is associated with increasing health care costs. ${ }^{3}$

Surgery has been the main treatment of varicose veins for years. However, several less invasive techniques have recently been developed. One of these is FS. In FS, sclerosing foam is injected into the varicose vein. This causes endothelial damage, leading to sclerothrombus formation and resulting in occlusion of the vein.

To date, discussions about the safety of foam have not been conclusive. Gillet described 27 systemic side effects in 1025 patients, with side effects varying from migraine to transient ischemic attack. ${ }^{4}$ Guex reported 49 incidents during 12,173 POL liquid and foam treatments, most of which were visual disturbances. ${ }^{5}$

The abovementioned side effects are proposed to be caused by the systemic distribution of foam. Fundamental research however, demonstrated that sclerosants are neutralized by blood proteins already a few seconds after injection. ${ }^{6}$ To date, no research has been able to track the sclerosing gas after injection. However, several authors have published results indicating systemic distribution of sclerosant after FS. Ceulen and Wright identified microemboli in the right atrium and ventricle of the heart shortly after foam therapy. ${ }^{7,8}$

Because side effects are believed to be caused by a systemic distribution of foam, preventive measures have been taken to stop foam from leaking into the deep venous system. Manual compression of the groin is one of the techniques believed to reduce this leakage. Of the vascular surgeons in the United Kingdom responding to a questionnaire, $63 \%$ said they gave direct pressure to the junction during foam sclerotherapy. ${ }^{9}$

In this article, we aimed to assess whether blocking the SFJ reduces foam from entering the deep venous system.

\section{Methods}

To visualize small foam particles unseen by duplex, we mixed POL $1 \%$ with pertechnetate $\left({ }^{99 m} \mathrm{TcO}_{4}{ }^{-}\right)$, a radioactive substance. Pertechnetate is among the materials used as a flow tracer, e.g., to evaluate the function of the left ventricle of the heart. ${ }^{10}$ Using a gammacamera, the ${ }^{99 m T c}$ allows for the detection of foam in the treated vein and leakage from the treated vein into the deep venous system. We used an average of $140 \mathrm{MBq}{ }^{99 \mathrm{~m} T c}$, which resulted in an effective dose to the patient of about $1.8 \mathrm{mSv}$. For comparison, the effective dose due to natural radiation in the Netherlands is $2.0 \mathrm{mSv}$ per year. 
Before using POL-99mTc foam, we wanted to be sure that pertechnetate would not influence foam stability. Therefore, foam half time (FHT) was measured for both the standard foam used in FS and the pertechnetate-labeled POL-99mTc foam.

\section{POL-99m Tc mixture creation}

The following standardized technique was employed to create POL-99mTc-foam and measure its stability. ${ }^{11}$ A sterile $6 \mathrm{~mL}$ syringe was used to draw up $1.0 \mathrm{~mL}$ of POL $1 \%$ liquid and a sterile $1.0 \mathrm{~mL}$ syringe was used to draw up $0.5 \mathrm{~mL}$ of pertechnetate-saline solution. The pertechnetate-saline solution was mixed with the POL $1 \%$ using a Stainless Steel 2-Way connector. A sterile $6 \mathrm{~mL}$ syringe with $4.0 \mathrm{~mL}$ of air was connected by a 3-way connector (BD Connecta Luer-Lok 360 Becton Dickinson Infusion Therapy AB, SE 25106 Helsingborg, Sweden) to the $6 \mathrm{~mL}$ syringe with the $1.5 \mathrm{~mL}$ POL-${ }^{99 \mathrm{~m} T c}$ mixture. Using the Tessari technique, the sclerosant-99m Tc and air were drawn back and forth with 20 pump movements to produce $5.5 \mathrm{~mL}$ of sclerosing ${ }^{99 \mathrm{~m} T c-f o a m}$.

\section{In vitro experiment - POL-99mTc mixture stability vs. POL stability}

Standard foam was made using the Tessari technique, as described above. Although we do not normally do so, we added $0.5 \mathrm{~mL}$ of $0.9 \%$ saline solution to prepare foam in this study. We used the saline solution because the sclerosing foams used in this study are not intended to provide a therapeutic effect, rather are intended to be used for imaging the distribution pattern of foam after injection. By using a $0.9 \%$ saline solution for the production of standard foam, we enlarged the homogeneity and comparability of both sclerosing foams. Then, a sterile $6 \mathrm{~mL}$ syringe was used to draw up $1.0 \mathrm{~mL}$ of POL $1 \%$ and $0.5 \mathrm{~mL}$ of $0.9 \%$ saline. This 1.5 $\mathrm{mL}$ POL-saline solution was mixed with $4.0 \mathrm{~mL}$ air to produce the foam. With $5.5 \mathrm{~mL}$ of foam filling the $6 \mathrm{~mL}$ syringe, the syringe was disconnected from the 3-way connector and placed vertically, with the rubber piston of the syringe on the bottom, and the timer was started. As the foam degenerated back into its constituents, the sclerosing solution was found to gradually re-form at the bottom of the syringe. When the bottom of the solution's meniscus attained a volume of exactly $0.75 \mathrm{~mL}$ (half of the original sclerosing volume of $1.5 \mathrm{~mL}$ ), the timer was stopped, and the time in seconds was recorded. This time was defined as FHT (T1/2). The time that was needed for POL foam to completely return into liquid was also recorded (T1). This process was repeated for the POL-99mTc mixture (Table 1). All recordings were performed at an ambient temperature of $20^{\circ} \mathrm{C}$. 
Table 1. FHT of POL foam with and without $99 \mathrm{mTc}$.

\begin{tabular}{|c|c|c|c|c|c|c|c|c|c|c|}
\hline & \multicolumn{2}{|c|}{ Measurement 1} & \multicolumn{2}{|c|}{ Measurement2 } & \multicolumn{2}{|c|}{ Measurement3 } & \multicolumn{2}{|c|}{ Measurement4 } & \multicolumn{2}{|c|}{ Average (SD) } \\
\hline & $T 1 / 2$ & $\mathrm{~T} 1$ & $T 1 / 2$ & $\mathrm{~T} 1$ & $T 1 / 2$ & $\mathrm{~T} 1$ & $T 1 / 2$ & $\mathrm{~T} 1$ & $T 1 / 2$ & $\mathrm{~T} 1$ \\
\hline POL foam & 1.7 & 2.5 & 1.8 & 2.7 & 1.7 & 2.6 & 1.8 & 2.7 & $1.7(0.1)$ & $2.6(0.1)$ \\
\hline POL ${ }^{99 m} \mathrm{Tc}$ foam & 1.8 & 2.7 & 1.7 & 2.7 & 1.7 & 2.7 & 1.8 & 2.5 & $1.7(0.1)$ & $2.6(0.1)$ \\
\hline
\end{tabular}

$\mathrm{T} 1 \frac{1}{2}=\mathrm{FHT}=$ Time in which half of the original amount of liquid had reformed from the foam (in minutes).

$\mathrm{T} 1$ = Time in which the total amount of foam had reduced to liquid (in minutes).

$\mathrm{SD}=$ Standard deviation

\section{In vivo experiment - Treating GSV with POL-99mTc foam}

\section{Treatment groups}

A randomly selected group of outpatients with primary isolated GSV incompetence were used. Eight limbs of 8 patients (all female, mean age 51) were assigned to two groups: Group 1 was treated with ligation of the SF-junction followed by POL-99mTc FS 14 days after operation. Group 2 was given the POL-99m Tc FS under manual compression of the groin. Group 3 (control group) was given the POL-99mTc FS without manual compression of the groin (Table 2). An ethics committee approved the study and written informed consent was obtained from all patients. The study was conducted according to the guidelines of the Declaration of Helsinki.

Table 2. Treatment characteristics of each patient.

\begin{tabular}{lll}
\hline Patient & Treatment & Compression of SF-junction \\
\hline 1 & FS & Yes \\
2 & FS & Yes \\
3 & FS & Yes \\
4 & Crossectomy + FS & No \\
5 & Crossectomy + FS & No \\
6 & Crossectomy +FS & No \\
7 & FS & No \\
8 & FS & No \\
\hline
\end{tabular}

\section{Treatment modalities}

\section{Foam sclerotherapy}

FS was performed in the outpatient clinic following the European consensus guidelines. ${ }^{12}$ Incompetent GSV was detected with a 5-12 MHz duplex probe (MyLab25 sonography apparatus, Esaote Pie Medical Benelux B.V.). The patient was placed in the supine position and the patient's leg was slightly elevated. The GSV was then injected with foam using a $21 \mathrm{G}$ Venflon about $5 \mathrm{~cm}$ above the knee under duplex guidance. The needle was pulled back and the POL-99mTc-foam was injected. During the injection, the SFJ was manually compressed in 3 
patients who did not undergo surgery, until full vasospasm occurred and blood-flow velocity decreased to zero. The duration of compression was 4.75 minutes on average, starting at the time of injection. In 2 patients the SFJ was not compressed during the injection of foam.

\section{Crossectomy}

Patients were given a pre-operative local anesthetic. The surgery involved an incision in the groin crease medial to the pulse emitted by the femoral artery. The GSV was disconnected up to the connection with the common femoral vein. After identification of the femoral vein, the GSV and all of its sidebranches at the SFJ were ligated and transected. The incision was then closed. Fourteen days after surgery, we confirmed with duplex that the SFJ was successfully ligated. The patients were then treated with FS.

\section{Scintigraphic imaging}

For the visualization of ${ }^{99 \mathrm{~m} T c}$ we used a single head Siemens Diacam gamma camera (Siemens Gammasonics, Hoffman Estate, Illinois, USA) with a low energy high resolution collimator, a $20 \%$ energy window around the $140 \mathrm{keV}$ photo peak and a dual head Skylight gamma camera (Philips Medical Systems, Best, The Netherlands). A dynamic study was started just before injection, acquiring frames every ten seconds for 10 to 15 minutes.

\section{Analysis of scintigraphic images}

Image evaluation was performed using the standard Siemens Icon computer platform. The analysis was performed by first drawing regions of interest around veins containing ${ }^{99 \mathrm{~m} T \mathrm{C}}$ activity and then generating time - activity curves. The total ${ }^{99 m} \mathrm{Tc}$ activity remaining in the GSV was quantified as a function of time (Figure 1). In addition, the decrease per minute

\section{Time-activity curve}

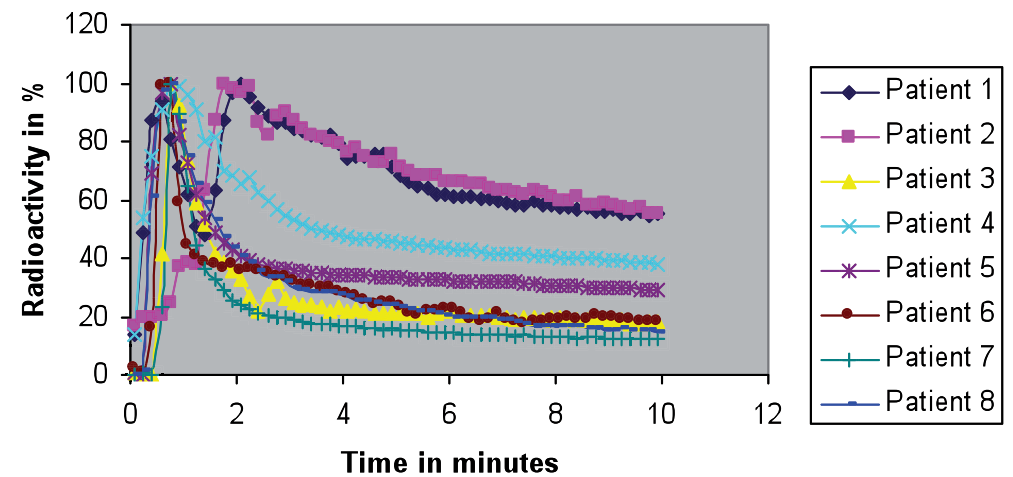

Figure 1. Time activity curves of ${ }^{99 \mathrm{~m} T C}$ activity in GSV after injection of sclerosans containing ${ }^{99 \mathrm{~m} T C-}$ pertechnetate. 
of ${ }^{99 \mathrm{~m} T c}$ activity in the GSV was calculated by fitting a linear trend line over the two minute interval directly after the peak using Microsoft Excel. The peak activity was taken as $100 \%$.

\section{Results}

\section{In vitro experiment - Measuring POL-99mTc vs POL stability}

Prior to treatment, POL-99mTc stability was measured compared to POL $1 \%$ stability only (Table 1). The time that was needed to re-form half of POL-99mTc foam back into liquid was 1.7 minutes on average $(S D=0.1)$. The same time was recorded for POL-only foam. For both substances, the time until all foam had turned completely into liquid was 2.6 minutes $(S D=0.1)$. In conclusion, no differences in foam stability were noted between POL with and without ${ }^{99 \mathrm{~m} T c}$.

\section{In vivo experiment - Treating the GSV with POL-99mTc}

In this experiment, five patients were treated for incompetence of the GSV with a POL-99mTc mixture only, three of them underwent manual compression of the SFJ during foam injection. Another three patients were underwent a crossectomy prior to the POL-99mTc treatment. An average of $6.5 \mathrm{~mL}$ (5.5-10 mL) of sclerosing foam was used to treat the GSV. Patients 1 and 2 received a split injection because a larger amount of POL-99mTc foam was needed to achieve

Table 3. Reduction of ${ }^{99 \mathrm{~m}} \mathrm{Tc}$ activity in GSV in percent-point per minute and remaining ${ }^{99 \mathrm{~m}} \mathrm{Tc}$ activity remaining after 2.6 minutes following polidocanol-99mTc foam injection.

\begin{tabular}{|c|c|c|}
\hline Patient & Reduction of ${ }^{99 \mathrm{~m}} \mathrm{Tc}$ activity (in \% $\mathrm{min}^{-1}$ ) & $\%{ }^{99 \mathrm{~m}} \mathrm{Tc}$ activity 2.6 minutes after injection \\
\hline \multicolumn{3}{|c|}{ FS + compression } \\
\hline 1 & 9 & 89 \\
\hline 2 & 7 & 82 \\
\hline 3 & 36 & 27 \\
\hline Average & 17 & 66 \\
\hline \multicolumn{3}{|c|}{$\mathrm{FS}+$ crossectomy } \\
\hline 4 & 23 & 60 \\
\hline 5 & 28 & 37 \\
\hline 6 & 19 & 34 \\
\hline Average & 23 & 43 \\
\hline \multicolumn{3}{|c|}{ FS control group } \\
\hline 7 & 36 & 21 \\
\hline 8 & 31 & 34 \\
\hline Average & 34 & 28 \\
\hline
\end{tabular}


full vasospasm. The radioactivity did not stay in the GSV in all patients, despite blocking the SFJ by compression or ligation (Graph 1 ). The amount of radioactivity was reduced by an average of $34 \%$ in the FS with compression group 2.6 minutes after injection, leaving $66 \%$ of pertechnetate activity in the GSV. In the ligation group, pertechnetate activity was reduced by $57 \%$ after the same time, leaving an average ${ }^{99 \mathrm{~m} T c}$ of $43 \%$. In the control group (FS without compression) the nuclear activity showed an average decrease of $72 \%$, leaving $28 \%$ of pertechnetate activity in the GSV. The rate of reduction during manual compression of the SF-junction was $17 \%$ per minute. This rate was $23 \%$ in the ligation group during the same time and $34 \%$ in the control group (Table 3).

\section{Discussion}

Several authors have found indirect proof for systemic distribution of sclerosant foam. ${ }^{13}$ This finding is consistent with the results we describe in this article. However, until now, no research has been done at the source of injection. In this study, we demonstrate by imaging the GSV during FS that foam does not stay in the treated vein. Although the amount of foam floating into the femoral vein was not fully stopped by manual compression or ligation of the SFJ, the decrease of radioactivity was reduced in comparison to the control group. After 2.6 minutes, ${ }^{99 \mathrm{mTc}}$ activity had reduced to $28 \%$ of the peak activity, indicating that $72 \%$ had leaked away from the GSV in the control group. In patients receiving compression or ligation the decrease of radioactivity was $55 \%$ of the peak activity, indicating that $45 \%$ had leaked away from the GSV. As demonstrated by our in vitro trials, it took 2.6 minutes for the foam to have been reduced to liquid. If this is the same in vivo, this would mean that foam and not liquid sclerosant enters the deep venous system during FS.

In our study, manual compression of the groin appeared a more effective measure than ligation of the SFJ. We propose that this difference occurred because two of three patients in the first group received a split injection. We hypothesize that due to the vein spasm resulting from the first injection, the remaining amount of foam was not able to leak away as quickly as in patients who received a single injection. This hypothesis seems to be in agreement with the results of Yamaki ${ }^{14}$, who measured the amount of foam flowing to the deep system using one or multiple injections. However, our result could also have occurred because the second injection might have leveled out the decline in ${ }^{99 \mathrm{~m}} \mathrm{Tc}$.

In vitro trials did not show a change in foam stability due to the presence of ${ }^{99 \mathrm{~m} T c}$. This was to be expected because ${ }^{99 \mathrm{~m}} \mathrm{Tc}$ is present in trace amounts only. Therefore, we do not expect foam to have behaved differently due to the addition of ${ }^{99 \mathrm{~m} T c}$. Nevertheless, a shortcoming of this study is that POL was mixed instead of being labeled with radioactivity. Theoretically, 
one cannot be certain that POL and ${ }^{99 m} \mathrm{Tc}$ move together. However, considering the mass

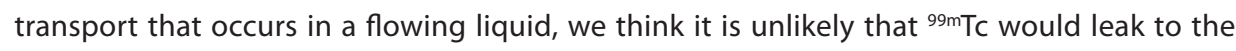
deep venous system, whereas POL would not.

Our study results were in accordance with earlier findings by Hill ${ }^{15}$ who recently recorded echogenic phenomena in the right half of the heart during FS. During FS the SFJ was compressed manually, either with or without simultaneous leg elevation. The intensity of the echogenic bolus observed was equal in both groups.

In conclusion, on the basis of this study, we showed that blockage of the SFJ reduces, however not completely stops the amount of foam leaking away to the deep venous system. 


\section{References}

1. Beebe-Dimmer JL, Pfeifer JR, Engle JS, Schottenfeld D. The epidemiology of chronic venous insufficiency and varicose veins. Ann Epidemiol. 2005;15:175-84.

2. Eberhardt RT, Raffetto JD. Chronic venous insufficiency. Circulation. 2005;111:2398-409.

3. Evans CJ, Fowkes FG, Ruckley CV, Lee AJ. Prevalence of varicose veins and chronic venous insufficiency in men and women in the general population: Edinburgh Vein Study. J Epidemiol Community Health. 1999;53:149-53.

4. Gillet JL, Guedes JM, Guex JJ, et al. Side-effects and complications of foam sclerotherapy of the great and small saphenous veins: a controlled multicentre prospective study including 1,025 patients. Phlebology. 2009;24:131-8.

5. Guex JJ, Allaert FA, Gillet JL, Chleir F. Immediate and midterm complications of sclerotherapy: report of a prospective multicenter registry of 12,173 sclerotherapy sessions. Dermatol Surg. 2005;31:123-8; discussion 8.

6. Parsi K, Exner T, Connor DE, et al. The lytic effects of detergent sclerosants on erythrocytes, platelets, endothelial cells and microparticles are attenuated by albumin and other plasma components in vitro. Eur J Vasc Endovasc Surg. 2008;36:216-23.

7. Rush JE, Wright DD. More on microembolism and foam sclerotherapy. N Engl J Med. 2008;359: 656-7; author reply 7.

8. Ceulen RP, Sommer A, Vernooy K. Microembolism during foam sclerotherapy of varicose veins. N Engl J Med. 2008;358:1525-6.

9. O'Hare JL, Earnshaw JJ. The use of foam sclerotherapy for varicose veins: a survey of the members of the Vascular Society of Great Britain and Ireland. Eur J Vasc Endovasc Surg. 2007;34:232-5.

10. Nahar T, Croft L, Shapiro R, et al. Comparison of four echocardiographic techniques for measuring left ventricular ejection fraction. Am J Cardiol. 2000;86:1358-62.

11. Rao J, Goldman MP. Stability of foam in sclerotherapy: differences between sodium tetradecyl sulfate and polidocanol and the type of connector used in the double-syringe system technique. Dermatol Surg. 2005;31:19-22.

12. Breu FX, Guggenbichler S. European Consensus Meeting on Foam Sclerotherapy, April, 4-6, 2003, Tegernsee, Germany. Dermatol Surg. 2004;30:709-17; discussion 17.

13. Coleridge Smith P. Foam and liquid sclerotherapy for varicose veins. Phlebology. 2009;24 Suppl 1: 62-72.

14. Yamaki T, Nozaki M, Sakurai $H$, et al. Multiple small-dose injections can reduce the passage of sclerosant foam into deep veins during foam sclerotherapy for varicose veins. Eur J Vasc Endovasc Surg. 2009;37:343-8.

15. Hill D, Hamilton R, Fung T. Assessment of techniques to reduce sclerosant foam migration during ultrasound-guided sclerotherapy of the great saphenous vein. J Vasc Surg. 2008;48:934-9. 


\section{CHAPTER 8}

\section{Lateral venous ulceration and insufficiency of the small saphenous vein.}

R.P. Ceulen

A. Kessels

J.C. Veraart

P.A. van Neer

Dermatol Surg. 2007;33:727-30. 


\section{Abstract}

Background Leg ulcers located on the lateral aspect of the ankle can be of venous origin. The most significant aetiologic mechanism is increased ambulatory venous pressure due to varicose veins, even when the clinical signs are minimal. Isolated incompetence of the SSV has been documented by certain authors as being of no importance in the pathogenesis of venous ulceration. In the current study, however, we present 3 cases that demonstrate the opposite.

Objective We report three cases and a review of literature.

Results We describe three cases in which lateral ulceration was caused by SSV incompetence and that exhibited healing following successful FS. By applying statistical analysis based on the data of two different publications on venous ulceration, we find that there is small but clear evidence for the relationship between lateral ulceration and SSV incompetence.

Conclusion SSV incompetence can cause venous ulceration on the lateral aspect of the ankle. 


\section{Introduction}

Patients suffering from venous hypertension due to valvular incompetence of one or more of the deep, superficial, or perforating veins may develop venous leg ulcers. Venous ulcers occur considerably more frequently on the medial aspect of the ankle. ${ }^{1}$ The aetiology of lateral ulcers includes peripheral arterial disease, venous valvular incompetence, and hypertensive ulceration (Martorell ulcer). ${ }^{2}$ In the past, the role of isolated incompetence of the SSV was doubted as an aetiologic cause of lateral ulceration. ${ }^{3}$ In this article, we describe three patients with ulcers on the lateral aspect of the ankle for which we demonstrate SSV incompetence to be the cause.

\section{Case reports}

\section{Case 1}

A 66-year-old male patient with a history of long-standing, recurrent lateral venous ulceration of his left leg was treated in our clinic. Despite compression therapy with four-layer bandages, the ulcer exhibited no improvement. Colour-flow duplex imaging of the left leg revealed reflux of the entire SSV, a normal deep venous system, and no valvular incompetence of the GSV. No perforating vein exhibited reflux. The ankle-brachial pressure index was normal. We treated the SSV with FS with $1 \mathrm{~mL}$ of $1 \%$ POL foam and continued the compression therapy. The lateral ulceration healed after a few weeks and remained closed until the most recent follow-up 8 months after healing. Colour-flow duplex imaging revealed no reflux in the SSV at 6 or 8 months.

\section{Case 2}

An 88-year-old female patient was seen in our department because of an ulceration of the lateral left ankle (Figure 1). This ulcer had been present for approximately 3 months and was treated by compression bandaging. No peripheral arterial disease was observed. Colour-flow duplex imaging revealed SSV incompetence and a normal GSV and deep venous system. No perforating vein incompetence was observed. We performed FS of the SSV with $1 \%$ POL foam in combination with compression therapy. The ulceration healed within 6 weeks (Figure 2). At follow-up, the lateral ulcer had remained closed for 8 months after healing. The colour-flow duplex imaging revealed no reflux in the SSV. 


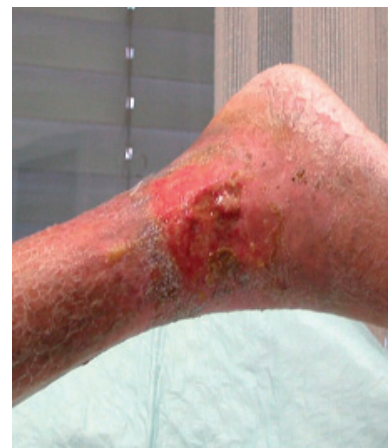

Figure 1. Venous leg ulceration located on the lateral side of the left ankle.

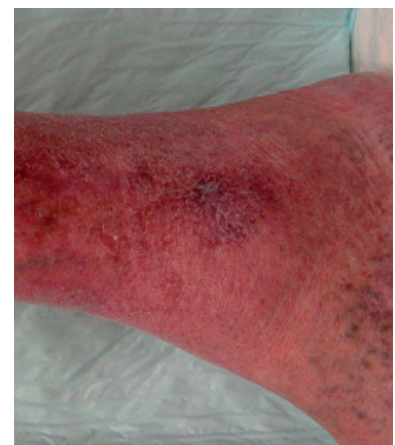

Figure 2. Healed venous leg ulceration 6 weeks after FS.

\section{Case 3}

An 86-year-old female patient was referred to our clinic with a history of long-standing venous ulceration in both legs. She had not been previously treated for venous incompetence and had no history of deep venous thrombosis. The leg ulcers on the medial and lateral aspect of the left leg had been present for 2 years without healing despite compression therapy. A vascular laboratory investigation revealed moderate arterial disease (ankle-brachial pressure index, 70\%). Colour-flow duplex imaging revealed valvular incompetence of both the GSV and the SSV. No anterolateral saphenous veins or saphenous branches fed the SSV. The deep venous system was normal. The patient refused an operation; therefore, we first performed FS of the GSV with $5 \mathrm{~mL}$ of $1 \%$ POL foam. The medial ulcer healed within 4 weeks. The lateral ulcer persisted. After 4 weeks, we again performed FS with an injection of the SSV with $3 \mathrm{~mL}$ of $1 \%$ POL foam. Colour-flow duplex imaging at 6 weeks revealed moderate reflux of the SSV. Again, FS with 1\% POL foam was performed. The lateral ulceration healed within 10 weeks after the first FS session to treat the SSV. Five months following the first treatment, both the GSV and the SSV exhibited no reflux.

\section{Discussion}

Leg ulceration is a common clinical and socioeconomic problem. The prevalence of lower extremity ulceration secondary to chronic venous disease has been estimated to be $0.5 \%$ to $1 \%$ in the adult Western population and is strongly correlated with increased age. ${ }^{4}$ Venous ulcers occur most frequently in the gaiter area, with the medial area affected in $60 \%$ and the lateral side in $20 \%$ of cases. ${ }^{1}$ The aetiology of venous ulceration is multifactorial, but there is general agreement that the most significant mechanism is increased ambulatory venous pressure. Venous hypertension leads to damage to the microcirculation, lipodermatosclero- 
sis, and white atrophy, resulting in ulceration. ${ }^{5}$ Venous hypertension is caused by deep and/ or superficial venous incompetence. It is estimated that as many as $50 \%$ of venous ulcers are caused by superficial venous reflux alone, without concomitant deep or perforating venous incompetence. ${ }^{6}$ In most cases, the GSV is involved. The correction of this source of reflux has been demonstrated to improve ulcer healing and to reduce the long-term ulcer recurrence rate. ${ }^{7-9}$

The SSV begins on the dorsolateral aspect of the foot and ascends to the popliteal fossa. Therefore, it is reasonable to expect that incompetence of this system will lead to clinical signs of chronic venous disease and to ulceration on the lateral aspect of the ankle. However, the role of the SSV in the aetiology of lateral leg ulceration is still not completely understood. In addition to venous valvular incompetence, the differential diagnoses of lateral ulceration include peripheral arterial disease, hypertensive ischemic ulcers (i.e., Martorell's ulcer), ulcers that are associated with posttraumatic sympathetic dystrophy, embolic ulcers, ulcers that are associated with hematologic disorders and vasculitis. ${ }^{10}$

We searched medical literature databases to investigate the role of SSV incompetence in the development of lateral venous ulceration. We searched for publications mentioning the treatment or investigation of lateral venous ulceration, including randomised controlled trials, cohort studies with controls, case-control studies, patient series without controls, and articles with expert opinion. We performed computerised searches of electronic databases, including the Cochrane Library, PubMed, MEDLINE, EMBASE, Current Controlled Trials (CCTs), and ClinicalTrials.gov. The searches were performed in January 2006.

In 1975, Fluckiger was the first to describe venous ulceration on either the lateral or the medial malleolus due to SSV incompetence. ${ }^{11}$ In 1976, Dodd and Cockett described the clinical symptoms of incompetence of the SPJ.12 The skin area below and behind the lateral malleolus exhibited venular dilatation, eczema, swelling, and ulceration. According to Dodd and Cockett, however, anatomical variations of the SSV are so common that skin lesions appear near the medial malleolus as well. Swelling, skin changes, and ulceration occur only when the entire SSV is involved. ${ }^{12}$ In the early 1990s, Thibault stressed the role of an incompetent SSV in causing lateral ulceration of the ankle. ${ }^{13}$ He reported an incidence of SSV incompetence of $12 \%$, which was confirmed by Almgren and Eriksson, who described an incidence of $15 \% .{ }^{14}$ With the study of Labropoulos and colleagues in 1994, the suspicion of the role of the SSV in causing leg ulceration was raised. ${ }^{13}$ These authors described the correlation between clinical symptoms and reflux confined to different parts of the superficial venous system in 255 limbs. Isolated SSV incompetence was observed in 33\% of the legs. Clinical symptoms, such as swelling, skin changes, and ulceration were reported to occur only when the entire SSV was involved.

Statistical evidence for the role of SSV incompetence in causing lateral venous ulceration was found in five articles from the late 1990s. One article did not differentiate between lateral and medial ulcers. Payne and coworkers investigated the role of incompetence of both 
the SSV and the popliteal vein in the aetiology of leg ulcers. ${ }^{3}$ They performed colour-flow duplex imaging on 186 limbs with varicose veins or venous skin changes. The ulcer site was not mentioned. In this study, SSV reflux was significantly associated with an incidence of ulceration of $41 \%$ compared to $27 \%$ when the SSV was competent. Bass and colleagues described 20 patients with long-standing venous ulceration located on the lateral aspect of the leg. ${ }^{2}$ Colour-flow duplex imaging demonstrated isolated incompetence at the SPJ in all of the limbs. Following ligation of the SPJ, all of the ulcers healed within 12 weeks. This report failed, however, to mention a colour-flow duplex imaging investigation of the GSV. ${ }^{2}$ Bello and colleagues performed colour-flow duplex imaging on 122 legs with venous ulceration. ${ }^{8}$ Thirteen patients exhibited isolated SSV incompetence, with an equal distribution of medial and lateral ulcers. Ninety-three patients exhibited isolated GSV incompetence, of which $23 \%$ and $67 \%$ exhibited venous ulcers on the lateral and medial aspect of the ankle, respectively. ${ }^{8}$ This relationship between SSV incompetence and lateral ulceration is statistically significant (Chi-squared test, Table 1).

Table 1. Statistical Analysis of the Relationship of Small Saphenous Vein incompetence and Lateral Ulceration Based on the Studies of Adam et al. ${ }^{17}$ and Bello et al..$^{*}$

\begin{tabular}{lllll}
\hline Study & Vein examined & $\begin{array}{l}\text { Ulcerations medial malleolus } \\
\text { (absolute numbers and percentage) }\end{array}$ & $\begin{array}{l}\text { Ulcerations lateral malleolus } \\
\text { (absolute numbers and percentages) }\end{array}$ & $\begin{array}{l}\text { Statistical analysis } \\
\text { (Chi-square test) }\end{array}$ \\
\hline Adam & GSV & $129(\mathrm{n}=196) ; 65 \%$ & $37(\mathrm{n}=196) ; 19 \%$ & \\
& SSV & $12(\mathrm{n}=35) ; 35 \%$ & $23(\mathrm{n}=35) ; 64 \%$ & $\mathrm{p}<0.01$ \\
Bello & GSV & $62(\mathrm{n}=83) ; 75 \%$ & $21(\mathrm{n}=83) ; 25 \%$ & \\
& SSV & $7(\mathrm{n}=13) ; 54 \%$ & $6(n=13) ; 46 \%$ & \\
\hline
\end{tabular}

*In this table we display the incidence of isolated reflux of either the GSV or the SSV in relationship to the site of ulceration (medial or lateral aspect of the ankle. GSV, great saphenous vein; SSV, small saphenous vein.

In 2003, de Rijcke and coworkers described a series of 13 patients with lateral venous ulceration and incompetent perforating veins. ${ }^{14}$ Following subfascial endoscopic perforating vein surgery, venous ulcerations persisted in six patients, three of whom had no incompetent perforating vein; however, there was coexisting venous reflux at the SPJ. These authors concluded that this clinical observation would support the hypothesis that SPJ reflux has a role in the genesis of lateral leg ulcers. ${ }^{14}$

Adam and colleagues assessed 689 patients with leg ulceration using colour-flow duplex imaging and carefully detailed each individual patient with respect to the reflux pattern, relating this information to the ulcer site. ${ }^{15} \mathrm{~A}$ lateral ulcer was present as well in only $19 \%$ of the patients with isolated GSV incompetence, whereas $64 \%$ of the patients with isolated SSV incompetence exhibited lateral ulceration. Although the authors concluded that the ulcer site does not predict the pattern of superficial reflux, the relationship between SSV incompetence and the presence of lateral ulceration is clear (Table 1). ${ }^{15}$ 


\section{Conclusion}

In this article, we describe three cases in which lateral ulceration was caused by SSV incompetence and that healed following FS of the incompetent SSV. We searched all English language literature to investigate the relationship between SSV incompetence and venous ulceration. There is clear evidence of a relationship between SSV incompetence and lateral ulcers of the leg. Therefore, we recommend considering venous pathology as the cause of lateral leg ulceration, with a prominent role for the SSV. Colour-flow duplex imaging should be used both as a diagnostic and a therapeutic aid because it is very simple to treat the saphenous vein incompetence by FS. We used this technique to successfully avoid the requirement for surgical intervention in our elderly patients. 


\section{References}

1. Nelzen $\mathrm{O}$, Bergqvist $\mathrm{D}$, Lindhagen $\mathrm{A}$. Venous and non-venous leg ulcers. clinical history and appearance in a population study. Br J Surg 1994;81:182-7.

2. Bass $A$, Chayen $D$, Weinmann EE, Ziss $M$. Lateral venous ulcer and short saphenous vein insufficiency. J Vasc Surg 1997;25:654-7.

3. Payne SP, London NJ, Newland CJ, et al. Investigation and significance of short saphenous vein incompetence. Ann R Coll Surg Engl 1993;75:354-7.

4. Callam MJ. Epidemiology of varicose veins. Br J Surg 1994;81:167-73.

5. van Rij AM, Solomon C, Christie R. Anatomic and physiologic characteristics of venous ulceration. J Vasc Surg 1994;20:759-64.

6. Shami SK, Sarin S, Cheatle TR, et al. Venous ulcers and the superficial venous system. J Vasc Surg 1993;17:487-90.

7. Barwell JR, Taylor M, Deacon J, et al. Surgical correction of isolated superficial venous reflux reduces long-term recurrence rate in chronic venous leg ulcers. Eur J Vasc Endovasc Surg 2000; 20:363-8.

8. Bello M, Scriven M, Hartshorne T, et al. Role of superficial venous surgery in the treatment of venous ulceration. Br J Surg 1999;86:755-9.

9. Scriven JM, Hartshorne T, Bell PR, et al. Single-visit venous ulcer assessment clinic: the first year. Br J Surg 1997;84:334-6.

10. Miller A, Ruzicka T. Differential diagnosis of leg ulcers. Hautarzt 2001;52:593-603.

11. Fluckiger P. Direct medial parva-ulcer. Vasa 1975;4:187-8.

12. Dodd H, Cockett FB. The pathology and surgery of the veins of the lower limb. Edinburgh, London and New York: Churchill, Livingstone, 1976.

13. Thibault P, Bray A, Wlodarczyk J, Lewis W. Cosmetic leg veins: evaluation using duplex venous imaging. J Dermatol Surg Oncol 1999;16:612-8.

14. Almgren B, Eriksson I. Valvular incompetence in superficial, deep and perforator veins of limbs with varicose veins. Acta Chir Scand 1990;156:69-74.

15. Labropoulos $N$, Leon $M$, Nicolaides $A N$, et al. Superficial venous insufficiency: correlation of anatomic extent of reflux with clinical symptoms and signs. J Vasc Surg 1994;20:953-8.

16. de Rijcke PA, Hop WC, Wittens $\mathrm{CH}$. Subfascial endoscopic perforating vein surgery as treatment for lateral perforating vein in- competence and venous ulceration. J Vasc Surg 2003;38:799-803.

17. Adam DJ, Naik J, Hartshorne T, et al. The diagnosis and management of 689 chronic leg ulcers in a single-visit assessment clinic. Eur J Vasc Endovasc Surg 2003;25:462-8 


\section{CHAPTER 9}

\section{Literature review: treatment of small saphenous varicose veins.}

R.P. Ceulen*

S.S. Tellings*

A. Sommer

* These authors contributed equally to this work

Phlebology. 2011;26:179-84. 


\section{Abstract}

In $15 \%$ of all patients with varicosis, the condition is caused by insufficiency of the SSV. In the past, it was common to surgically remove the entire SSV; however, minimally invasive techniques have recently been used for a significant number of varicose vein treatments. The aim of this paper is to review the literature of all of the treatment modalities for SSV insufficiency. The search aimed to identify all of the published papers that describe one or more treatments for SSV insufficiency. International literature databases were searched for articles that were eligible for this review. The articles that described one or more treatment technique for SSV insufficiency were eligible for this review. Moreover, studies describing SSV and GSV were included as long as there was clear distinction in the results between the two groups. The studies were excluded if they did not use ultrasound examination to qualify outcome, as this is the gold standard for evaluating venous insufficiency. Seventeen articles were included in this review. Five articles on surgical treatment reported success rates varying from $24 \%$ to $100 \%$ (follow-up period: 1.5-60 months). Ten articles on endovenous laser ablation (EVLA) reported success rates varying from $91 \%$ to $100 \%$ (follow-up period: $1.5-36$ months). Two articles on FS reported success rates varying from $82 \%$ to $100 \%$ (follow-up period: 1.5-11 months). Statistical analyses demonstrated a significant difference $(p<0.05)$ in the success rate of surgery (47.8\%) versus that of EVLA/FS (94.9\%). Most of the complications for all of the treatment techniques were mild and self-limiting. The rates of deep venous thrombosis were not often reported, and among the articles in which it was mentioned, the reported frequency varied from $1.8 \%$ to $3.5 \%$ (surgery) and from $2.5 \%$ to $5.7 \%$ (EVLA/FS). In the absence of large, comparative randomised clinical trials, minimally invasive techniques appear to have a tendency towards better results than surgery for the treatment of the SSV insufficiency. 


\section{Introduction}

Lower extremity venous insufficiency is a very common medical condition affecting approximately $15 \%$ of men and $25 \%$ of women in Western countries. ${ }^{1}$ Insufficiency of the GSV is the most common form of this condition. In $15 \%$ of all of the patients with varicosis, the condition is caused by SSV insufficiency. ${ }^{2}$ Chronic venous insufficiency encompasses a large spectrum of symptoms, including fatigue and cramps, dermato- and liposclerosis, and ulceration. ${ }^{3}$ In the past, it was common to surgically remove the entire SSV; however, research has shown that the clinical results are not always as expected and that severe side effects, such as damage of the nervus suralis, are not uncommon. Until recently, surgery was perceived as the standard treatment for SSV insufficiency. ${ }^{4-8}$ In recent years, minimally invasive techniques, such as EVLA, RFA and FS, have taken over a significant number of varicose vein treatments. The results regarding the anatomical success, complications and patient friendliness of these procedures are promising. ${ }^{9}$ The success rates of the endovenous treatments and of surgery for GSV insufficiency have been widely investigated; however, much less is known regarding the treatment of SSV insufficiency. It is important to note that the GSV and the SSV are two distinct entities. The pressure column of these veins differs, the length of the treated area is shorter for the SSV, the neighbouring nerves are nearer in the case of the SSV and the SSV runs in the fascia over nearly its entire length.

Although it is suggested that endovenous techniques are more effective than surgery, no large randomised trials have been performed to conclusively demonstrate this. The objective of this article is to systematically review the publications on surgical and endovenous treatment options of SSV insufficiency and to compare them with respect to their effectiveness and complications.

\section{Methods}

\section{Literature search}

The aim of the search was to identify all of the published papers describing one or more treatments for SSV insufficiency. To achieve this aim, PubMed, Medline, Embase and Cochrane library were searched through for articles eligible for this review. The studies were initially identified and screened on their abstract. If the abstract appeared suitable, the studies were reviewed to determine if they could be included. In addition to the primary search results, 'related article' links and the references of each article were used to identify appropriate articles.

Mesh terms: 'Ligation', 'Surgery', 'Varicose-Veins', 'Catheter-Ablation', 'Laser-Therapy', 'Sclerotherapy,',Saphenous-Vein,' 'ultrasonography'. 
Search terms used in algorithms: 'Vein insufficiency,' 'Vein incompetence,', 'Varicosis', 'Varicose veins,' 'Small saphenous vein', 'Lesser saphenous vein,' 'Short saphenous vein', 'Foam sclerotherapy,, 'Radiofrequency ablation', 'Radiofrequency obliteration', 'Laser surgery', 'Endovenous laser ablation', 'Endovascular laser ablation', 'Endovenous laser treatment,' 'Surgery', 'Stripping,',Ligation', 'Crossectomy', 'Duplex', 'Ultrasound'.

\section{Inclusion criteria}

All randomised controlled trials, non-randomised controlled trials, cohort-studies with controls, case-control studies, retrospective studies, patient series without controls and articles with expert opinions investigating one or more treatment techniques for SSV insufficiency were eligible for this review. Moreover, studies describing SSV and GSV were included if they made a clear distinction in their results between the two groups. All of the types of surgical treatments and endovenous techniques were included, as were any combination of these treatments. No restrictions as to the type of sclerosant used in the FS were made, as there is no proof that one is superior to the others. ${ }^{10}$

The studies that were published in English, German, Spanish, French and Dutch were eligible for inclusion. No restrictions were made with respect to the publication year of the study.

\section{Exclusion criteria}

Studies were excluded if they did not use ultrasound (US) examination to qualify the outcome, as this is the gold standard for evaluating venous insufficiency; furthermore, this qualification increases the homogeneity of the analysis. We excluded studies that used liquid sclerosant because this treatment is considered less effective than foam. ${ }^{11}$

\section{Standardisation of outcome measures}

The articles were reviewed with respect to the primary results and conclusions regarding the following parameters: outcome, complications, patient satisfaction and cost- and timeeffectiveness.

Although all of the studies used US examination to evaluate the outcome, the definitions of treatment success varied. The technical endpoint of all of the treatments was anatomical success. Not all of the included papers described similar definitions for their outcome measure.

The following definitions for outcome were accepted as equal and listed in Table 1 under the heading 'definition of outcome': 'a reflux route of the remaining part of the short saphenous vein', 'clinical recurrence of varicose veins was defined as appearance of new varicose 
Table 1. Outcome.

\begin{tabular}{|c|c|c|c|c|c|c|c|c|c|}
\hline No. & Author & Year & Country & $\begin{array}{l}\text { Study } \\
\text { type }\end{array}$ & Treatment & $\begin{array}{l}\text { No. } \\
\text { limbs }\end{array}$ & $\begin{array}{l}\text { Follow-up } \\
\text { (months) }\end{array}$ & $\begin{array}{l}\text { Success } \\
\text { rate }\end{array}$ & Definition of outcome \\
\hline 1 & Allegra & 2007 & Italy & 2 & surgery & 132 & 60 & 0.70 & recurrence \\
\hline 2 & Dumas & 2007 & $\begin{array}{l}\text { The } \\
\text { Netherlands }\end{array}$ & 3 & surgery & 84 & 3.8 & 0.24 & reflux \\
\hline 3 & O'Hare & 2008 & UK & 2 & surgery & 204 & 12 & 0.40 & reflux \\
\hline 4 & Rashid & 2002 & UK & 1 & surgery & 59 & 1.5 & 0.59 & disconnection SPJ \\
\hline 5 & Whitely & 2006 & UK & 1 & surgery & 52 & $?$ & 1.00 & recurrence \\
\hline 6 & Gibson & 2007 & USA & 2 & EVLA & 210 & 3 & 0.96 & occlusion \\
\hline 7 & Huisman & 2008 & $\begin{array}{l}\text { The } \\
\text { Netherlands }\end{array}$ & 2 & EVLA & 169 & 3 & 0.98 & occlusion \\
\hline 8 & Jung & 2008 & Korea & 1 & EVLA & 41 & 3 & 0.93 & recurrence \\
\hline 9 & Kontothanassis & 2009 & Italy & 2 & EVLA & $229 / 66$ & $2 / 24$ & $0.99 / 0.97$ & recanalisation \\
\hline 10 & Nwaejike & 2008 & UK & 1 & EVLA & 66 & 14 & 1.00 & $\begin{array}{l}\text { recurrence/ } \\
\text { recanalisation }\end{array}$ \\
\hline 11 & Park 1 & 2008 & Korea & 2 & EVLA & 390 & 12 & 0.94 & occlusion \\
\hline 12 & Park 2 & 2008 & Korea & 2 & EVLA & 96 & $1 / 36$ & $0.96 / 1.00$ & occlusion/recanalisation \\
\hline 13 & Proebstle & 2003 & Germany & 2 & EVLA & 37 & 6 & 1.00 & recanalisation \\
\hline 14 & Ravi & 2006 & USA & 2 & EVLA & $101 / 37$ & $0.5 / 36$ & $0.91 / 0.92$ & reflux/recanalisation \\
\hline 15 & Theivacumar & 2007 & UK & 2 & EVLA & $68 / 48$ & $3 / 6$ & $1.00 / 1.00$ & occlusion \\
\hline 16 & Darke & 2006 & UK & 2 & FS & 23 & 1.5 & 1.00 & occlusion \\
\hline 17 & Smith & 2006 & UK & 2 & FS & 141 & 11 & 0.82 & occlusion \\
\hline
\end{tabular}

SPJ = Saphenopopliteal junction; EVLA = endovenous laser ablation; FS = foam sclerotherapy

veins not present following surgical treatment', 'successful disconnection of the incompetent SPJ', 'some SSV incompetence', 'vein reflux was defined as retrograde flow, as shown on duplex, of over 0.5 seconds', 'occlusion of superficial varicosities by palpation and ultrasound imaging,',non-compressible vein and no blood flow seen within the entire ablated SSV', 'SSV closure,', saphenous vein occlusion and venous reflux elimination', 'successful occlusion of the SSV, defined as the absence of flow on color Doppler imaging,' 'recanalization phenomenon observed by duplex scanning', 'any occlusion less than the complete treatment length was scored as partially occluded'.

\section{Statistical analyses}

The studies used either success or failure as the outcome measure. To standardise the outcomes, the failure rates were converted into success rates. The failure percentage was subtracted from 1.00 to give the success rate. 
A Chi-squared test was used to compare the percentages of success following treatment for both surgery and the endovenous techniques. A p-value of $<0.05$ was considered statistically significant. All of the data were analysed with computer software (SPSS, Version 15.0, SPSS, Inc., Chicago, IL, USA).

\section{Results}

\section{Literature search}

Of all of the screened abstracts and articles, 33 articles were reviewed. Of these 33 articles, 17 met the inclusion criteria. Of these 17 articles, 5 reported on different types of surgery (3 stripping, 1 stripping versus ligation alone and 1 ligation with stab avulsion), 10 reported on EVLA and 2 reported on FS.

\section{Outcome}

\section{Surgery}

Five articles publishing results on the surgical treatment of SSV insufficiency used ligation of the SPJ, stripping or both. ${ }^{4-8}$ The number of patient legs included in the studies ranged from 52 to 204 . The follow-up length was unknown for 1 study, and the others had a wide range, from 1.5 months to 5 years. The success rates varied from $24 \%$ to $100 \% ; 1$ article reported no significant difference between stripping and ligation alone (45\% versus $35 \%$ ).

\section{EVLA}

Ten articles reported results on EVLA. ${ }^{12-21}$ The number of patient legs included varied from 37 to 390 . The follow-up period was 0.5 month to 3 years. The success rates varied from $91 \%$ to $100 \%$.

\section{FS}

Two articles published results on FS.22,23 The number of patient legs included was 23 and 141. The follow-up periods were 1.5 and 11 months, respectively. The success rates were $100 \%$ and $82 \%$; SSVs with a diameter $\leq 5 \mathrm{~mm}$ demonstrated higher occlusion rates ( $86 \%$ vs. $77 \%$ ). The total number of injections varied from 1 to 3 (Table 1 ).

\section{Statistical analysis}

In the 17 included articles, a total of 1804 legs were treated, of which 479 (26.6\%) were treated by surgery (mean follow-up of 22.5 months) and 1325 (73.4\%) were treated by EVLA 
and FS (mean follow-up 11.6 months). The surgical study by Whitely ${ }^{8}$ was excluded because the follow-up period was not reported.

The overall surgical success rate was $47.8 \%$. For EVLA/FS, this rate was $94.9 \%$; this difference is statistically significant (Table 2 ).

Table 2. Success rates.

\begin{tabular}{lllll}
\hline & $N$ & $\begin{array}{l}\text { Success rate } \\
(\%)\end{array}$ & $P$ & $\begin{array}{l}\text { Mean follow-up (range) } \\
\text { (in months) }\end{array}$ \\
\hline Surgery & 479 & $47.8 \%$ & $<0.001$ & $22.5(1.5-60)$ \\
EVLA/FS & 1325 & $94.9 \%$ & $11.6(1.5-36)$ \\
\hline
\end{tabular}

\section{Complications}

\section{Surgery}

Two studies on surgery reported no major complications following the surgery. ${ }^{4,6}$ The 3 other articles found DVT in $1.8 \%, 2 \%$ and $3.5 \%$ of patients. ${ }^{5,7}, 8$ The extension of the DVT was not mentioned. Sural nerve damage was reported in 1 article with an incidence of $2.1 \% .^{8}$ The frequency of paraesthesia was reported to be between $1.7 \%$ and $34 \%$ and was self-limiting during the follow-up period in most cases. ${ }^{5-8}$ No significant difference in the rate of numbness was reported when comparing stripping with ligation alone $(28 \% \text { versus } 28 \%)^{6}$ (Table 3 ).

Table 3. Complications.

\begin{tabular}{|c|c|c|}
\hline & Major & Minor \\
\hline Surgery & $\begin{array}{l}\text { DVT } 1.8-3.5 \% \\
\text { Sural nerve damage } 2.1 \%\end{array}$ & Paresthesia 1.7 - 34\% \\
\hline EVLA & DVT $1.3-5.7 \%$ & $\begin{array}{ll}\text { - } & \text { Echymosis / pain: no } \%, \text { mentioned as often } \\
\text { - } & \text { Paresthesia } 1.3-11 \% \\
\text { - } & \text { Thrombophlebitis } 0-8 \%\end{array}$ \\
\hline FS & - & $\begin{array}{ll}\text { - } & \text { Thrombophlebitis } 5 \%{ }^{23} \\
\text { - } & \text { Hyperpigmentation } 24 \%{ }^{23}\end{array}$ \\
\hline
\end{tabular}

EVLA = endovenous laser ablation; $\mathrm{FS}$ = foam sclerotherapy; DVT = deep vein thrombosis

\section{EVLA}

DVT was reported at a rate of $1.3 \%$ (3 patients) ${ }^{15}, 2.5 \%$ (1 patient with pre-existent thrombotic problems $)^{19}$ and $5.7 \%$ (12 patients) $)^{12}$. Paraesthesia occurred in $1.3-11 \%$ of the treated legs. ${ }^{12-15,17-19,21}$ Phlebitis was observed in 0-8\% of the cases. ${ }^{13-15,17,19,21}$ Ecchymosis and shortterm pain were common, and all of the cases spontaneously resolved within a short period of time. ${ }^{17-21}$ 
Articles that examined FS reported no major complications following treatment. Thrombophlebitis and pigmentation were common minor complications that resolved over time. ${ }^{22,23}$

\section{Patient satisfaction}

Six studies described patient satisfaction following treatment (4 on EVLA $14,15,19,20$ and 2 on surgery ${ }^{4,5}$ ) and reported a decline in symptoms following the treatment. Two of these studies used the Abderdeen Varicose Vein Severity Score (AVVSS) and the Venous Clinical Severity Score (VCSS), and 2 used un-validated questionnaires and reported non-significant results. The 2 articles that examined surgery report a subjective symptom reduction in the treated patients using un-validated clinical severity scores (not significant in 1 study).

\section{Cost- and-time-effectiveness}

The cost-effectiveness of the treatments is sparingly discussed in the reviewed articles. A study compared EVLA to RFA (although no SSV was treated with RFA) and concluded that the choice of either technique depends on the cost of the equipment, the disposables and the procedure time. ${ }^{18}$ With respect to FS vs. surgery, 2 articles stated that the differences between the 2 treatments are self-evident regarding costs (no specific costs are mentioned). ${ }^{21,22}$

\section{Discussion}

In this analysis, studies that discuss different treatment modalities for SSV insufficiency were reviewed.

We demonstrated significant differences in outcomes in favour of the minimally invasive techniques. However, it should be noted that the articles are very heterogeneous and therefore are difficult to compare.

Until now, no RCT has been conducted comparing surgery and endovenous techniques for SSV insufficiency. Van den Bos et al. concluded that for lower extremity vein insufficiency, minimally invasive techniques appear to be at least as effective as surgery; however, no clear distinction in their conclusion was made between the GSV and the SSV. ${ }^{9}$

We demonstrated that both stripping and ligation of the SSV exhibit results that are characterised by high failure rates. However, it should be noted that the articles examining surgery are difficult to compare due to the lack of standardisation regarding the definition of outcome and the techniques used. Using a questionnaire survey, Winterborn ${ }^{26}$ confirmed our observations that surgical techniques show great variation: most surgeons (75.7\%) ligate the SSV as close as possible to the SPJ after following the SSV into the popliteal fossa but do 
not routinely expose the popliteal vein. The majority (55.1\%) of surgeons excise a proximal segment up to $10 \mathrm{~cm}$ long. Only $14.5 \%$ routinely strip the SSV. ${ }^{26}$ The primary complication that is feared with respect to SSV surgery is damage of the sural nerve. Only a small number of major complications related to nerve injury were described in the articles. The primary complication was numbness in the treated area, but this was self-limiting in nearly all of the cases. Atkin ${ }^{27}$ observed a $4.7 \%$ incidence of common peroneal nerve injury, which was selflimiting in all of the cases.

EVLA shows good treatment results, with initial occlusion rates nearing $100 \%$. However, no large studies have been performed with a long-term follow-up. Kontothanassis ${ }^{15}$ illustrates the relevance of the diameter of the SSV. Three patients with SSV diameters of 13, 9 and 10 $\mathrm{mm}$ exhibited recanalisation after one week, one week and two months, respectively. A recanalisation rate of $5.9 \%$ was observed among a subgroup of diameters of $9-13 \mathrm{~mm}$ versus $1.3 \%$ for smaller diameters. The primary complications observed following EVLA were minor and self-limiting. A concern following EVLA (and RFA) is DVT, and the occurrence rates described were variable, reaching as high as $5.7 \%$ ( 1 patient). However, the rates are not described in all of the articles, and the definitions are vague. Sural nerve damage is not common following EVLA. This conclusion was also reached by Rashid ${ }^{7}$, who stated that concerns regarding sural nerve damage should be minimal, as tumescent anaesthesia protects this nerve.

An initial positive effect of FS is demonstrated, with occlusion rates of 82-100\%. However, the long-term effects are uncertain, as a small population was discussed with a short followup period. Van den Bos et al. demonstrated a 77\% (range 69-84\%) success rate for FS for GSV insufficiency. After adjusting for follow-up, FS was as effective as surgery. ${ }^{9}$ The minor complications, including thrombophlebitis and hyperpigmentation, are self-limiting. However, hyperpigmentation may be an important cosmetic consideration in the long-term. ${ }^{22}$

The six articles that discuss patient satisfaction demonstrate improvements following treatment, but not all of the results that are reported, for both EVLA and surgery, are significant. However, explanations of the precise contents of the questionnaires are lacking. Medeiros, Mekako and Rasmussen all compared EVLA with surgery for varicose veins and demonstrated that patient satisfaction is independent of the type of treatment used. An improvement in patient satisfaction was reported for both techniques; however, one study favoured EVLA. ${ }^{28-30}$

The cost-effectiveness of the treatments is sparingly discussed in the reviewed articles. Nijsten et al. stated in a review that EVLA is more cost-effective than RFA because EVLA is less expensive and takes less time to perform. ${ }^{24}$ It appears clear that FS is superior to surgery with respect to cost- and time-effectiveness. The costs for EVLA and RFA compared with those of surgery have not been evaluated thoroughly. In their meta-analysis, Van den Bos et al. concluded that cost-effectiveness assessments are lacking. ${ }^{9}$ 
Due to the variance in the anatomy of the SSV and the popliteal fossa, surgery is not simple to perform. Preoperative US screening is important to have a clear idea of the SSV and SPJ anatomy of the patient, as surgical failure is often attributable to anatomical variance..$^{25}$

It is suggested that in addition to the known neovascularisation that occurs following saphenous vein surgery, high recurrence following SSV-SPJ ligation may be due to a long stump that is left behind because of the anatomical variance of the SSV. ${ }^{4}$ Stripping in addition to ligation appears to improve the outcome, which implies that endovenous techniques that directly target the truncal vein are efficient treatment modalities. ${ }^{6}$ Moreover, the results are less positive for surgery for recurrent SSV, which appears to be a strong argument for the use of endovenous techniques.

An important factor to consider when investigating treatment modalities for SSV insufficiency is the variable anatomy of the SSV and its junction with the popliteal vein. Gibson ${ }^{12}$ and Kontothanassis ${ }^{15}$ address this factor, arranging their patients into anatomical subgroups. However, their results do not take these subgroups into account. In the past century, several studies have been performed that describe the anatomy of the SSV, reporting a range of $16-47.6 \%$ of SSVs that do not cross the popliteal vein. This variation may have consequences for choosing a treatment and for the treatment result.

This review demonstrates the lack of papers published specifically on the treatment of SSV insufficiency, in particular, those that report on large study groups and long follow-up periods. Although we demonstrated a statistically significant difference in outcome in favour of EVLA, the results of the reviewed articles do not allow for definite conclusions to be drawn with respect to the ideal treatment for SSV insufficiency. More research is required in this field. Several trials are ongoing, and the results can be expected in the years ahead.

\section{Conclusion}

In the absence of large, comparative randomised clinical trials, minimally invasive techniques appear to trend towards better results than surgery. However, the evidence regarding the best treatment should be made clearer for all of the physicians that practice phlebology. It is unlikely that there will be a single, universally accepted treatment for varicose veins given that the choice of treatment depends on the individual patient, for whom the signs, symptoms and preferences will be variable. The different treatment modalities will also have to face cost/time-effectiveness analyses. There is a strong requirement for trials (preferably randomised) with long follow-up periods that compare the available treatment modalities. 


\section{References}

1. Beebe-Dimmer JL, Pfeifer JR, Engle JS, et al., The epidemiology of chronic venous insufficiency and varicose veins. Ann Epidemiol. 2005;15:175-84.

2. Almgren B, Eriksson E. Valvular incompetence in superficial, deep and perforator veins of limbs with varicose veins. Acta Chir Scand. 1990;156:69-74.

3. Neumann HAM, Tazelaar DJ. Leerboek Flebologie. Uitgeverij LEMMA bv, 2003. Utrecht 2003.

4. Allegra C, Antignani PL, Carlizza A. Recurrent varicose veins following surgical treatment: our experience with five years follow-up. Eur J Vasc Endovasc Surg. 2007;33:751-6.

5. Dumas BE, Spronk S, Boelhouwer RU, et al. Subfascial ligation at three different levels versus partial exeresis of the incompetent short saphenous vein: a randomized clinical trial. J Vasc Nurs. 2007;25:12-8.

6. O'Hare JL, Vandenbroeck CP, Whitman B, et al. A prospective evaluation of the outcome after small saphenous varicose vein surgery with one-year follow-up. J Vasc Surg. 2008;48:669-73; discussion 674.

7. Rashid HI, Ajeel A, Tyrrell MR. Persistent popliteal fossa reflux following saphenopopliteal disconnection. Br J Surg. 2002;89:748-51.

8. Whiteley MS, Lewis G, Holdstock JM, et al. Minimally invasive technique for ligation and stripping of the small saphenous vein guided by intra-operative duplex ultrasound. Surgeon. 2006;4: 372-377.

9. van den Bos R, Arends L, Kockaert M, et al. Endovenous therapies of lower extremity varicosities are at least as effective as surgical stripping or foam sclerotherapy: Meta-analysis and metaregression of case series and randomized clinical trials. J Vasc Surg. 2009;49:230-9.

10. Rao J, Wildermore JK, Goldman MP. Double-blind prospective comparative trial betweern foamed and liquid polidocanol and sodium tetradecyl sulfate in the treatment of varicose and telangiectatic leg veins. Dermatol Surg. 2005;31:631-5; discussion 635

11. Hamel-desnos C, Desnos P, Wollman JC, et al. Evaluation of the efficacy of polidocanol in the form of foam compared with liquid form in sclerotherapy of the greater saphenous vein: initial results. Dermatol Surg. 2003;29:1170-5; discussion 1175.

12. Gibson KD, Ferris BL, Polissar N, et al. Endovenous laser treatment of the small [corrected] saphenous vein: efficacy and complications. J Vasc Surg. 2007;45:795-801; discussion 801-3.

13. Huisman LC, Bruins RM, van den Berg M, et al. Endovenous Laser Therapy of the Small Saphenous Vein: Prospective Analysis of 150 patients, a Cohort Study. Eur J Vasc Endovasc Surg. 2009;38: 199-202.

14. Jung IM, Min SI, Heo SC, et al. Combined endovenous laser treatment and ambulatory phlebectomy for the treatment of saphenous vein incompetence. Phlebology. 2008;23:172-7.

15. Kontothanassis D, Di Mitri R, Ferrari Ruffino S, et al. Endovenous laser treatment of the small saphenous vein. J Vasc Surg. 2009;49:973-979.e1.

16. Nwaejike N, Srodon PD, and Kyriakides C. Endovenous Laser Ablation for Short Saphenous Vein Incompetence. Ann Vasc Surg. 2009;23:39-42.

17. Park SJ, Yim SB, Cha DW, et al. Endovenous laser treatment of the small saphenous vein with a 980-nm diode laser: early results. Dermatol Surg. 2008;34:517-24; discussion 524.

18. Park SW, Hwang JJ, Yun IJ, et al. Endovenous laser ablation of the incompetent small saphenous vein with a 980-nm diode laser: our experience with 3 years follow-up. Eur J Vasc Endovasc Surg. 2008;36:738-42. 
19. Proebstle TM, Gül D, Kargl A, et al. Endovenous laser treatment of the lesser saphenous vein with a 940-nm diode laser: early results. Dermatol Surg. 2003;29:357-61.

20. Ravi R, Rodriguez-Lopez JA, Trayler EA, et al. Endovenous ablation of incompetent saphenous veins: a large single-center experience. J Endovasc Ther. 2006;13:244-8.

21. Theivacumar NS, Beale RJ, Mavor Al, et al. Initial experience in endovenous laser ablation (EVLA) of varicose veins due to small saphenous vein reflux. Eur J Vasc Endovasc Surg. 2007;33:614-8.

22. Darke SG, Baker SJ. Ultrasound-guided foam sclerotherapy for the treatment of varicose veins. $\mathrm{Br}$ J Surg. 2006;93:969-74.

23. Smith PC. Chronic venous disease treated by ultrasound guided foam sclerotherapy. Eur J VasC Endovasc Surg. 2006;32:577-83.

24. Nijsten T, van den Bos RR, Goldman MP, et al. Minimally invasive techniques in the treatment of saphenous varicose veins. J Am Acad Dermatol. 2009;60:110-9.

25. Tong Y, Royle J. Recurrent varicose veins after short saphenous vein surgery: a duplex ultrasound study. Cardiovasc Surg, 1996;4:364-7.

26. Winterborn RJ, Campbell WB, Heather BP, et al. The management of short saphenous varicose veins: a survey of the members of the vascular surgical society of Great Britain and Ireland. Eur J Vasc Endovasc Surg. 2004;28:400-3.

27. Atkin GK, Round T, Vattipally VR, et al. Common peroneal nerve injury as a complication of short saphenous vein surgery. Phlebology, 2007;22:3-7.

28. de Medeiros CA, Luccas GC. Comparison of endovenous treatment with an $810 \mathrm{~nm}$ laser versus conventional stripping of the great saphenous vein in patients with primary varicose veins. Dermatol Surg. 2005;31:1685-94.

29. Mekako Al, Hatfield J, Bryce J, et al. A nonrandomised controlled trial of endovenous laser therapy and surgery in the treatment of varicose veins. Ann Vasc Surg. 2006;20:451-7.

30. Rasmussen LH, Bjoern L, Lawaetz M, et al. Randomized trial comparing endovenous laser ablation of the great saphenous vein with high ligation and stripping in patients with varicose veins: short-term results. J Vasc Surg. 2007;46:308-15. 


\section{CHAPTER 10}

\section{General discussion}

\section{Based on:}

Ceulen RP, Vernooy K.

More on microembolism and Foam Sclerotherapy.

N Engl J Med. 2008;359:656-657.

Ceulen RP, Vernooy K.

Reply to letter regarding article titled 'Microembolism during foam sclerotherapy of varicose veins' in the New England Journal of Medicine.

Phlebology. 2008;23:250. 



\section{Effectiveness of foam sclerotherapy}

At the time that we began to perform ultrasound-guided sclerotherapy in the Maastricht University Medical Centre (MUMC) as a premium treatment for varicose veins, no other endovenous techniques, such as RFA or EVLA, had been established. We first used liquid sclerosing agents, but only for a short period; soon, sclerosing foam became of interest. From that moment forward, it became clear that the opinions with respect to the best treatment for varicose veins varied greatly among physicians.

Dermatologists were convinced that because of the stronger effect of foam compared to liquid, the results that had been put forward in favour of surgery for truncal varicose veins (e.g., Hobbs' study²) were out-dated. In addition, dermatologists accused surgeons that they disfigured their patients with the scars of varicose vein surgery. Alternatively, surgeons accused the dermatologists of disfiguring their patients with hyperpigmentation in the course of the treated veins after sclerotherapy. It is said that during the summertime at the Sint Servaasbrug in Maastricht, you can recognise which skirt-wearing female patient was treated by a surgeon and which one was treated by a dermatologist. In the early 2000 s, the influence of the referral policy of the general practitioner was remarkable in determining whether a patient would be treated by a surgeon or by a dermatologist. This complete arbitrariness and the lack of scientific evidence led us to design a comparative study in which the longpracticed and assumed proven surgical strip was compared to the modern, minimally invasive FS. In this randomised multicentre clinical trial with a follow-up period of 2 years, we demonstrated that FS is not inferior to surgery and reduces hospital costs by EUR 1050 per patient. From these numbers, one could conclude that FS should be the first choice treatment for varicose saphenous veins. However, this is not the case, perhaps because of the lack of uniform definitions of success and failure in the international literature. This makes comparisons to other studies difficult, which is a recurrent observation in several meta-analyses. Where most other randomised trials ${ }^{3,4}$ merely use the presence of reflux in the GSV as an outcome and based whether a treatment succeeded or whether re-treatment was needed on this anatomical-physiological result, we choose to combine patient complaints with venous reflux as a measure for success, as this best reflects clinical practice.

\section{Standardisation of foam sclerotherapy}

In this thesis, we attempted to enhance the standardisation of FS. There are two important aspects of FS: 1. the method used to create foam, and 2. the actual treatment of the patient. A literature search revealed that foam is created in many different ways, with large variations in, e.g., the type of sclerosant, the concentration of the sclerosant, the ratio liquid/air, the type of gas, and the material of the syringes. What is agreed upon is that every physician wants to 
create stable foam. We tested in vitro the majority of these variables and demonstrated that only the concentration of the POL and the time between the creation of the foam and the injection appears to influence the stability of foam; thus, these factors determine the quality of the produced foam. The next step was investigating the method of the actual treatment of the patient: the use of a needle or a Venflon, the different concentrations POL foam, the subsequent compression therapy and the safety procedures, such as blocking the SFJ. We demonstrated that the influence of the different variables on the production of foam and the execution of the treatment is limited and does not lead to large differences in outcome with respect to effectiveness and local or systemic side effects. Alternatively, it is often concluded in the literature that directly comparing RCTs on FS is very difficult, and the argument again returns to the effects of the multiple variations of the techniques and methods of foam production and treatment. Thus, the question arises whether these conclusions are correct. In our opinion, the answer is no. When a lack of standardisation of the technique and the method do not lead to a lack of quality, then the treatment is very forgiving. Hence, further research regarding the best foam properties, the best treatment methods, and further standardisation, is no longer necessary.

\section{Safety of foam sclerotherapy}

In chapter 6, we reported transient neurologic symptoms in 2 patients following FS. We subsequently screened 33 patients with echocardiography and demonstrated intra-cardiac gas emboli in all of the patients during FS. In patients with a patent foramen ovale, foam microemboli were present in both the right and the left side of the heart. ${ }^{5}$ This report had a significant impact within the medical community, and it was the most blogged-about paper published in the NEJM in 2008. This impact is understandable, as minimally invasive techniques, such as chemical ablation with foam sclerosants, are attractive alternatives to the more invasive EVLA and stripping procedures, that is, unless these new technique decrease patient safety due to potential life-threatening side effects, i.e., cerebral arterial distribution of the foam. On behalf of Vasculab, an Internet forum for phlebologists, Simka et al. published a comment regarding our letter. ${ }^{6}$ The authors questioned the clinical significance of the presence of gas bubbles in the left heart in patients with PFO in correlation with the reported neurological complications. This questioning was based on the report of Guex, who demonstrated in a series of 12,713 patients, half of whom were treated with foamed sclerosants, that the incidence of transient events was very low (0.16-0.27\%). ${ }^{7}$ However, our report is the first published study investigating the systemic distribution of foam during FS following the observation of neurological symptoms in two patients. We performed FS following the European consensus guidelines ${ }^{8}$ and demonstrated that a common event in all of the patients undergoing FS was the presence of foam microembolisms, or 'small echo- 
genic structures', as suggested by the consensus meeting in $2006 .{ }^{9}$ In a significant number of patients, a patent foramen ovale (PFO) was present, resulting in a microembolism in the left side of the heart. Rush and Wright confirmed the observation of intracardiac gas emboli in both the right and left sides of the heart during FS in patients with a PFO. ${ }^{10}$ Moreover, in our two index patients, further examination revealed a PFO. From these observations, we concluded that microembolisms induced by FS potentially cause neurological symptoms in the presence of a PFO. Although no scientific evidence is available, we are convinced that the injection of foam prepared by mixing polidocanol with room air results in air emboli with an active sclerosant coating. The occurrence of neurological symptoms in patients with PFO is likely related to the total amount of microembolism in the left side of the heart and is subsequently PFO size-dependent. It is surprising that none of the five patients with a PFO described in our study developed neurological symptoms. However, we neither quantified the amount of microembolism in the left side of the heart nor the size of the PFO in these patients. In accordance with our data, Regan et al. reported that embolisms following FS were detected in the medial cerebral artery of $90 \%$ of the patients with a PFO. ${ }^{11}$ None of these patients exhibited neurological symptoms or abnormalities on MRI examination.

Foam can be produced with a variety of preparation techniques that result in differences in the bubble size and the reabsorption rate. We applied the double syringe technique, which led to larger bubbles than Rush's specifically engineered Varisolve technique, which dispenses foam with a highly controlled bubble-size distribution. Moreover, for polidocanol foam preparation, Rush used a very low nitrogen gas mixture, whereas we used room air, which is associated with increases in bubble number and size. ${ }^{11,12}$ Interestingly, Morrisson demonstrated that side effects significantly decreased if $\mathrm{CO} 2$ rather than air was employed to make the sclerosing foam. ${ }^{13}$ We believe that FS is a safe procedure, and routine PFO screening before FS is not recommended. We also believe that patients developing overt neurological complaints after FS should receive an additional echocardiographic examination to determine if a PFO is present.

\section{The practice of foam sclerotherapy today and in the future}

FS is no longer the newest treatment for varicose veins. While we were focussing on FS, EVTA techniques were introduced on a large scale. These techniques appear to be very effective and exhibit high success rates for short-term follow-ups. EVTA techniques have been implemented as the new standard for the treatment of varicose veins in many countries. Nevertheless, meta-analyses have found that many of the included studies were non-comparative, primarily due to a lack of standardisation..$^{14,15}$ 
Does this mean that there is no longer room for FS? The answer is certainly not. However, a consensus should be reached regarding the proper indications for FS. Given that we demonstrated that FS is a cost-effective treatment for varicose veins, this technique has a unique niche, which is also evidenced by several other factors. First is the need for the patient's choice. Patient preference is indispensible in today's society, and patients prefer minimally invasive treatments with no downtime and as few side effects as possible. This was demonstrated in our RCT that compared FS with surgery. In this trial, 26 patients refused the treatment to which they had been randomised: 24 of the patients refused surgical treatment. Second, patients with chronic venous disease are often elderly and suffering from co-morbidities and other contraindications for surgery. For these patients, minimally invasive FS, which can be easily performed in an outpatient setting, offers a good first choice treatment. Because FS is cheap, patient-friendly and has nearly no side effects, re-treatment is justified in cases of failure following long-term follow-up. The third consideration for FS is from the perspective of the physician. Treatment with FS follows the current trend of the greater popularity of minimally invasive techniques. FS is simple to learn, making it an accessible technique for different physicians, such as phlebologists, dermatologists, surgeons and radiologists. Furthermore, FS can be easily repeated if necessary.

Finally, there are several situations when limitations or contraindications arise for treatment by standard stripping or modern EVTA techniques, for example, in tortuous veins, in anatomically complex and thus inoperable recurrent and residual veins, in insufficient perforating veins, in venous malformations and in ascending varicose veins that begin at the level of the SSV and the distal GSV. FS is particularly important in the advanced stage of chronic venous insufficiency (CEAP stages $C_{4^{\prime}} C_{5}$ and $C_{6}$ ), when complications appear, including dermatosclerosis, induration, oedema, lymphedema, active ulcers or ulcer scarring. Therefore, it is necessary that future RCTs stratify the participants by the severity of their symptoms, such as by the VCSS and/or other measures of disease severity, including physical examination or imaging findings.

It should be clear that the treatment of CVD is not a matter of life or death. However, CVD can have a great impact on patient's health-related quality of life and is comparable to other chronic diseases in that it is associated with high health care costs. ${ }^{16}$ The treatment of varicose veins should prevent the occurrence of important complications, such as leg ulcerations, which have a lifetime prevalence of $1-2 \% .{ }^{17}$ Approximately half of all leg ulcers are caused by superficial varicose veins. ${ }^{18}$ However, it is nearly impossible to predict which patient with C2 varicose veins will eventually develop a leg ulcer. It is known that treatments of venous leg ulcers are expensive. By treating C2 varicose veins, we are able to cut in half the incidence of venous ulcers in the long-term, and hence lowering healthcare costs. Therefore, choosing a cost-effective therapy for C2 varicose veins appears obvious. Recently, Dutch health care insurance companies (College Voor Zorgverzekeraars - CVZ) decided to no longer reimburse 
for the treatment of C2 varicose veins. This decision goes against the guidelines of general practitioners, surgeons and dermatologists, who recommend the treatment of insufficient saphenous veins. ${ }^{19,20}$ Based on the data in this thesis, in which we conclusively demonstrated FS to be a cost-effective therapy for C2 varicose veins, the CVZ should rescind and alter this decision. We strongly recommend making the much less expensive FS the first-line treatment for varicose veins. 


\section{References}

1. Wright D, Gobin JP, Bradbury AW. Varisolve ${ }^{\oplus}$ polidocanol microfoam compared with surgery or sclerotherapy in the management of varicose veins in the presence of trunk vein incompetence: European randomized controlled trial. Phlebology. 2006;21:180-90.

2. Hobbs JT. Surgery and sclerotherapy in the treatment of varicose veins. A random trial. Arch Surg. 1974;109:793-6.

3. Blaise S, Bosson JL, Diamand JM. Ultrasound-guided sclerotherapy of the great saphenous vein with $1 \%$ vs. $3 \%$ polidocanol foam: a multicentre double-blind randomised trial with 3-year followup. Eur J Vasc Endovasc Surg. 2010;39:779-86.

4. Darke SG, Baker SJ. Ultrasound-guided foam sclerotherapy for the treatment of varicose veins. $\mathrm{Br}$ J Surg. 2006;93:969-74.

5. Ceulen RP, Sommer A, Vernooy K. Microembolism during foam sclerotherapy of varicose veins. N Engl J Med. 2008;358:1525-6.

6. Guex JJ, Raymond-Martimbeau P, Simka M, Passariello F. Letter regarding article titled 'microembolism during foam sclerotherapy of varicose veins' in the New England Journal of Medicine. Phlebology. 2008;23:249; author reply 50.

7. Guex JJ, Allaert FA, Gillet JL, Chleir F. Immediate and midterm complications of sclerotherapy: report of a prospective multicenter registry of 12,173 sclerotherapy sessions. Dermatol Surg. 2005;31:123-8; discussion 8.

8. Rabe E, Pannier-Fischer F, Gerlach H, et al. Guidelines for sclerotherapy of varicose veins (ICD 10: 183.0, 183.1, 183.2, and 183.9). Dermatol Surg. 2004;30:687-93; discussion 93.

9. Breu FX, Guggenbichler S. European Consensus Meeting on Foam Sclerotherapy, April, 4-6, 2003, Tegernsee, Germany. Dermatol Surg. 2004;30:709-17; discussion 17.

10. Rush JE, Wright DD. More on microembolism and foam sclerotherapy. N Engl J Med. 2008;359: 656-7.

11. Regan JD, Gibson KD, Rush JE, Shortell CK, Hirsch SA, Wright DD. Clinical significance of cerebrovascular gas emboli during polidocanol endovenous ultra-low nitrogen microfoam ablation and correlation with magnetic resonance imaging in patients with right-to-left shunt. J Vasc Surg. 2011;53:131-7.

12. Eckmann DM, Kobayashi S, Li M. Microvascular embolization following polidocanol microfoam sclerosant administration. Dermatol Surg. 2005;31:636-43.

13. Morrison N, Neuhardt DL, Rogers $\mathrm{CR}$, et al. Comparisons of side effects using air and carbon dioxide foam for endovenous chemical ablation. J Vasc Surg. 2008;47:830-6.

14. van den Bos R, Arends L, Kockaert M, et al. Endovenous therapies of lower extremity varicosities: a meta-analysis. J Vasc Surg. 2009;49:230-9.

15. Mundy L, Merlin TL, Fitridge RA, Hiller JE. Systematic review of endovenous laser treatment for varicose veins. Br J Surg. 2005;92:1189-94.

16. Kaplan RM, Criqui MH, Denenberg JO, et al. Quality of life in patients with chronic venous disease: San Diego population study. J Vasc Surg. 2003;37:1047-53.

17. Margolis DJ, Bilker W, Santanna J, Baumgarten M. Venous leg ulcer: incidence and prevalence in the elderly. J Am Acad Dermatol. 2002;46:381-6.

18. Magnusson MB, Nelzen O, Risberg B, Sivertsson R. A colour Doppler ultrasound study of venous reflux in patients with chronic leg ulcers. Eur J Vasc Endovasc Surg. 2001;21:353-60.

19. Nederlands Huisartsen Genootschap. NHG-standaard varices. www.artsennet.nl. 
20. Nederlandse Vereniging voor Heelkunde en Nederlandse vereniging voor Dermatologie en Venereologie. Richtlijn diagnostiek en behandeling van varices. Utrecht, 2007. 

CHAPTER 11

Summary|Samenvatting 



\section{Summary}

Chapter one provides a general introduction to this thesis. Lower extremity venous insufficiency is a common health problem in Western countries, and its prevalence increases with age. Varicose veins have long been considered a cosmetic problem, one that affects emotional well-being but is not a source of disability. Varicose veins, however, are frequently the cause of discomfort and pain. Varicosity has a substantial impact on patients' quality of life. In its later stage, it can cause physical signs, such as oedema and skin changes. We then speak of chronic venous disease (CVD). Venous ulceration of the lower leg is the end point of CVD and affects approximately $1 \%$ of the population at some point in their lives. Nearly $50 \%$ of all venous leg ulcers are the result of superficial venous insufficiency, although it is nearly impossible to predict which patient with varicose veins will develop a venous ulcer. The lack of effective treatments and the recurrent nature of the disease place a heavy burden on the resources and budgets of health care systems. The treatment of varicose veins can reduce the incidence of venous ulceration by $50 \%$ and therefore is likely to be cost-effective. The keystone for the management of CVD is the proper diagnosis and accurate classification of the underlying venous problem. The widespread availability of duplex ultrasonography has greatly enhanced the evaluation of the venous system of the lower extremities. With the use of CEAP classification, it is possible to apply an orderly system for the descriptive clinical signs of venous disease $(C)$, aetiology $(E)$, anatomy $(A)$ and pathophysiology $(P)$; the status of each patient can therefore be precisely evaluated. For many years, the standard treatment for varicose veins was surgery and was based on a large randomised controlled trial performed by Hobbs et al. They compared surgery with liquid sclerotherapy in treating varicosity of the great saphenous vein (GSV) and demonstrated that surgery was more effective. Because open surgical treatment with stripping of the varicose veins performed under general anaesthesia was associated with pain, the potential for wound complications and a loss of working days, the demand for minimally invasive and less expensive procedures increased. One such technique is ultrasound-guided foam sclerotherapy (FS). FS is a variant of liquid sclerotherapy in which the liquid/air mixture (foam) is injected into the varicose vein under guidance of duplex ultrasonography. FS is approximately four times as effective as liquid sclerotherapy. In addition, FS is less invasive than surgery, and other possible advantages include reduced health care costs and a shorter post treatment down-time. The global development of FS as a standard treatment was still in its infancy when we planned our first steps to systematically investigate different aspects of this technique. In this thesis, we focused on the effectiveness, costs, on the technical and procedural details with respect to the properties of the produced 
foam and the occurrence and prevention of local and systemic side effects of FS. Finally, we attempted to summarise the current understanding of FS as a treatment for small saphenous vein (SSV) incompetence-induced CVD.

In chapter two, we investigated whether FS is a cost-effective alternative to high ligation and stripping of the GSV. Therefore, we performed a multi-centre, randomised controlled, noninferiority trial. Four hundred sixty patients with primary incompetence of the saphenofemoral junction (SFJ) and GSV (measured over a distance of at least $20 \mathrm{~cm}$ in the upper leg) and with a reflux time greater than 0.5 seconds were randomised to one of two treatments. Of the 233 patients who were randomised to FS, 230 were treated. Of the 227 patients who were assigned to stripping, 200 were treated, and 27 withdrew from the study. Twenty-four of these patients refused treatment by surgery. After 2 years of follow up, the probability of the combination of reflux and symptoms was similar in the FS and surgery groups: $11.3 \%$ (24/213) and 9.0\% $(16 / 177)$, respectively $(p=0.30)$. However, reflux, irrespective of venous symptoms occurred significantly more frequently in the FS group (35\%) than in the surgery group $(21 \%)(p=0.002)$. The cost analysis included the costs of outpatient visits, treatment (FS or stripping), retreatment, and the complementary treatment of the GSV during follow-up. We calculated the mean hospital costs per patient over 2 years to be EUR 774 for FS and EUR 1824 for stripping. After 2 years, we observed no significant differences in decreased VCSS, symptom relief or the VAS scores between the FS and the surgery groups. The overall number of side effects was very low. With respect to surgery, the side effects were limited to wound infection (2\%), haematoma (1.5\%) and paraesthesia (3\%). In FS, thrombophlebitis (7.5\%) and hyperpigmentation (5.6\%) were the most common side effects. In conclusion, the findings of this large trial support the hypothesis that FS is not inferior to stripping for the treatment of GSV incompetence. A major advantage of FS is that it results in a 2.4-fold reduction in costs at the hospital level. Therefore, FS represents a cost-effective approach as a non-invasive treatment for incompetent saphenous veins.

Worldwide, the foam for FS is produced by mixing a sclerosant with a gas. Mixing is primarily performed using the double syringe system, in which two syringes are connected using a three-way stopcock. In chapter three, we describe an experimental study to investigate the specific details regarding this foam production process and to determine how the most stable foam can be prepared. Foam stability is measured in foam half time (FHT) and bubble size. To measure the FHT, the foam was created, the syringe containing the foam was placed precisely vertically and a timer was set. To measure the bubble size, the prepared foam was sprayed onto a perspex test device and photographed under a microscope, and the data were processed using a mathematical software system. The measured FHT was 115-157 seconds for $1 \%$ POL and 143-192 seconds for 3\% POL. One percent POL foam ( $t=0$ seconds) resulted in a mean bubble size of $71 \pm 9 \mu \mathrm{m}$, which increased when the foam was maintained horizontally in the syringe: $102 \pm 12 \mu \mathrm{m}$ at 30 seconds and $121 \pm 20 \mu \mathrm{m}$ at 60 seconds. The 
other clinical relevant parameters, i.e., the freshness of the POL solution (new versus re-used foam), the syringe size ( $3 \mathrm{~mL}$ versus $5 \mathrm{~mL}$ ), the liquid-to-air ratio (1:3 versus 1:4), the number of pump cycles (10 versus 30 ) and the use of needles of varying gauges or a Venflon, had no significant influence on the FHT or on bubble size.

Historically, to achieve full obliteration of varicose GSVs, sclerotherapy liquids with high concentrations of detergents were used. Since foam sclerosing agents were first applied, the question has arisen whether high concentrations are also needed to achieve better results. To evaluate the efficacy and the side effects of $1 \%$ and $3 \%$ POL foam, we designed the RCT that is described in chapter four. Over 6 months, we randomised 80 patients with primary GSV incompetence in combination with SFJ incompetence to receive FS with either $1 \% \mathrm{POL}$ or 3\% POL. Post-treatment compression was applied using a combination of a class 1 antiembolism and class 2 medical elastic stockings for a period of 6 weeks. As a primary outcome parameter, we measured obliteration of the treated vein after a 1-year follow-up with duplex ultrasound. Full occlusion was achieved in $69 \%$ in the $1 \%$ POL group vs. $82 \%$ in the $3 \% \mathrm{POL}$ group. ( $p=0.249$, Chi-squared test). As a secondary outcome measure, we investigated the incidence of side effects. Thrombophlebitis was observed in $32 \%$ of the patients in the $1 \% \mathrm{POL}$ group and in $50 \%$ of the patients in the $3 \% \mathrm{POL}$ group. After 1 year, this side effect resolved without sequelae in nearly all of the patients. The incidence of post sclerotic discoloration decreased in both of the groups but was still present after 1 year in $8 \%$ of the patients in the $1 \%$ POL group and in $18 \%$ of the patients in the $3 \%$ POL group $(p=0.221)$.

In chapter five, we investigated the effect of compression following FS on the rates of occlusion and side effects, taking into account the diameter of the treated vein. Therefore, we designed a randomised controlled trial in which 72 patients with primary incompetent GSVs were divided into two groups based on GSV diameter (group $1 \leq 0.5 \mathrm{~cm}$ and group $2>0.5$ $\mathrm{cm}$ ) and treated with FS. The patients were then randomised to compression therapy using the combination of a pelotte and class 1 (18-21 mmHg) and class $2(23-32 \mathrm{mmHg}$ ) hosiery for a period of 0,1 or 4 weeks. After 12 weeks of follow-up, all of the patients underwent a physical examination, and the treated GSVs were examined by duplex ultrasound imaging. Clinical symptoms showed similar improvement in all randomisation groups compared with pre-treatment assessment. In the $\leq 0.5$ group, complete occlusion was showed in $84 \%$ ( 0 week compression), 92\% (1 week compression) and 84\% (4 weeks compression) of patients. In the $>0.5$ group, full obliteration was obtained in $84 \%$ ( 0 week compression), $84 \%$ ( 1 week compression) and $92 \%$ (4 weeks compression) of patients. We found a significant rate of phlebitis arising after 1, 4 and 8 weeks only in those patients without compression, regardless of the size of the vein. Hyperpigmentation related to thrombophlebitis was reported in $82 \%$ of patients in the $>0.5 \mathrm{~cm}$ group $(\mathrm{p}<0.01)$. As a result of phlebitis, patients in the $>0.5$ group, patients in the 0 -wk compression group and patients who stopped compression because 
of the study protocol reported significantly more pain. The reported satisfaction rates were equivalent in all groups. Although compression following foam sclerotherapy did not result in higher rates of obliteration, it did prevent side effects such as thrombophlebitis, hyperpigmentation and feelings of pain, particularly in GSVs with a diameter $>0.5 \mathrm{~cm}$. However, this protective quality of compression diminishes when compression ends, even after 4 weeks.

In chapter six, we reported the occurrence of transient scotomas and a migraine attack in two individuals immediately after FS. Intrigued by these clinical observations, we monitored the systemic distribution of foam by echocardiography in 33 patients during FS. Immediately following injection, we detected foam particles in both the right atrium and the ventricle in all of the examined patients. In 5 patients, we also detected micro-embolisms in the left side of the heart. In these 5 subjects, a right-to-left shunt through a patent foramen ovale (PFO) was present on echocardiography. However, none of these patients suffered from neurological symptoms. Because the neurological signs observed in the two index patients could reflect adverse effects of foam sclerotherapy due to a right-to-left shunt, we subsequently examined both of these patients by echocardiography and demonstrated a patent foramen ovale in each. In this study, we demonstrated that systemic foam distribution is a common phenomenon during foam sclerotherapy, but this results in serious neurological symptoms in fewer than $0.2 \%$ of patients, despite the fact that the prevalence of PFO in the general population is $26 \%$.

Following the observation that transient neurological effects are likely caused by the systemic distribution of the injected foam, we became interested in whether blockage of the SFJ during FS by either manual compression or high ligation are adequate safety procedures for preventing foam leaking into the deep venous system. In chapter seven, we added radioactive pertechnetate $\left({ }^{99 \mathrm{~m}} \mathrm{TcO}_{4}^{-}\right)$to the foam solution to visualise the distribution of microbubbles. In vitro experiments verified the stability of the produced radioactive foam. Using a gamma camera, the ${ }^{99 \mathrm{~m}} \mathrm{Tc}$ allows the detection of foam in the treated vein and leakage of the foam from the vein into the deep venous system. In 3 patients, the SFJ was surgically ligated first and was subsequently treated with FS. In another 3 patients, the GSV was injected with foam while the SFJ was manually compressed. Two patients functioned as a control group, and their GSVs were treated with FS without blocking the SFJ. Measuring the radioactivity, we observed leakage of the foam from the GSV in all of the patients, despite blocking the SFJ by compression or ligation. However, we demonstrated that blockage of the SFJ reduces the amount of foam entering the deep venous system.

In chapter eight, we described three patients with chronic venous leg ulcerations caused by incompetence of the GSV and/or the SSV. After treatment with FS, obliteration of the incompetent vein was achieved, and the ulcers healed quickly. Using FS, we successfully avoided the requirement for surgical treatment in our elderly patients. 
Chapter nine describes a systematic literature review of the surgical and endovenous techniques for the treatment of varicose SSVs. We included 17 studies with a total of 1804 treated legs, of which 479 (27\%) were treated surgically, 1161 (64\%) were treated by EVLA, and 164 (9\%) were treated by FS. An important inclusion criterion was the use of ultrasound examination to qualify the outcome. Five studies on stripping demonstrated success rates from $24 \%$ to $100 \%$ (follow-up: 1.5-60 months). Ten articles on EVLA reported success rates varying from 91\% to $100 \%$ (follow-up period: $1.5-36$ months), and 2 articles examining FS reported success rates varying from $82 \%$ to $100 \%$ (follow-up period: $1.5-11$ months). After adjusting for outcome, we demonstrated a statistically significant difference in the success rates between stripping (48\%) and EVLA/FS (95\%). However, it should be noted that the articles are very heterogeneous and are therefore difficult to compare.

In chapter ten, we place the contents of this thesis in a modern context. We discuss the consequences of the previous decade's rapidly evolving therapies of chronic venous disease, with a primary focus on FS. We discuss why it is so difficult, due to a lack of evidence and uniform definitions, to correctly estimate the value of other studies. We then discuss our experimental studies and their enhancing of the standardisation of FS. Thereafter, we discuss the different theories regarding the safety of FS, especially potential controversies that theoretically exists. The discussion ends with a reflection on the position of FS in daily practice and perspectives on the future of this research. 



\section{Samenvatting}

Hoofdstuk één geeft een algemene inleiding tot dit proefschrift. Chronisch veneuze insufficiëntie is een veelvoorkomend gezondheidsprobleem in de Westerse wereld en de prevalentie stijgt met de leeftijd. Varices worden vaak gezien als een cosmetisch probleem dat wel het emotionele welbevinden beïnvloedt, maar niet tot invaliditeit leidt. Varices kunnen echter wel veel klachten veroorzaken en blijken een substantiële invloed op de kwaliteit van leven te hebben. In een gevorderd stadium kunnen varices zichtbare symptomen veroorzaken zoals oedeem en huidproblemen. We spreken dan van chronisch veneuze ziekte. Het ulcus cruris aan het onderbeen wordt veelal gezien als het eindstadium van deze ziekte en ongeveer $1 \%$ van de bevolking krijgt hier ooit mee te maken. Ongeveer 50\% van alle veneuze ulcera wordt veroorzaakt door insufficiëntie van oppervlakkige venen. Het is echter vrijwel onmogelijk om te voorspellen welke patiënten met varices uiteindelijk een veneus ulcus zullen ontwikkelen. Door de hoge kosten die gepaard gaan met behandeling van veneuze ziekten zoals de behandeling van het ulcus cruris, en het recidiverende karakter dat dit ziektebeeld kent, is er sprake van een groot socio-economisch probleem. Doordat de behandeling van varices de incidentie van veneuze ulcera met $50 \%$ kan verminderen, is het hoogst waarschijnlijk zo dat deze behandelingen uiteindelijk het totaal aan kosten van chronisch veneuze ziekten reduceert. De hoeksteen van deze behandeling is het accuraat diagnosticeren en classificeren van het onderliggende veneuze probleem. Dat wordt tegenwoordig gedaan met behulp van duplex echografie. Met behulp van de CEAP classificatie kan de status van iedere patiënt worden gecategoriseerd $(C=$ klinische kenmerken, $E=$ etiologie, $A=$ anatomie, $P=$ pathofysiologie).

Jarenlang werden varices behandeld door deze chirurgisch te verwijderen (strippen). De voorkeur voor dit strippen werd gebaseerd op een grote gerandomiseerde studie welke gepubliceerd werd door Hobbs in 1974. Hij vergeleek het strippen met sclerotherapie waarbij een vloeibaar sclerosans in de varix werd gespoten teneinde deze zieke ader te doen laten verkleven. Hobbs toonde aan dat strippen effectiever was. Strippen werd echter veelal gedaan onder narcose en werd geassocieerd met pijn. Tevens was er kans op wond complicaties en er was sprake van productiviteitsverlies ten gevolge van de herstelperiode die de patiënt in acht moest nemen. Hierdoor nam de vraag in de loop van de jaren toe naar minder invasieve en minder dure behandelingsmethoden. Een behandeltechniek die met de komst van echografie zijn intrede heeft gedaan is echo-sclerotherapie (ESCT). Hierbij wordt onder geleide van echografie de varix in beeld gebracht en het sclerosans ingespoten. In tegenstelling tot bij sclerotherapie wordt bij ESCT niet langer een vloeibaar sclerosans ingespoten, 
maar een schuim dat wordt verkregen door het vloeibare sclerosans te mengen met lucht. ESCT is ongeveer vier keer zo effectief als sclerotherapie met een vloeibaar sclerosans. Daarnaast is ESCT minder invasief dan strippen. Andere mogelijke voordelen zijn de lage kosten en de kortere herstelperiode na de behandeling waardoor de patiënt sneller weer aan het werk kan. De ontwikkeling van ESCT stond nog in de kinderschoenen toen wij de eerste stappen zetten om systematisch de verschillende aspecten van deze techniek te onderzoeken. In dit proefschrift hebben we ons gericht op de effectiviteit, de kosten, de technische en procedurele bijzonderheden met betrekking tot de eigenschappen van het geproduceerde schuim en het optreden en de preventie van lokale en systemische neveneffecten van ESCT.

In hoofdstuk twee hebben we onderzocht of ESCT een kosteneffectief alternatief is voor het strippen van de vena saphena magna (VSM). We beschrijven de resultaten van een gerandomiseerde studie die in meerdere ziekenhuizen werd uitgevoerd, waar bij 460 patiënten hun primaire insufficiënte VSM werd behandeld met ESCT of strip. Van de 233 patiënten die werden gerandomiseerd voor ESCT, werden er 230 behandeld. Van de 227 patiënten die werden gerandomiseerd voor strip werden er 200 behandeld en 27 trokken zich terug van wie er 24 weigerden om zich te laten opereren. Twee jaar na behandeling werden alle patiënten onderzocht middels duplex echografie. Het resultaat in beide groepen bleek gelijk (gedefinieerd als reflux VSM + veneuze klachten): ESCT 11.3\% (24/213) en strip 9.0\% (16/177) ( $p=0.30)$. Echter, reflux onafhankelijk van veneuze symptomen kwam significant vaker voor in de ESCTgroep (35\%) dan in de chirurgie groep (21\%) $(p=0.002)$. De kostenanalyse omvatte de kosten van poliklinische bezoeken, behandeling (ESCT of strippen), herbehandeling, en eventuele aanvullende behandelingen tijdens de follow-up periode. Uit onze berekeningen bleek dat de gemiddelde ziekenhuiskosten voor ESCT per patiënt per 2 jaar EUR 774 bedragen en voor strippen EUR 1824. Na 2 jaar zagen we geen significante verschillen in verminderde VCSS, verlichting van de symptomen of de VAS-scores tussen de patiënten in de ESCT en de strip groep. Het totaal aantal neveneffecten bleek in beide groepen zeer laag. Met betrekking tot de strip waren de neveneffecten beperkt tot wondinfectie (2\%), hematoom (1.5\%) en paresthesie (3\%). Tromboflebitis (7.5\%) en hyperpigmentatie (5.6\%) waren de meest voorkomende neveneffecten na ESCT. Concluderend ondersteunen de bevindingen van deze grote studie de hypothese dat voor de behandeling van de insufficiënte VSM ESCT gelijkwaardig is aan strippen. Een groot voordeel van ESCT is dat het resulteert in een 2.4-voudige vermindering van de kosten op ziekenhuis niveau. Daarom is ESCT een kosteneffectieve en niet invasieve behandeling voor de insufficiënte VSM.

Wereldwijd wordt het schuim voor ESCT gemaakt door het mengen van een sclerosans met een gas. Dit mengen gebeurt voornamelijk met behulp van het 'double syringe system' waarbij twee spuiten zijn verbonden door middel van een driewegkraan. In hoofdstuk drie beschrijven we een experimentele studie om de specifieke details van dit productieproces 
te onderzoeken en om te bepalen hoe het meest stabiele schuim kan worden gemaakt. Stabiliteit van het schuim wordt gemeten in 'schuimhalfwaardetijd' (SHT) en belgrootte. Om de SHT te meten werd eerst het schuim gemaakt, en vervolgens de spuit met het schuim precies verticaal geplaatst en werd een timer aangezet. Om de belgrootte te meten werd schuim op een perspex testapparaat gespoten en onder een microscoop gefotografeerd. De gegevens werden vervolgens verwerkt met behulp van een wiskundig software systeem. De gemeten SHT was 115-157 seconden voor 1\% polidocanol (POL) en 143-192 seconden voor $3 \%$ POL. 1\% POL schuim ( $\mathrm{t}=0$ seconden) resulteerde in een gemiddelde belgrootte van $71 \pm$ $9 \mu \mathrm{m}$, dat toenam als het schuim horizontaal werd gehouden in de injectiespuit: $102 \pm 12 \mu \mathrm{m}$ na 30 seconden en $121 \pm 20 \mu \mathrm{m}$ na 60 seconden. De andere klinische relevante parameters (de versheid van de POL oplossing (vers versus hergebruikt schuim), de spuit ( $3 \mathrm{~mL}$ versus 5 $\mathrm{mL}$ ), de vloeistof/lucht verhouding (1:3 versus $1: 4$ ) het aantal pomp cycli (10 versus 30 ) en naalden van verschillende gauges of Venflon bleken geen significante invloed op de SHW of belgrootte te hebben.

In het verleden werden hoge concentraties vloeibaar sclerosans gebruikt bij sclerotherapie om volledige occlusie van de insufficiënte VSM te bewerkstelligen. Toen schuim voor het eerst werd toegepast, vroeg men zich af of hierbij ook hoge concentraties benodigd waren om betere resultaten te bereiken. Om de werkzaamheid en de neveneffecten van 1\% en $3 \%$ POL schuim te evalueren, hebben we een gerandomiseerde gecontroleerde studie uitgevoerd die wordt beschreven in hoofdstuk vier. Gedurende 6 maanden hebben we 80 patiënten met primaire insufficiënte VSM gerandomiseerd voor ESCT behandeling met schuim gemaakt uit óf $1 \%$ POL óf $3 \%$ POL. Compressie na de behandeling bestond uit een combinatie van een klasse 1 anti-trombose kous en een klasse 2 therapeutisch elastische kous voor een periode van 6 weken. De primaire uitkomstmaat was occlusie van de behandelde vene, gemeten met duplex echografie, 1 jaar na behandeling. Volledige occlusie werd gezien bij $69 \%$ in de $1 \%$ POL groep versus $82 \%$ in de $3 \%$ POL groep ( $p=0.249$, Chi-kwadraat test). De secundaire uitkomstmaat was de incidentie van neveneffecten. Tromboflebitis werd bij $32 \%$ van de patienten in de $1 \%$ POL groep en in 50\% van de patiënten in de 3\% POL groep gezien. Na 1 jaar was dit neveneffect bij bijna alle patiënten geheel verdwenen zonder dat er sprake was van enig restletsel. De incidentie van postsclerotische verkleuring daalde in beide groepen, maar was na 1 jaar nog steeds aanwezig bij $8 \%$ van de patiënten in de $1 \%$ POL groep en bij $18 \%$ van de patiënten in de $3 \%$ POL groep $(p=0.221)$.

In hoofdstuk vijf hebben we het effect van compressie na ESCT op occlusie van de behandelde VSM en het optreden van neveneffecten onderzocht. We hebben onderscheid gemaakt in de diameter van de te behandelen VSM. Hiertoe hebben we een gerandomiseerde gecontroleerde studie opgezet, waarin 72 patiënten met een primair insufficiënte VSM werden ingedeeld in 2 groepen (groep $1 \leq 0.5 \mathrm{~cm}$ en groep $2>0.5 \mathrm{~cm}$ ) en vervolgens werden behandeld 
met ESCT. Compressie met een pelotte in combinatie met een klasse $1(18-21 \mathrm{~mm} \mathrm{Hg}$ ) en een klasse 2 (23-32 mm Hg) kous voor een periode van 0, 1 óf 4 weken werd volgens randomisatie in beide groepen toegepast. Na 12 weken follow-up ondergingen alle patiënten lichamelijk onderzoek en de behandelde VSM werd onderzocht met duplex echografie. Met betrekking tot de klinische symptomen zagen we een gelijkwaardige verbetering in alle groepen in vergelijking met vóór de behandeling. Met duplex echografie hebben we aangetoond dat de mate van occlusie na 3 maanden follow-up niet afhankelijk is van de diameter van de VSM. In de $\leq 0.5 \mathrm{~cm}$ groep werd volledige occlusie bereikt in $84 \%$ ( 0 weken compressie), $92 \%$ (1 week compressie) en $84 \%$ ( 4 weken compressie). In de $>0.5 \mathrm{~cm}$ groep werd volledige occlusie gevonden in $84 \%$ ( 0 weken compressie), 84\% ( 1 week compressie) en 92\% (4 weken compressie). Een opvallend resultaat was de significante aanwezigheid van flebitis na 1, 4 en 8 weken bij de patiënten die gerandomiseerd waren voor 0 weken compressie en bij patiënten bij wie compressie werd gestopt na 1 of 4 weken volgens protocol. Hierbij speelde de doorsnede van de VSM geen rol. Hyperpigmentatie ten gevolge van tromboflebitis werd gezien bij $82 \%$ van de patiënten in de $>0.5 \mathrm{~cm}$ groep $(\mathrm{p}<0.01)$. Ten gevolge van flebitis, rapporteerden patiënten in de $>0.5$ groep, patiënten in de 0 weken compressie groep en patiënten bij wie de compressie gestaakt was volgens protocol, significant meer pijn. Na het afronden van de follow-up periode meldden alle patiënten dezelfde mate van tevredenheid over de behandeling van hun varices. In deze studie tonen we aan dat compressie na ESCT niet leidt tot betere resultaten met betrekking tot occlusie van het behandelde bloedvat, maar het voorkomt wel het ontstaan van hinderlijke neveneffecten zoals tromboflebitis, hyperpigmentatie en pijn, met name bij patiënten die een VSM hebben met een diameter $>0.5 \mathrm{~cm}$. Echter vermindert dit beschermende en daarmee comfort verhogende effect van compressie op het moment dat de kous wordt uitgedaan, zelfs nog na 4 weken.

In hoofdstuk zes beschrijven we voorbijgaande scotomen en een migraine aanval bij twee patiënten onmiddellijk na ESCT. Geïntrigeerd door deze observaties hebben wij de systemische verspreiding van schuim onderzocht met behulp van echocardiografie bij 33 patiënten tijdens ESCT. Onmiddellijk na injectie zagen we bij alle onderzochte patiënten schuim partikels in zowel het rechter atrium alsmede ook in het rechter ventrikel. Bij 5 patiënten zagen we ook micro-embolieën in de linker hart helft. Bij alle 5 patiënten bestond er een rechts-links shunt door het patent foramen ovale (PFO) dat zichtbaar werd tijdens echocardiografie. Echter, geen van deze patiënten ontwikkelde neurologische verschijnselen. Omdat de neurologische symptomen waargenomen bij de twee index patiënten de schadelijke effecten van ESCT als gevolg van een rechts-links shunt konden weerspiegelen, hebben we deze twee patiënten onderzocht met behulp van echocardiografie. Beiden bleken een PFO te hebben. In deze studie hebben we aangetoond dat systemische verspreiding van schuim een veel voorkomend fenomeen is tijdens ESCT. Dit leidt echter slechts in minder dan $0.2 \%$ 
van de patiënten tot ernstige neurologische symptomen, ondanks het feit dat de prevalentie van PFO in de algemene bevolking $26 \%$ is.

Naar aanleiding van de constatering dat voorbijgaande neurologische effecten waarschijnlijk worden veroorzaakt door de systemische verspreiding van het ingespoten schuim, raakten we geïnteresseerd in de vraag of afdrukken van de SF-crosse tijdens ESCT, hetzij door handmatige compressie of door crossectomie, adequate procedures zijn om te voorkomen dat schuim in het diep veneuze systeem lekt. In hoofdstuk zeven hebben we radioactief pertechnetaat (99mTcO4-) toegevoegd aan het schuim om de verspreiding van het schuim te visualiseren. In vitro experimenten bevestigden de stabiliteit van het geproduceerde radioactieve schuim.

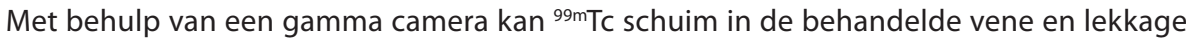
van het schuim in het diepe veneuze systeem worden waargenomen. Bij 3 patiënten werd de SF-crosse eerst chirurgisch geligeerd en vervolgens werd de VSM met ESCT behandeld. Bij 3 andere patiënten werd schuim in de VSM gespoten, terwijl de SF-crosse handmatig werd gecomprimeerd. Twee patiënten fungeerden als controle groep en bij hen werd de VSM behandeld met ESCT zonder dat de SF-crosse werd geblokkeerd. Tijdens het meten van de radioactiviteit, zagen we bij alle patiënten lekkage van schuim uit de VSM, ondanks het blokkeren van de SF-crosse door manuele compressie of crossectomie. We zagen echter wel dat het blokkeren van de SF-crosse de hoeveelheid schuim dat het diepe veneuze systeem in gaat, vermindert.

In hoofdstuk acht beschrijven we drie patiënten met chronisch veneuze ulceraties aan de onderbenen die werden veroorzaakt door insufficiëntie van de VSM en/of de VSP. Ten gevolge van behandeling met ESCT werd de insufficiëntie van de onderliggende venen opgeheven met als gevolg dat hierop volgend de ulceraties snelle genezing vertoonden. Door de toepassing van ESCT hebben we deze oudere patiënten met succes een alternatief voor chirurgisch ingrijpen kunnen aanbieden.

Hoofdstuk negen beschrijft een systematisch literatuuronderzoek naar de chirurgische en endoveneuze technieken voor de behandeling van de insufficiënte VSP. We includeerden 17 studies met in totaal 1804 behandelde benen, waarvan 479 (27\%) chirurgisch, 1161 (64\%) met EVLA en 164 (9\%) met ESCT behandeld werden. Een belangrijk inclusiecriterium was het gebruik van duplex echografie om de uitkomst te kwalificeren. Vijf studies naar chirurgisch strippen laten een succespercentage zien van 24\% tot 100\% (follow-up: 1.5 - 60 maanden).

Tien studies naar EVLA melden succespercentages variërend van $91 \%$ tot $100 \%$ (follow-up periode: 1.5 - 36 maanden), en twee artikelen over ESCT laten succespercentages zien variërend van $82 \%$ tot $100 \%$ (follow-up periode: 1.5 tot 11 maanden). Na correctie voor uitkomst, hebben we een statistisch significant verschil aangetoond in de succespercentages tussen 
strippen (48\%) en EVLA / FS (95\%). Er moet echter worden opgemerkt dat de studies zeer heterogeen en derhalve moeilijk te vergelijken zijn.

In hoofdstuk tien plaatsen we de inhoud van dit proefschrift in een moderne context. We inventariseren wat de gevolgen zijn van de snelle evolutie van de diverse behandelingsmogelijkheden voor chronisch veneuze insufficiëntie met een primair focus op ESCT. We bespreken waarom het zo moeilijk is, door een gebrek aan bewijs en eenduidige definities, om de juiste waarde van andere studies in te schatten. Vervolgens bespreken we onze experimentele studies en de manier waarop zij de standaardisering van ESCT hebben verbeterd. Daarna bediscussiëren we de verschillende theorieën over de veiligheid van ESCT, in het bijzonder enkele potentiële controverses die in theorie bestaan. De discussie wordt afgesloten met een reflectie op de positie van ESCT in de dagelijkse praktijk en perspectieven over de toekomst van dit onderzoek. 


\section{Curriculum Vitae}

Roeland Petrus Maria Ceulen werd geboren op 30 oktober 1977 te Meijel. In 1996 deed hij eindexamen VWO aan het Peellandcollege Deurne. Het zelfde jaar begon hij met de studie geneeskunde aan de Universiteit Maastricht. Na het voltooien van het artsexamen in 2002 begon hij als arts-assistent op de afdeling dermatologie van het academisch ziekenhuis Maastricht (azM), alwaar hij in 2003 startte met de opleiding tot dermatoloog bij prof. dr. P.M. Steijlen. In 2008 rondde hij deze opleiding af en bleef tot maart 2009 als dermatoloog in deeltijd verbonden aan het azM. Sinds 2008 is hij als dermatoloog werkzaam in het Albert Schweitzer ziekenhuis te Dordrecht, vanaf september 2011 ook in het Beatrix Ziekenhuis te Gorinchem. In augustus 2011 trouwde hij met Sarah Tellings. 



\section{Grants \& Awards}

\section{Grants}

ZonMW doelmatigheidsonderzoek ronde 2005

FOAM-study. Cost minimization study comparing surgery versus duplex guided foam sclerotherapy of varicose veins: a randomized controlled study.

\section{Awards}

\section{Bauerfeind Research Award 2007}

How to utilize compression therapy after ultrasound guided sclerotherapy with foam for the treatment of varicose veins, a randomized controlled trial.

World Congress of the International Union of Phlebology (UIP)- Kyoto Chapter Meeting. Kyoto, Japan, juni 2007.

North Sea Award 2007

Foam Sclerotherapy of the great saphenous vein with polidocanol foam $1 \%$ versus $3 \%$. Benelux North Sea Meeting on Venous Diseases. Antwerpen, België, mei 2007. 



\section{List of publications}

Ceulen RP, Bullens-Goessens YI, De Haan MW, Veraart JC. Chronic external iliac vein obstruction as a cause of leg ulceration. Eur J Dermatol. 2004;14:350-2.

Baijens L, Speyer R, Linssen M, Ceulen RP, Manni JJ. Rejection of injectable silicone "Bioplastique" used for vocal fold augmentation. Eur Arch Otorhinolaryngol. 2007;264:565-8.

Ceulen RP, Bullens-Goessens YI, Pi - van de Venne SJ, Nelemans PJ, Veraart JC, Sommer A. Outcomes and side effects of duplex-guided sclerotherapy in the treatment of great saphenous veins with $1 \%$ versus $3 \%$ polidocanol foam: results of a randomized controlled trial with 1-year follow-up. Dermatol Surg. 2007;33:276-81.

Van Steensel MA, Ceulen RP, Delhaas T, de Die-Smulders C. Two Dutch brothers with Borrone dermato-cardio-skeletal syndrome. Am J Med Genet A. 2007;143A:1223-6.

Ceulen RP, Kessels A, Veraart JCJM, van Neer PA. Lateral venous ulceration and incompetence of the small saphenous vein. Dermatol Surg. 2007;33:727-30.

Ceulen RP, Frank J, Poblete-Gutiérrez P. Nail pigmentation due to hydroxycarbamide. Int J Dermatol. 2007;46:13-5.

Ceulen RP, Sommer A, Vernooy K. Microembolism during foam sclerotherapy of varicose veins. N Engl J Med. 2008;358:1525-6.

Ceulen RP, Vernooy K. More on microembolism and Foam Sclerotherapy. N Engl J Med 2008;359:656-657.

Ceulen RP, Vernooy K. Reply to letter regarding article titled 'Microembolism during foam sclerotherapy of varicose veins' in the New England Journal of Medicine. Phlebology 2008;23:250.

Ceulen RP, Van Marion AM, Steijlen PM, Frank J, Poblete-Gutiérrez P. Multiple unilateral skin tumors suggest type 1 segmental manifestation of familial syringoma. Eur J Dermatol. 2008; 18:285-8. 
Vissers WH, van Meurs T, Goldschmidt WF, Ceulen RP, Assen Y, Kuck N, Nijboer P, de Waard M. Residents' perspectives on dermatology training in Dutch university medical centres in 2006. Br J Dermatol. 2008;159:736-8.

Ceulen RP, Jagtman EA, Sommer A, Teule GJ, Schurink GW, Kemerink GJ. Blocking the saphenofemoral junction during ultrasound-guided foam sclerotherapy-- assessment of a presumed safety-measure procedure. Eur J Vasc Endovasc Surg. 2010;40:772-6.

Ceulen RP, Tellings SS, Sommer A. Surgery and endovenous techniques for the treatment of small saphenous varicose veins: a review of the literature. Phlebology. 2011;26:179-84.

Van Deurzen B, Ceulen RP, Tellings SS, Van der Geld CW, Nijsten T. Polidocanol concentration and time affect the properties of foam used for sclerotherapy. Dermatol Surg. 2011;37:144855 .

Shadid N, Ceulen RP, Nelemans PJ, Dirksen CD, Veraart JC, Schurink GW, Van Neer PA, Van der Kley JJ, De Haan EF, Sommer A. Randomized clinical trial of ultrasound-guided foam sclerotherapy versus surgery for the incompetent great saphenous vein. Br J Surg. 2012 May 25. [Epub ahead of print]

Ceulen RP, Essers SM. Does compression influence the outcome of foam sclerotherapy of great saphenous veins: a randomised controlled trial in a subgroup with a diameter $\leq 0.5 \mathrm{~cm}$ compared with a subgroup of $>0.5 \mathrm{~cm}$. Submitted

\section{Book chapters}

Ceulen RP. Sklerotherapie der Vena saphena magna mit Polidocanol-Schaum Wirkung und Nebenwirkung verschiedener Konzentrationen. In Praktische Sklerotherapie. Hübner K (Hrsg.), et al. 2008 ( $2^{\text {nd }}$ ed) and 2011 ( $3^{\text {rd }}$ ed), in print. 


\section{CHAPTER 12}

\section{Dankwoord}





\section{Dankwoord}

Op de eerste plaats gaat mijn dank uit naar alle patiënten die zowel toestemming hebben gegeven voor het gebruik van hun medische gegevens, alsmede veelvuldig naar het ziekenhuis zijn gekomen voor al dan niet extra onderzoeken in het kader van mijn promotieonderzoek. Zonder hun bereidwilligheid en medewerking zou dit proefschrift nooit tot stand zijn gekomen.

Vanaf het moment dat ik mijn eerste wetenschappelijke stappen heb gezet en er nog geen sprake was van een promotietraject, tot het moment van vandaag dat het proefschrift voltooid is, hebben heel veel collega's, vrienden, familie en andere omstanders op enige wijze bijgedragen aan het tot stand komen van dit boek. Omdat ik me realiseer dat het een onmogelijke opgave is om iedereen bij naam te noemen en niemand te vergeten, spreek ik vanaf deze plaats mijn hartelijke dank uit aan allen.

Een speciaal woord van dank gaat uit naar de volgende personen.

Prof. dr. Peter Steijlen. Jij bent de persoon die de ruimte hebt gecreëerd waarin ik kon promoveren. Wat in 2002 zou beginnen als een agiko-traject in het laboratorium, werd uiteindelijk een aios-traject in de kliniek, maar wel met die afspraak dat er tijd zou worden gereserveerd voor wetenschap, en zo geschiedde. Als promotor keek je vanaf de zijlijn geïnteresseerd mee, en faciliteerde daar waar nodig was. Met name in de maanden dat ik noodgedwongen uit de roulatie was, heb ik jouw begrip, steun en hulp als zeer waardevol ervaren, waarvoor ik je hartelijk wil danken.

Dr. Kevin Vernooy. Welke cardioloog publiceert nou samen met een dermatoloog..?! Het was in afgelopen jaren overigens niet ons eerste creatieve idee... wel het meest succesvolle! Dank je Kevin dat je mijn paranimf wilt zijn, maar met name voor jouw onvoorwaardelijke vriendschap!

Ruud Nellen. Als er iemand is die van zeer dichtbij alle wel en wee van mijn promotieonderzoek heeft meegemaakt, aangehoord (al dan niet bij een geopend polikliniek raam) en als klankbord heeft gefungeerd, dan ben jij dat geweest Ruud. Heel blij ben ik dat jij mijn paranimf wilt zijn. Uiteraard mijn dank hiervoor, maar daarnaast zeker ook voor jouw vriendschap!

Dr. Joep Veraart. Tijdens de studie geneeskunde ben $\mathrm{jij}$ de persoon geweest die mijn interesse in de "vasculaire dermatologie" wist te wekken. Gedurende mijn wetenschappelijke stage liet je me kennis maken met een grote diversiteit aan flebologische ziekten. Jij creëerde voor mij een agnio baan, de perfecte manier om te onderzoeken of het vak dermatologie mijn 
interesse kon wekken. Tijdens de eerste periode van mijn opleiding stond je met raad en daad klaar voor mij, zeker ook bij het opzetten en uitvoeren van de eerste klinische studie met betrekking tot schuimsclerose. Ook daarna, al was het soms van afstand, waren je suggesties en opmerkingen van toegevoegde waarde. Dank je wel voor jouw betrokkenheid en voor het vertrouwen dat je altijd in mij hebt gehad. Ik vind het leuk dat je plaats wilt nemen in de promotiecommissie.

Dr. Patty Nelemans. Hartelijk dank voor jouw scherpe blik op de statistiek. Van jou heb ik geleerd hoe wetenschappelijke experimenten/studies op te zetten en resultaten te analyseren. Tijdens het interpreteren van de onderzoeksgegevens liet jij mij inzien hoe betrekkelijk p-waardes kunnen zijn. Jouw gedegen statistische onderbouwingen en tekstuele suggesties hebben stevig bijgedragen aan de kwaliteit van onze studies, subsidieaanvragen en publicaties.

Nadia Shadid. Jouw vasthoudendheid en zeer nauwkeurige werkwijze is een zeer belangrijke factor geweest in het slagen van de ZonMW studie.

Prof. dr. Maurice van Steensel. Hartelijk dank voor het beoordelen van mijn proefschrift en het plaatsnemen in de promotiecommissie. Maar daarnaast ook voor jouw steun in met name de eindfase van het onderzoek. Toen ik al werkzaam was in Dordrecht creëerde jij de mogelijkheden in het azM zodat ik toch in de gelegenheid kon zijn om de laatste experimenten uit te voeren.

Prof. dr. Tamar Nijsten. Hartelijk dank voor het beoordelen van mijn proefschrift en het plaatsnemen in de promotiecommissie. Ik wil je daarnaast met nadruk bedanken dat je mij de mogelijkheid hebt gegeven om mee te werken aan het artikel over de karakteristieken van schuim.

Prof. dr. Tammo Delhaas, prof. dr. Geert-Jan Dinant en dr. James Lawson. Dank voor het beoordelen van mijn proefschrift en het plaatsnemen in de promotiecommissie.

Prof. dr. Martino Neumann. Hartelijk dank voor je doortastend inzicht onder meer op flebologisch gebied, waar ik afgelopen jaren veel van heb geleerd. Ik waardeer het zeer dat je bereid bent om plaats te nemen in de promotiecommissie.

Stig Essers, Bas Pi van de Venne en Evelien Jagtman. Jullie hebben mij een grote dienst bewezen bij het assisteren tijdens de vele research spreekuren en daarnaast bij het verwerken van data. 
Dr. Jorge Frank. Jouw redigerende vaardigheden hebben zeker bijgedragen aan de publicatie in de NEJM. Hartelijk dank dat je dit belangeloos hebt gedaan.

Dr. Anja Sommer. In de beginfase zijn we experimenten gestart die nauwelijks hebben geleid tot bruikbare uitkomsten. Jij hebt mij daardoor het inzicht gegeven dat wetenschap niet altijd resulteert in bevredigende resultaten. Hoewel onze meningen niet altijd gelijk gestemd waren, hebben we toch enkele mooie artikelen gepubliceerd.

Dr. Gerrit Kemerink. Dank voor jouw inhoudelijke en technische ondersteuning op het gebied van de nucleaire beeldvorming.

Alle (voormalige) aios, staf en polimedewerkers Dermatologie azM. Dank voor jullie ondersteuning, interesse en flexibiliteit waardoor ik mijn onderzoek kon doen.

Secretariaat Dermatologie azM. Van onschatbare waarde zijn jullie inspanningen en ondersteuning geweest vanaf de eerste tot en met de laatste dag.

Jaap, Ronald en Sybren. Ik ben me er dagelijks van bewust hoe fijn het is om gelijkgestemde, gezellige en humorrijke collega's te hebben.

Mijn ouders. Zonder jullie was ik nooit geweest wie ik ben, hoe ik ben en waar ik ben. Dank jullie wel voor alle mogelijkheden die jullie mij altijd hebben geboden en jullie vertrouwen in mij.

Paul, Barbe, Thera, Ben en Yentl, dank jullie wel voor jullie steun en interesse. Ik ben blij met jullie.

Lieve Sarah, je weet het wel.. X 